\title{
The New Neurobiology of Severe Psychiatric Disorders and Its Implications for Laws Governing Involuntary Commitment and Treatment
}

\author{
E. Fuller Torrey, M.D., ${ }^{1}$ and Ken Kress, J.D., Ph.D. ${ }^{2}$
}

Table of Contents

I. Introduction and Historical Context
A. Common Law Overrulings and Statutory Changes Resulting from Medical Advances
B. Medical Advances and Legal Theory
C. A Brief Historical Context of Mental Health Law
D. A Brief Description of Parts II-VI

II. Understanding the Causes of Schizophrenia
A. Before 1975: A Scientific Muddle
B. Since 1975: A Biological Disease
1. Structural Abnormalities
2. Neurological Abnormalities
3. Neuropsychological Abnormalities
4. Neurophysiological Abnormalities
5. Cerebral Metabolic Abnormalities

III. Anosognosia: Competence To Make Informed Treatment Decisions

A. Before 1975: Confined to Neurology

B. Since 1975: Established in Psychiatry

1. Alzheimer's Disease and Huntington's Disease

2. Schizophrenia

3. Anatomical Localization of Anosognosia

4. Consequences of Anosognosia
a. Noncompliance with Medication
b. Relapse, Homelessness, and Incarceration
c. Violent Behavior 
IV. The Lanterman-Petris-Short Act: California, 1969
A. Assumptions Regarding the Causes of Psychiatric Disorders
B. Assumptions Regarding Competence To Make Informed Treatment Decisions
C. Effects of the Lanterman-Petris-Short Act

V. The Lessard Decision: Wisconsin, 1972
A. Assumptions Regarding the Causes of Psychiatric Disorders
B. Assumptions Regarding Competence To Make Informed Treatment Decisions
C. Effects of the Lessard Decision

VI. Implications of the New Biology for Laws Governing Involuntary Commitment and Treatment: Principles for Consideration for Future Mental Health Legislation
A. Individuals with schizophrenia and other severe psychiatric disorders should be regarded as equal to individuals with other chronic brain disorders
B. An assessment for anosognosia should be routinely included in all determinations of competency
C. Provision for assisted treatment should be available in all states and used when necessary

VII. Conclusions 


\section{Introduction and Historical Context}

Every student of the law knows that changed circumstances are a ground for overruling precedents and repealing statutes. For example, Justice Cardozo, in rewriting product liability law stated, "Precedents drawn from the days of travel by stage coach do not fit the conditions of travel today. The principle that the danger must be imminent does not change, but the things subject to the principle do change. They are whatever the needs of life in a developing civilization require them to be." ${ }^{3}$ Similarly, the United States Supreme Court in the Admiralty context, when rejecting the traditional common law triple duty standard for owners and occupiers of land, stated:

The distinctions which the common law draws between licensee and invitee were inherited from a culture deeply rooted to the land, a culture which traced many of its standards to a heritage of feudalism. In an effort to do justice in an industrialized urban society, with its complex economic and individual relationships, modern common-law courts have found it necessary to formulate increasingly subtle verbal refinements, to create subclassifications among traditional common-law categories, and to delineate fine gradations in the standards of care which the landowner owes to each. Yet even within a single jurisdiction, the classifications and subclassifications bred by the common law have produced confusion and conflict. As new distinctions have been spawned, older ones have become obscured. Through this semantic morass the common law has moved, unevenly and with hesitation, towards "imposing on owners and occupiers a single duty of reasonable care in all circumstances."

Sometimes, new laws are necessary because we used to live differently than we do now. Laws appropriate to feudal times are in apropos in modern civilization. On other

\footnotetext{
MacPherson v. Buick Motor Co., 111 N.E 1050 (1916).

Kermarec v. Compagnie Generale, 358 U.S. 625, 630-631, 79 S.Ct. 406, 410, 3 L.Ed.2d 550

(footnotes omitted); see also Jones v. United States, 362 U.S. 257, 266, 80 S.Ct. 725, 4 L.Ed.2d 697.
} 
occasions, our lifestyle has not changed but our beliefs about the world—both its physical properties and the psychology or biology of humans-have changed. Although this Article focuses mostly on changes in scientific beliefs, changed circumstances are also relevant to our main thesis.

We have seen that laws and judicial decisions may, in retrospect, no longer be useful, or may even prove to have been mistaken when they were created. They are, at most, based upon some subset of the sum total of information available at the time the laws and decisions are created. That information itself is always incomplete, and sometimes mistaken. When knowledge advances, it is wise and necessary to reconsider legislation, regulation, and common law decisions that were based upon prior views. This is especially true for laws governing medicine, a field that has changed, and is continuing to change, rapidly and profoundly as science advances.

\section{A. Common Law Overrulings and Statutory Changes Resulting from Medical} Advances

Many medical advances have spawned overrulings of traditional doctrine. For example, since the thirteenth century, there has been a common law principle that originated in England, stating that an act causing death is not a homicide if the death occurs more than a year and a day after the act was committed. ${ }^{5}$ This so-called year and a day rule has been understood as a substantive principle of criminal law, conclusively presuming that an injury inflicted more than a year and a day before the victim dies does

5 United States v. Jackson, 528 A.2d 1211, 1214 (D.C.1987); State v. Ruesga, 619 N.W.2d 377, 380 (Iowa 2000); People v. Stevenson, 416 Mich. 383, 331 N.W.2d 143, 145 (1982); State v. Vance, 328 N.C. 613, 403 S.E.2d 495, 498 (1991); State v. Picotte, 661 N.W.2d. 381, 385 (Wis. 2003). 
not cause the death, with the result that the injurer is not guilty of homicide. ${ }^{6}$ However, with modern technology, it is now possible to keep some brain-damaged individuals alive for many years after an assault, thus turning the assault into a homicide years later. In State v. Picotte, Chief Justice Shirley Abrahamson, writing for the Wisconsin supreme court, stated that one of the traditional justifications for the rule was that the primitive state of thirteenth-century medical knowledge had made it difficult to establish causation beyond a reasonable doubt after a great deal of time had elapsed between the injury to the victim and the victim's death. ${ }^{7}$ However, the court continued, "advances in medical science that permit causes of death to be identified with great certainty have undermined [this] justification., ${ }^{, 8}$ For these and other reasons, courts in at least a dozen states have abrogated the year and a day rule as anachronistic, based primarily on advances in medical science. ${ }^{9}$ It is likely that most — if not all— jurisdictions that consider the rule in the future will abrogate it as well.

Similarly, advances in medical science have changed our understanding of death from primarily cessation of heart, circulatory, and respiratory function to cessation of

\section{Picotte, 661 N.W.2d at 385.}

Picotte, 661 N.W.2d at 390.

Id.

9 In Rogers v. Tennessee, 532 U.S. 451 (2001), the Supreme Court held that the Tennessee's judicial abrogation of the year and a day rule was not a violation of the Due Process Clause. The Court reasoned that every court to have recently considered the year and a day rule had pointed to advances in medical science and related science as undermining the usefulness of the rule. Id. at 461. In State of Iowa v. Ruesga, 619 N.W.2d 377, 380 (Iowa 2000), the court noted that ten courts had abrogated the year and a day rule. Although the court did acknowledge that the rule had been legislatively abrogated in 1860, the court largely relied on advancements in medical science as support for concluding that the year and a day rule was no longer a valid defense. Id. at 380 .

In New Mexico (State v. Gabehart, 836 P.2d 102, 103 (N.M. Ct. App. 1992)), the New Mexico Court of Appeals considered whether courts or legislatures should abolish the year and a day rule. The court found that courts have the power to judicially abrogate common-law doctrines that "have proven anachronistic." Id. The court relied on advances in medical and criminal science as illustrating that the year and a day rule was anachronistic. Id.

In North Carolina (State v. Hefler, 299 S.E. $2 d 456$ (N.C. Ct. App. 1983)), the court denied the defendant's motion to dismiss based on the common law year and a day rule. The court stated that the "advances in medical science and improvement of diagnostic skills relative to the prolongation of human life obviate the need for (the year and a day) rule." Id. at 459. 
brain and nervous system function. Because killing is causing death, this change is the basis for the demise of the year and a day rule. The Connecticut supreme court provides a list of considerations that courts should consider in determining whether advancements in medical science justify overruling prior common law rules. ${ }^{10}$ These factors include: ${ }^{11}$

1) Whether the issue has ever been raised before; in this case, it counts in favor of seriously considering switching to brain death that this is an issue of first impression;

2) The valuable quality of common law as active and dynamic, and changing to meet the needs of a growing society;

3) The absurdity of a prohibition against taking into account new medical equipment that can more accurately diagnose and determine medical facts;

4) The policy of courts not to ignore change or disregard reality;

5) That reasonable evolving medical standards should play a dominant role in relevant legal rules in the absence of overriding contrary considerations;

6) The plain meaning doctrine;

7) Plain meaning should be enlarged or narrowed, as appropriate, under changed circumstances;

8) Statutory construction is not "a ritual to be observed by unimaginative adherence to well-worn professional phrases," quoting Justice Frankfurter; ${ }^{12}$

State v. Guess, 244 A.2d 643, 649 (Conn. 1998).

Id.

Felix Frankfurter, Some Reflexions on the Reading of Statutes, 47 Columbia.L.Rev. 527, 529 (1947). 
9) The doctrine that the common law may look to the policies underlying statutes. $^{13}$

Much legislation is passed as a result of changed circumstances. Some of that legislation is responsive to scientific advances. For example, many states have adopted legislation redefining death as cessation of brain function. ${ }^{14}$

\section{B. Medical Advances and Legal Theory}

There are two major kinds of theories of law, natural law and legal positivism. Natural law asserts the existence of some necessary or constitutive relationship between law and critical morality, that is, moral propositions whose truth is independent of the beliefs of society or its conventions: some would call it absolute morality. By contrast, legal positivism maintains that there is no necessary connection between law and morality; any connection is merely contingent. Law is a matter of social fact.

We will briefly describe how changed circumstances, especially scientific advances, are dealt with by one of each kind of theory. Michael Moore, a natural law theorist, urges that the term 'death' is a natural kind term, like 'cow,' 'lithium,' or 'gold.' By contrast, 'pencil' and 'store' are not natural kinds but artificial constructs whose meaning depends upon human purpose and usages. One major theory of the reference, semantics, or meaning of such terms is that their meaning is determined by scientific investigation. Moore accepts this theory of language in general and applies it to legal 
language in particular. Cows, lithium, and gold are whatever science discovers them to be. ${ }^{15}$ Thus, cows are whatever are four-legged mammals with udders, that moo, and so on. Similarly, lithium is the lightest metal, with atomic number 3, a melting point of 180.5 degrees centigrade, and a boiling point of 1342 degrees centigrade. It is a monovalent cation that belongs to the group of alkali metals together with sodium, potassium and other elements with which it shares some of its properties. Lithium can replace sodium in extracellular fluid and during the process of depolarization it has an extremely rapid intracellular influx and so on.

The reference of the term 'death' in particular is one that it is the job of science, especially medical science, to discover. Moore therefore supports the movement by courts to overturn common law definitions of death as cessation of heart, lung, circulatory functions, and consciousness by cessation of brain function when scientists tell us that cessation of brain function is a more accurate definition of death. ${ }^{16}$

The legal positivist Melvin Eisenberg develops his theory of law as a coherent reconstruction of social morality, policy, and experiential propositions. ${ }^{17}$ Experiential propositions are propositions "about the way world works." ${ }^{18}$ Among experiential propositions that play a role in adjudication are "the laws of the physical and biological sciences. ${ }^{19}$ Experiential propositions, including especially laws of psychology, mediate between policies, principles and doctrinal rules. ${ }^{20}$ Eisenberg is careful to note that courts can make mistakes about scientific and other propositions about the world. When other

15 SAul A. KRIPKe, NAming AND NeCESSITy (1973); Hilary Putnam, The Meaning of 'Meaning', in COLLECTED PAPERS, vol. 3 (1981).

16 Michael S. Moore, A Natural Law Theory of Interpretation, 58 S. CAL. L. REV. 277, 293-94, 322-28(1985).

Melvin Aron Eisenberg, The NATURe Of The COMMON LAW (1988).

Id. at 37 .

Id. at 38 .

Id at 39 . 
courts and the larger discourse about such propositions raise questions about their validity, courts must pull back and either revise the rule or explain why the criticism is not founded. One source of such criticism is law review articles. ${ }^{21}$ It is our purpose in writing this Article to stimulate courts into reconsidering doctrine that is based upon beliefs about mental illness that are now outdated.

\section{A Brief Historical Context of Mental Health Law}

This Article describes advances in our scientific understanding of severe psychiatric disorders and evaluates the implications of these advances for laws governing involuntary hospitalization and treatment. Civil commitment, a more familiar term for involuntary hospitalization, is perhaps the most controversial area of mental health law. This Article illuminates this area by analyzing the underlying medical facts, legal policies, and moral principles. As such, it throws light on an area of law that has been, and continues to be, controversial.

Beginning in the 1960s, virtually all states undertook major changes in their mental health laws. These changes have had a profound effect on the practice of psychiatry and on psychiatric services. For example, in 1955, there were 559,000 individuals hospitalized in state psychiatric hospitals in the United States. Based on the increase in the general population since that time, if a comparable per population number of individuals were similarly hospitalized today, they would number approximately one million. In fact, there are fewer than 50,000 individuals so hospitalized, meaning that 95\% of individuals who would have been hospitalized fifty years ago have been

21 Id at $41-42$. 
effectively deinstitutionalized. ${ }^{22}$ Changes in state mental health laws and judicial

decisions beginning in the late 1960s played a major role in promoting this

deinstitutionalization.

It is generally accepted that the outcome of deinstitutionalization has not been as favorable as had been originally hoped. Many would say that it has been a dismal failure. The number of homeless individuals with severe psychiatric disorders has risen steadily in recent decades, and they now constitute at least one-third of all homeless individuals. ${ }^{23}$ A relationship between deinstitutionalization and homelessness has been clearly established. ${ }^{24}$ Hallucinating men and women are now standard urban fixtures on the sidewalks of American cities and mid-sized towns.

The number of severely psychiatrically ill individuals in America's jails and prison has also risen steadily, with estimates of their total ranging from $7 \%$ to $16 \%$ of all those incarcerated. ${ }^{25}$ The majority of these individuals have been charged with misdemeanor crimes, often directly related to behavior attributable to their psychiatric disorder. Often, individuals discharged from state psychiatric hospitals end up in jail

22 E. Fuller Torrey, OUT OF THE SHADOws: CONFRONTING AMERICA's MENTAL ILLNESS CRISIS (1997) (hereinafter TORREY, OUT OF THE SHADOWS).

23 Estimates of the total number of homeless persons in the United States have varied widely, but multiple studies have reported that at least one-third of them have a serious psychiatric disorder, predominantly schizophrenia or bipolar disorder. See, for example, TORREY, OUT OF THE SHADOWS, 17, for a review.

24 Studies of psychiatric patients discharged from state hospitals in Massachusetts, Ohio, and New York found that between $27 \%$ and $38 \%$ of the patients became homeless within six months of discharge. See Robert E. Drake et al., Housing Instability and Homelessness among Aftercare Patients of an Urban State Hospital, 40 HosP. COMM. PSYCHIATRY 46 (1989); John R. Belcher, Rights versus Needs of Homeless Mentally Ill Persons, 33 SOCIAL WORK 398 (1988); John R. Belcher, Defining the Service Needs of Homeless Mentally Ill Persons, 39 HosP. COMM. PsYCHIATRY 1203 (1988); Malcolm Gladwell, Backlash of the Benevolent, WASHINGTON Post, Jan. 22, 1995, at A1, A18.

25 The percentage of inmates reported as having psychiatric disorders has varied in different surveys depending on how "psychiatric disorders" was defined. In the most publicized study, released by the U.S. Department of Justice in 1999, it was estimated that $16 \%$ of individuals incarcerated in American jails and prisons had a severe psychiatric disorder. Since there are over two million individuals incarcerated, this would suggest that approximately 320,000 of them have a severe psychiatric disorder. See Paula M. Ditton, Mental Health and Treatment of InMates And Probationers, Bureau of Justice Statistics Special Report, Office of Justice Programs, U.S. Department of Justice, Washington, D.C. (1999). 
within months of being discharged. ${ }^{26}$ It has also been alleged that individuals with severe psychiatric disorders, especially those who are not receiving treatment, are responsible for an increasing number of violent acts, including homicides. ${ }^{27}$

\section{A Brief Description of Parts II-VI}

Part II of this Article describes scientific advances in understanding severe psychiatric disorders that have occurred since 1975. Severe psychiatric disorders primarily include the diagnoses of schizophrenia, bipolar (manic-depressive) disorder, and major depression with or without psychotic features. We focus on schizophrenia, rather than discussing all severe mental illnesses, in order to keep the presentation to a manageable length.

Part III describes recent advances in understanding anosognosia and its application to severe psychiatric disorders. Although anosognosia is one aspect of the broader scientific advances described in Part II, because of its importance, it is crucial for understanding mental health laws and thus deserves its own section.

26 For example, a study of patients discharged from Ohio's Columbus State Hospital reported that $32 \%$ of those diagnosed with schizophrenia had been arrested and jailed within six months. These individuals were arrested because of being "threatening in their behaviors" and exhibiting bizarre behaviors "such as walking in the community without clothes and talking to themselves." See John R. Belcher, Are Jails Replacing the Mental Health System for the Homeless Mentally Ill? 24 COMMUNITY MENT. HEALTH J. 185 (1988).

27 A 1988 U.S. Department of Justice study reported that individuals with a history of psychiatric illness, not including drug or alcohol abuse, were responsible for $4.3 \%$ of all homicides in the United States; see John M. Dawson and Patrick A. Langan, Murder IN FAMILIES, Bureau of Statistics Special Report, Office of Justice Programs, U.S. Department of Justice, Washington, D.C. (1988). A study published by the National Institute of Mental Health reported that "the SPMI (severe and persistently mentally ill) population without substance(abuse)-related disorders may be responsible for no more than about 3 percent of violent crime, with 3 to 5 times as much violence accounted for by the dually diagnosed (SPMI and substance disorders) population." See Henrick Harwood et al., THE ECONOMIC COSTS OF MENTAL ILLNESS, 1992, 1.5 (2000). 
Parts IV and V analyze two of the most important state mental health laws that were changed in the late 1960s and early 1970s: the Lanterman-Petris-Short Act, enacted in California in 1969, and the Lessard v. Schmidt decision, handed down by a three-judge District Court in Wisconsin in 1972. In both instances, the assumptions made at the time the laws were changed regarding the nature of severe psychiatric disorders and the competence of individuals to make informed treatment decisions are now known to be erroneous.

Part VI then examines the legal implications of current scientific knowledge for the Lanterman-Petris-Short Act and the Lessard decision as representative examples of state mental health laws. The implications can perhaps best be summarized in the words of Bertolt Brecht: "Intelligence is not to make no mistakes / But quickly to see how to make them good."28

II. Understanding the Causes of Schizophrenia

\section{A. Before 1975: A Scientific Muddle}

During the 1960s and early 1970s, when state laws governing involuntary commitment and treatment of psychiatric patients were undergoing revision in many states, the causes of schizophrenia were essentially unknown. There was, in fact, controversy regarding whether schizophrenia was even a disease entity. The American Handbook of Psychiatry, published in 1959, was probably the most influential psychiatric 
textbook of the 1960s. Its two chapters on schizophrenia approvingly quoted Thomas Szasz's early writings: “The problem of schizophrenia which many consider to be the core problem of psychiatry today. . . To put it simply: there is no such problem." ${ }^{29}$ This was written even prior to Szasz's 1961 book The Myth of Mental Illness, which widely popularized the idea that schizophrenia did not exist.

Insofar as schizophrenia did exist, the American Handbook of Psychiatry leaned heavily toward psychoanalytic explanations that were fashionable at that time. The textbook defined schizophrenia as "a specific reaction to an extreme state of anxiety, originated in childhood and reactivated later in life by psychological factors, ${ }^{, 30}$ and it devoted $75 \%$ of the two chapters on schizophrenia to various psychoanalytic explanations. Specifically, the textbook claimed: "Psychodynamic studies reveal that the road leading to schizophrenia had its beginning in the remote past of the patient, perhaps shortly after his birth." 31

In addition to psychoanalytic explanations for the cause of schizophrenia, psychiatric textbooks of this era also focused on the family, and specifically mothers, as

29 Silvano Arieti, Schizophrenia: Other Aspects; Psychotherapy, (hereinafter ARIETI, SCHIZOPHRENIA: OTHER ASPECTS), in S. Arieti (ed.), AMERICAN HANDBOOK OF PSYCHIATRY, VOL. 1, 501 (1959) (hereinafter ARIETI, AMERICAN HANDBOOK OF PSYCHIATRY, VOL. 1). Szasz has continued making similar statements for over forty years in the lay press and in books such as THE MANUFACTURE OF MADNESS, (1970) and SCHIZOPHRENIA: THE SACRED SYMBOL OF PSYCHIATRY (1976). Szasz's writings were very influential among lawyers who litigated most of the psychiatric court cases in the 1960s and 1970s. For example, Bruce Ennis, who has been called "the 'father' of the mental health bar" and who subsequently became chairman of the American Bar Association's Commission on the Mentally Disabled, said that he initially became interested in legal issues regarding the mentally ill when: "I went to a library and I looked under 'law and psychiatry' and found some books by a man named Thomas Szasz which I found interesting from a civil liberties perspective and I read more and I realized this was a very, very big problem about which most people, including myself, knew nothing"; see Rael Jean Isaac and Virginia C. Armat, MADNESS IN THE STREETS: How PSYCHIATRY AND THE LAW AB ANDONED THE MENTALLY ILL 109_ 110 (1990). When Ennis published his influential PRISONERS OF PSYCHIATRY in 1972, Szasz contributed a preface.

30 ARIETI, AMERICAN HANDBOOK OF PSYCHIATRY, VOL. 1, 501.

31 Silvano Arieti, Schizophrenia: The Manifest Symptomatology, the Psychodynamic and Formal Mechanisms (hereinafter ARIETI, SCHIZOPHRENIA: THE MANIFEST SYMPTOMATOLOGY), in ARIETI, AMERICAN HANDBOOK OF PSYCHIATRY, VOL. 1, 468. 
the cause of the disorder. The American Handbook of Psychiatry, for example,

prominently featured the theories of Theodore Lidz and his colleagues at Yale University, who had studied families with one member affected with schizophrenia. It summarized these theories as follows:

Many authorities consider the mother the main dynamic factor in the genesis of the child's future psychiatric condition, and have devised the classification 'schizophrenogenic mother.' She has been described in many ways: overprotective, hostile, overtly or subtly rejecting, overanxious, cold, and distant etc. In many cases she is found definitely unfit for motherhood. ${ }^{32}$

Szaszian, psychoanalytic, and family interaction theories continued to dominate professional thinking about the causes of schizophrenia throughout the 1960s and early 1970s, as measured by two other leading textbooks of psychiatry. The Theory and Practice of Psychiatry was published in 1966, and Modern Synopsis of Comprehensive Textbook of Psychiatry in $1972^{33}$; one book or the other was used by virtually every trainee in psychiatry, psychology, and psychiatric social work of that period.

In its chapter on schizophrenia, The Theory and Practice of Psychiatry picked up the Szaszian theme widely circulating at that time and asked: "Is it [schizophrenia] a disease? A maladjustment? A way of life?" Regarding possible causes of schizophrenia, the textbook acknowledged that "no satisfactory general etiological explanation exists at

32 ARIETI, SCHIZOPHRENIA: THE MANIFEST SyMPtOMATOLOGY, 469. Although such theories sound outlandish today, in the 1960s they were considered to be mainstream and were accepted by the majority of psychiatrists.

33 Frederick C. Redlich \& Daniel X. Freedman, THE THEORY AND PRACTICE OF PSYCHIATRY (1966) (hereinafter REDLICH \& FrEEDMAN, THEORY AND PRACTICE) and Alfred M. Freedman et al., ModerN SYNOPSIS OF COMPREHENSIVE TEXTBOOK OF PSYCHIATRY (1972) (hereinafter FREEDMAN ET AL., MODERN SYNOPSIS). 
present.... [O]ur knowledge represents more of a speculative game than an opportunity to assess an array of well-verified facts. . . In a word, we are still groping in darkness.."34 In discussing possible theories regarding the cause of schizophrenia, The Theory and Practice of Psychiatry devoted the majority of its discussion to psychoanalytic and family interaction theorists. Regarding the former, the textbook noted that psychoanalytic investigators assumed that factors predisposing to schizophrenia could be found in traumatic events in early childhood and that most utterances and behavior of individuals with schizophrenia are psychologically meaningful and represent repressed wishes of the individual. ${ }^{35}$

Family interaction theories of schizophrenia were also given prominence in The Theory and Practice of Psychiatry. The 1950s research of Theodore Lidz, cited in The American Handbook of Psychiatry, had been supplemented by the mid-1960s by the studies of several other researchers, especially Don D. Jackson and Gregory Bateson in California. Jackson and Bateson attributed the cause of schizophrenia to faulty communications between parent (especially mother) and child, which they claimed produced confusion and ultimately the symptoms of schizophrenia in the developing child. ${ }^{36}$ These family theories were prominently cited by individuals who were trying to change state mental health laws, as will be discussed in section IV.

\footnotetext{
34 REDLICH \& FREEDMAN, THEORY AND PRACTICE 459, 506, 486-87

35 REDLICH \& FREEDMAN, THEORY AND PRACTICE 500. As an example, the textbook cites the following: "A schizophrenic patient fell from a third-story window when he tried to launch a contraption that would permit him to fly to the sun. Like his famous model, Icarus, he failed. Is the patient's behavior more meaningful if we consider that he wanted to be close to his father and also compete with him? We believe it is." (496)

36 Specifically, Jackson and Bateson claimed that parents may produce schizophrenia in a child by using communications that put the child in a "double-bind." An example cited by The Theory and Practice of Psychiatry is as follows: "A mother gives her son two neckties for Christmas and when the boy appears wearing one, she asks disapprovingly, 'Didn't you like the other one?' Here the boy cannot in sanity wear
} 
Modern Synopsis of Comprehensive Textbook of Psychiatry, published in 1972, enumerated seven possible causal explanations of schizophrenia. Three of the six theories attributed schizophrenia to stress, another to "severe psychological trauma" early in life, another to "family environment and its interacting members," and the last to a mix of all of these. ${ }^{37}$ Overall in this textbook, two-thirds of the discussion on possible causes of schizophrenia focused on psychological causes. Family interaction theories were especially prominent and emphasized "the concept that the patient is a symptom of the family pathology and that serious mental disturbances are causally related to mental disease or psychopathology in parents." 38

Prior to 1975, possible biological causes of schizophrenia were also considered but not given prominence in textbooks of psychiatry. For example, the American Handbook of Psychiatry devoted $25 \%$ of its two chapters on schizophrenia to biological theories but largely relegated them to the past. "An enormous number of studies have been made in an attempt to determine the organic changes that cause, accompany, or are the result of schizophrenia. Their findings are not consistent, their interpretation controversial. ${ }^{, 39}$ Specifically discussed were genetic studies, "constitutional factors," "the endocrine glands," biochemical changes, and neuropathology. The biochemical investigations were said to be "almost entirely negative" and neuropathological studies of the brain to have "not revealed anything more definite than have the other organs."

both, and if he wears either or none he will displease his mother." (REDLICH \& FREEDMAN, THEORY AND PRACTICE 503).

FREEDMAN ET AL., MODERN SYNOPSIS 222.

FREEDMAN ET AL., MODERN SYNOPSIS 224.

ARIETI, SCHIZOPHRENIA: THE MANIFEST SYMPTOMATOLOGY, 485.

ARIETI, SCHIZOPHRENIA: THE MANIFEST SYMPTOMATOLOGY, 487, 488. 
In fact, if one examines early biological studies of schizophrenia with the benefit of hindsight, they anticipate successful biological studies that have been carried out since 1975. Studies of brain structure were done by pneumoencephalography, which involved injecting air into the brain's fluid-filled spaces (cerebral ventricles) and then taking Xrays. Five studies of individuals with schizophrenia were carried out prior to the introduction of antipsychotic medications; all showed enlargement of the cerebral ventricles in the patients, ${ }^{41}$ a finding that has been replicated many times in more recent studies.

Another common method for measuring biological abnormalities in individuals with schizophrenia in these early studies was done by electroencephalogram [EEG] Between 1941 and 1955, five controlled EEG studies of never-medicated patients with schizophrenia were carried out; all five reported that approximately twice as many patients as normal controls had abnormal EEGs. ${ }^{42}$ This is consistent with findings in recent studies.

A variety of neurological abnormalities were also described in patients with schizophrenia prior to the introduction of antipsychotic medication. Abnormal involuntary movements called dyskinesias were widely observed more than a century

${ }^{41}$ W. Jacobi \& H. Winkler, Encephalographische Studien auf Chronischen Schizophrenen, 81 ARCHIV FÜR PSYCHIATRIE UND NERVENKRANKHEITEN 299 (1927); M. Moore et al., Encephalographic Studies in Schizophrenia (Dementia Praecox), 89 AM. J. PSYCHIATRY 801 (1933); R. Lemke, Untersuchungen über die Soziale Prognose der Schizophrenia unter Besonderer Berücksichtigung des Encephalographischen Befundes, 104 ARCH. PSYCHIAT. NERVENKR. 89 (1935); J.F. Donovan et al., Some Observations on Leucotomy and Investigations by Pneumoencephalography, 95 J. MENT. SCI. 655 (1949);

G. Huber, PNEUMOENCEPHALOGRAPHISCHE UND PSYCHOPATHOLOGISCHE BILDER BEI ENDOGENEN PSYCHOSEN (1957).

42 K.H. Finley \& C.M. Campbell, Electroencephalography in Schizophrenia, 98 AM. J. PSYCHIATRY 374 (1941); M. Greenblatt, M., Age and Electroencephalographic Abnormality in Neuropsychiatric Patients: A Study of 1593 Cases, 101 AM. J. PsYChiATRY 82 (1944); G.H.A. Chamberlain \& J.G. Russell, The E.E.G.S of the Relatives of Schizophrenics, 98 J. MENT. SCI. 654 (1952); D. Hill, EEG in Episodic Psychotic and Psychopathic Behaviour: A Classification of Data, 4 EEG CLIN. NEUROPHYSIOL. 419 (1952); and R.J. Ellingson, The Incidence of EEG Abnormality among Patients with Mental Disorders of Apparently Nonorganic Origin: A Critical Review, 111 AM. J. PSYCHIATRY 263 (1954). 
ago. A review of the clinical records of over 600 patients in an English asylum between 1850 and 1890, for example, found descriptions of dyskinesias for almost one-third of the patients. ${ }^{43}$ Similarly, rigidity, tremor, and a slowing of physical movements were frequently described in the early years of the twentieth century as neurological signs of schizophrenia. ${ }^{44}$ Studies were also done on individuals with schizophrenia, demonstrating abnormalities in vestibular reactivity, which is the brain's mechanism that controls the person's sense of motion. ${ }^{45}$

In summary, in the United States prior to 1975, our understanding of the causes of schizophrenia was a muddle. One group of psychiatric professionals denied that the disease even existed. Among those who believed schizophrenia did exist, the majority believed that it was caused by traumatic experiences in early childhood and/or by faulty parenting and communications. A minority of psychiatric professionals believed that schizophrenia was a biological disease of the brain, but this theory was widely considered to be a relic of the past. Anyone who was considering changing mental health laws at that time would have been likely to conclude, after examining the existing professional literature, that the best scientific view was that schizophrenia was a psychological condition brought about by early childhood experiences and maladaptive parenting, not an organic disease of the brain. As we demonstrate in sections IV and V, that is what happened.

43 T. Turner, Rich and Mad in Victorian England, 19 PSYCHOL. MED. 29 (1989). For a summary of such studies, see E. Fuller Torrey, Studies of Individuals with Schizophrenia Never Treated with Antipsychotic Medications: A Review, 58 SCHIZOPHR. RES. 101 (2002).

44 See, for example, E. Kraepelin, DEMENTIA PRAECOX AND PARAPHRENIA 34 (1919), and P.J. Reiter, Extrapyramidal Motor-Disturbances in Dementia Praecox, 1 ACTA PSYCHIATR. NEUROL. SCAND. 287 (1926).

45 A. Angyal \& N. Blackman, Vestibular Reactivity in Schizophrenia, 44 ARCH. NEUROL. PSYCHIATRY 611 (1940); Andras Angyal \& Max A. Sherman, Postural Reactions to Vestibular Stimulation in Schizophrenic and Normal Subjects, 98 AM. J. PSYCHIATRY 857 (1942); and Gerald Fitzgerald \& E. Stengel, Vestibular Reactivity to Caloric Stimulation in Schizophrenics, 91 J. MENT. SCI. 93 (1945). 


\section{B. Since 1975: A Biological Disease}

Our understanding of the causes of schizophrenia has changed profoundly since 1975. Prior to that time, researchers were "groping in the darkness," in the words of one psychiatric textbook. Since 1975, literally hundreds of studies have been carried out proving beyond any reasonable doubt that schizophrenia is a disease of the brain. Although the precise cause of the disease is still being elucidated, among professionals, the consensus is virtually unanimous that schizophrenia is a brain disease. In this respect, schizophrenia is now thought to be similar to Alzheimer's disease, Parkinson's disease, multiple sclerosis, amyotrophic lateral sclerosis, and other disorders that are known to be diseases of the brain but whose precise causes are not yet known.

One way to compare pre-1975 views of psychiatry with contemporary views is by comparing standard textbooks of psychiatry. For example, the 7 th edition of the Comprehensive Textbook of Psychiatry, published in 2000, is a direct descendent of the first edition, published in 1972, as discussed above. In the 1972 edition, prior to the recent studies, $75 \%$ of the discussion of the causes of schizophrenia was allotted to psychological causes and 25\% to biological causes. Moreover, most of the discussion of psychological theories of schizophrenia is from a historical point of view. In the 2000 edition, only $10 \%$ of the discussion of the causes of schizophrenia is allotted to psychological causes, with the remaining $90 \%$ allotted to biological causes. ${ }^{46}$ Moreover, in theAmerican Psychiatric Press Textbook of Psychiatry, published in 1999, "social and (2000).

Benjamin J. Sadock \& Virginia A. Sadock, COMPREHENSIVE TEXTBOOK OF PSYCHIATRY, 7TH ED. 
family factors" regarding the causes of schizophrenia occupy only $6 \%$ of the text on this subject, while biological factors are discussed in the remaining $94 \% .{ }^{47}$ These textbooks reflect the important change in our understanding of schizophrenia that has taken place since 1975.

The remainder of this section will summarize studies that lead to the conclusion that schizophrenia has biological roots and is a disease of the brain. We will restrict the discussion to studies that have been carried out on individuals who had never been treated with antipsychotic medication; such individuals are frequently referred to as "neuroleptic naïve." There are two reasons for confining discussion to this group. First, antipsychotic medications themselves may also bring about biological changes in the brain; in fact, that is why such medications are effective in treating the symptoms of schizophrenia. Thus, by restricting the analysis to untreated patients, it becomes clear that whatever abnormalities are found are a consequence of the schizophrenia disease process and not due to medications. Second, some authors who oppose psychiatry have argued that schizophrenia is a consequence of medication, not a naturally occurring phenomenon. They have therefore concluded that modern psychiatric medications do more harm than $\operatorname{good}^{48}$

Studies of individuals with schizophrenia who had never been treated with antipsychotic medications at the time the studies were done can be divided into structural abnormalities, neurological abnormalities, neuropsychological abnormalities, neurophysiological abnormalities, and cerebral metabolic abnormalities.

47 Robert E. Hales et al. (eds.), THE AMERICAN PSYCHIATRIC PRESS TEXTBOOK OF PSYCHIATRY, 3RD ED. (1999).

48 Peter R. Breggin, TOXIC PSYCHIATRY (1991); Robert Whitaker, MAD IN AMERICA (2003). 


\section{Structural Abnormalities}

The modern era in schizophrenia research can be dated to 1976 with the

publication of the first research using the newly developed computerized axial

tomography (CT) brain scans, which showed that the brains of individuals with

schizophrenia have significantly larger fluid-filled spaces (cerebral ventricles) compared

to normal controls. The CT scan was the first technology allowing for visualization of

brain structures in living patients that could be used to statistically distinguish those with

schizophrenia from normal controls. ${ }^{49}$ Following the introduction of CT scans, magnetic

resonance imaging (MRI) scans have also become widely available for studying brain

structures.

Since 1976, a total of thirty-three studies of brain structure have been done on

individuals with schizophrenia who had never been medicated. ${ }^{50}$ All six studies that

49 Eve C. Johnstone et al., Cerebral Ventricular Size and Cognitive Impairment in Chronic Schizophrenia, 2 LANCET 924 (1976). This research was carried out at Northwick Park Clinical Research

Center in London. Although group differences are statistically significant, there is some overlap in ventricular size between individual patients with schizophrenia and normal controls, and so ventricular size cannot be used as a diagnostic marker.

$50 \quad$ S.C. Schulz et al., Treatment Response and Ventricular Brain Enlargement in Young Schizophrenic Patients, 19 PSYCHOPHARMACOL. BULl. 510-12 (1983); G. Degreef et al. Increased Prevalence of the Cavum Septum Pellucidum in Magnetic Resonance Scans and Post-Mortem Brains of Schizophrenic Patients, 45 PSYCHIATRY RES.: NEUROIMAGING 1-13 (1992); J. Lieberman et al., Qualitative Assessment of Brain Morphology in Acute and Chronic Schizophrenia, 149 AM. J. PSYCHIATRY 784-94 (1992); M.H. Chakos et al., Increase in Caudate Nuclei Volumes of First-Episode Schizophrenic Patients Taking Antipsychotic Drugs, 151 AM. J. PSYCHIATRY 1430-36 (1994); R.E. Gur et al., Subcortical MRI Volumes in Neuroleptic-Nä̈ve and Treated Patients with Schizophrenia, 155 AM. J. PSYCHIATRY 1711-17 (1998); M.S. Keshavan et al., Decreased Caudate Volume in Neuroleptic-Nä̈ve Psychotic Patients, 155 AM. J. PSYCHIATRY 774-78 (1998); L. Shihabuddin et al., Dorsal Striatal Size, Shape, and Metabolic Rate in Never-Medicated and Previously Medicated Schizophrenics Performing a Verbal Learning Task, 55 ARCH. GEN. PSYCHIATRY 235-43 (1998); P.W. Corson et al., Caudate Size in FirstEpisode Neuroleptic-Nä̈ve Schizophrenic Patients Measured Using an Artificial Neural Network, 46 BIOL. PSYCHIATRY 712-20 (1999); R.E. Gur et al., Reduced Gray Matter Volume in Schizophrenia, 56 ARCH. GEN. PSYCHIATRY 905-11 (1999); R.E. Gur et al., Reduced Dorsal and Orbital Prefrontal Gray Matter Volumes in Schizophrenia, 57 ARCH. GEN. PSYCHIATRY 761-68 (2000); R.E. Gur et al., Temporolimbic Volume Reductions in Schizophrenia, 57 ARCH. GEN. PSYCHIATRY 769-75 (2000); U. Ettinger et al., Magnetic Resonance Imaging of the Thalamus in First-Episode Psychosis, 158 AM. J. PSYCHIATRY 116-18 (2001); A.R. Gilbert et al., Thalamic Volumes in Patients with First-Episode Schizophrenia, 158 AM. J. PSYCHIATRY 618-24 (2001); W. Cahn et al., Brain Morphology in Antipsychotic-Nä̈ve Schizophrenia: A Study of Multiple Brain Structures, 181 (suppl 43) BR. J. PSYCHIATRY S66-72 (2002); W. Cahn et al., 
measured the size of the brain ventricles found them to be significantly enlarged. For

example, Gur et al. reported a $16 \%$ increase in ventricular volume in thirty-three never-

treated patients compared to sixty-five normal controls. Similarly, McCreadie et al.

reported a $20 \%$ increase in ventricular volume in forty-two patients compared to thirty-

one normal controls. In addition to ventricular size, abnormalities in brain structure in

never-treated individuals with schizophrenia have been reported for the frontal cortex,

temporal cortex, hippocampus, amygdala, cingulate, thalamus, cerebellum, corpus

callosum, and septum pellucidum. The only brain area that has been extensively studied

Brain Volume Changes in First-Episode Schizophrenia: A 1-Year Follow-up Study, 59 ARCH. GEN. PSYCHIATRY 1002-10 (2002); H. Gunduz et al., Basal Ganglia Volumes in First-Episode Schizophrenia and Healthy Comparison Subjects, 51 BIOL. PSYCHIATRY 801-808 (2002); C.C. Joyal et al., A Volumetric MRI Study of the Entorhinal Cortex in First Episode Neuroleptic-Naïve Schizophrenia, 51 BIOL. PSYCHIATRY 1005-1007 (2002); P. Karlsson et al., PET Study of $D_{1}$ Dopamine Receptor Binding in Neuroleptic-Nä̈ve Patients with Schizophrenia, 159 AM. J. PSYCHIATRY 761-67 (2002); M.S. Keshavan et al., Abnormalities of the Corpus Callosum in First Episode, Treatment Naïve Schizophrenia 72 J. NEUROL. NeUrosurg. Psychiatry 757-60 (2002); M.S. Keshavan et al., Cavum Septi Pellucidi in First-Episode Patients and Young Relatives at Risk for Schizophrenia, 7 CNS SPECTRUMS 155-58 (2002); R.G. McCreadie et al., Structural Brain Differences between Never-Treated Patients with Schizophrenia, with and without Dyskinesia, and Normal Control Subjects: A Magnetic Imaging Study, 59 ARCH. GEN. PsYCHIATRY 332-36 (2002); S. Tauscher-Wisniewski et al., Caudate Volume Changes in First Episode Psychosis Parallel the Effects of Normal Aging: A 5-Year Follow-Up Study, 58 SCHIZOPHR. RES. 185-88 (2002); G. Cherascu et al., Changes in Morphology of the Thalamus over Time in Subjects with Neuroleptic Nä̈ve Schizophrenia: Effects of Neuroleptic Treatment (abstract), 60 SCHIZOPHR. RES. 191 (2003); M. M. Haznedar et al., Cingulate Gyrus Gray and White Matter Volumes in Drug Nä̈ve Schizophrenia Patients (poster presentation), annual meeting of the American Psychiatric Association (May 2003); M. M. Haznedar et al., Hippocampus Volume and 3-D Metabolic Mapping in Drug-Nä̈ve Schizophrenia Patients (poster presentation), annual meeting of the American Psychiatric Association (May 2003); J. Hietala et al., Regional Brain Morphology and Duration of Illness in Never-Medicated First-Episode Patients with Schizophrenia (letter), 64 SCHIZOPHR. RES. 79-81 (2003); C.C. Joyal et al., The Amygdala and Schizophrenia: A Volumetric Magnetic Resonance Imaging Study in First-Episode Neuroleptic-Naüve Patients, 54 Biol. PsyChIATRY 1302-1304 (2003); J.-J. Kim et al., Morphology of the Lateral Superior Temporal Gyrus in Neuroleptic Nä̈ve Patients with Schizophrenia: Relationship to Symptoms, 60 SCHIZOPHR. RES. 173-81 (2003); A.L.T. Lacerda et al., Orbitofrontal Cortex in First-Episode Schizophrenia: An MRI Study (abstract), 53 BIOL. PSYCHIATRY 116S (2003); P.R. Szeszko et al., Smaller Anterior Hippocampal Formation Volume in Antipsychotic-Naïve Patients with First-Episode Schizophrenia, 160A M. J. PSYCHIATRY 2190-97 (2003); G. Venkatasubramanian et al., Corticocerebellar Alterations in Never-Treated Young Age at Onset Schizophrenia (abstract), 60 SCHIZOPHR. RES. 211 (2003); M. Konasale et al., Cerebellum Morphometry in First-Episode Psychotic Disorders: Regional Specificity for Psychotic Symptoms and Cognition (abstract), 55 BIOL. PSYCHIATRY 169S (2004); G. Venkatasubramanian et al., Longitudinal Study of MRI Gray Matter Volume in Treatment-Nä̈ve Schizophrenia: Evidence for Cognitive Dysmetria (abstract), 67 SCHIZOPHR. RES. 25 (2004). 
and for which the results of different studies have been contradictory is the basal ganglia, especially its caudate subdivision.

\section{Neurological Abnormalities}

Since 1976, at least thirty-three studies have reported significantly more neurological abnormalities in individuals with schizophrenia who had never been treated with antipsychotic medications compared to unaffected controls. The neurological abnormalities include abnormal spontaneous movements called dyskinesias, parkinsonian signs, neurological soft signs, and cerebellar signs.

Dyskinesias are spontaneous movements, usually involving the tongue, facial muscles, or arms. Eleven studies have demonstrated that such movements occur more often among never-treated individuals with schizophrenia than among normal controls. ${ }^{51}$ For example, Fenton et al. found that $23 \%$ of never-treated patients exhibited some form of spontaneous dyskinesia. Seven recent studies have also reported that never-treated patients with schizophrenia have neurological abnormalities resembling those seen in

51 D.G.C. Owens, Spontaneous Involuntary Disorders of Movement, 39 ARCH. GEN. PSYCHIATRY 452-61 (1982); D. Rogers, The Motor Disorders of Severe Psychiatric Illness: A Conflict of Paradigms, 147 BR. J. PSYCHIATRY 221-32 (1985); R.G. McCreadie et al., The Scottish First Episode Schizophrenia Study: I. Patient Identification and Categorisation, 150 BR. J. PSYCHIATRY 331-33 (1987); J.L. Waddington \& H.A. Youssef, The Lifetime Outcome and Involuntary Movements of Schizophrenia Never Treated with Neuroleptic Drugs: Four Rare Cases in Ireland, 156 BR. J. PSYCHIATRY 106-108 (1990); W. Fenton et al., Risk Factors for Spontaneous Dyskinesia in Schizophrenia, 51 ARCH. GEN. PSYCHIATRY 643-50 (1994); A. Chatterjee et al., Prevalence and Clinical Correlates of Extrapyramidal Signs and Spontaneous Dyskinesia in Never-Medicated Schizophrenic Patients, 152 AM. J. PsYCHIATRY 1724-29 (1995) (hereinafter ChatterJeE et AL., Prevalence And CliniCal Correlates); D.S. Fenn et al., Movements in Never-Medicated Schizophrenics: A Preliminary Study, 123P SYCHOPHARMACOLOGY 20610 (1996); R.G. McCreadie et al., Abnormal Movements in Never-Medicated Indian Patients with Schizophrenia, 168B R. J. PSYCHIATRY 221-26 (1996) (hereinafter MCCREADIE ET AL., ABNORMAL MoveMENTS); M. Gervin et al., Spontaneous Abnormal Involuntary Movements in First-Episode Schizophrenia and Schizophreniform Disorder: Baseline Rate in a Group of Patients from an Irish Catchment Area, 155 AM. J. PSYCHIATRY 1202-1206 (1998); B.K. Puri et al., Spontaneous Dyskinesia in First Episode Schizophrenia, 66 J. NeUROL. NeUROSURG. PSYCHIATRY 76-78 (1999) (hereinafter PURI ET AL., SPONTANEOUS DYSKINESIA); W. Honer et al., Are Movement Disorders a Part of the Syndrome or Consequences of Treatment? (abstract), 53 SCHIZOPHR. RES. 11 (2002). 
Parkinson's disease, including rigidity, tremor, and slowing of movements. ${ }^{52}$ Combining the studies, 91 out of 394 (23\%) never-treated patients showed parkinsonian signs.

Neurological abnormalities called soft signs have also been extensively investigated in individuals with schizophrenia. Soft signs include such things as being unable to identify the type of coin placed in the hand without looking at it. Since 1992 , fourteen research groups have assessed the presence of neurological soft signs in nevermedicated patients with schizophrenia. ${ }^{53}$ Finally, a recent study compared neurological

52 M.P. Caligiuri et al., Parkinsonism in Neuroleptic-Nä̈ve Schizophrenic Patients, 150 AM. J. PSyChiatry 1343-48 (1993); ChatTerJeE ET Al., PREVAlenCE AND CliniCAl CorRelates; McCREADIE ET AL., ABnormal Movements; L.C. Kopala et al., Risperidone in First-Episode Schizophrenia: Improvement in Symptoms and Pre-Existing Extrapyramidal Signs, 2 InTERNATIONAL JOURNAL OF

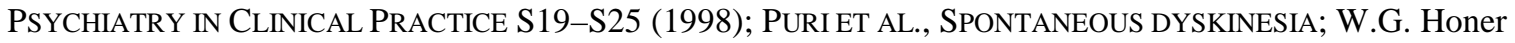
et al., Are Movement Disorders a Part of the Syndrome or Consequences of Treatment? (abstract), 53 SCHIZOPHR. RES. 11 (2002); and L. Cortese et al., Motor Abnormalities and Clinical Correlates in DrugNä̈ve, First Episode Patients with Schizophrenia (abstract), 53 SCHIZOPHR. RES. 55 (2002).

53 J. Schröder, J. et al., Neurological Soft Signs in Schizophrenia 6 SCHIZOPHR. RES. 25-30 (1992); P. Rubin, P. et al., Neurological Abnormalities in Patients with Schizophrenia or Schizophreniform Disorder at First Admission to Hospital: Correlations with Computerized Tomography and Regional Cerebral Blood Flow Findings 90 ACTA PSYCHIATR. SCAND. 385-90 (1994); R.D. Sanders et al. Neurological Examination Abnormalities in Neuroleptic-Nä̈ve Patients with First-Break Schizophrenia: Preliminary Results 151 AM. J. PSYCHIATRY 1231-33 (1994); S. Gupta et al., Neurological Soft Signs in Neuroleptic-Nä̈ve and Neuroleptic-Treated Schizophrenic Patients and in Normal Comparison Subjects 152 AM. J. PSYCHIATRY 191-96 (1995); L. Flyct et al., Neurological Signs and Psychomotor Performance in Patients with Schizophrenia, Their Relatives and Healthy Controls, 86 PSYCHIATRY RES. 113-29 (1999); S. Browne et al., Determinants of Neurological Dysfunction in First Episode Schizophrenia 30 PSYCHOL. MED. 1433-41 (2000); M.-O. Krebs et al., Validation and Factorial Structure of a Standardized Neurological Examination Assessing Neurological Soft Signs in Schizophrenia 45 SCHIZOPHR. RES. 245-60 (2000); M.-O. Krebs et al., Disorganisation Syndrome Is Correlated to Sensory Neurological Soft Signs in Medicated and Neuroleptic Nä̈ve Schizophrenic Patients (abstract) 53 SCHIZOPHR. RES. 232 (2002); T. Shibre et al., Neurological Soft Signs (NSS) in 200 Treatment-Nä̈ve Cases with Schizophrenia: A Community-Based Study in a Rural Setting 56 NORD. J. PSYCHIATRY 425-31 (2002); G. Venkatasubramanian et al., Neurological Soft Signs in Never-Treated Schizophrenia 108 ACTA PSYCHIATR. SCAND. 144-46 (2003); M.S. Keshavan et al., Diagnostic Specificity and Neuroanatomical Validity of Neurological Abnormalities in First-Episode Psychoses 160 AM. J. PSYCHIATRY 1298-1304 (2003); E.Y. Chen et al., Motor Soft Neurological Signs in First Episode Schizophrenia: A Two-Year Longitudinal Study (abstract) 60 SCHIZOPHR. RES. 129 (2003); P. Whitty et al., Prospective Evaluation of Neurological Soft Signs in First-Episode Schizophrenia in Relation to Psychopathology: State versus Trait Phenomena, 33 PSYCHOL. MED. 1479-84 (2003); and Russell E. Scheffer, Abnormal Neurological Signs at the Onset of Psychosis (submitted for publication). Studies of neurological soft signs are especially useful in understanding the role of antipsychotic medications in schizophrenia. Studies done on patients with schizophrenia who were on and off medications at the time of testing suggest that the medications either have no effect on the presence of neurological soft signs or decrease such neurological findings. See T.C. Manschreck et al., Disturbed Voluntary Motor Activity in Schizophrenic Disorder 12 PSYCHOL. MED. 7384 (1982); T. Kolakowska et al., Schizophrenia with Good and Poor Outcome. III: Neurological 'Soft' Signs, Cognitive Impairment and Their Clinical Significance 146 BR. J. PSYCHIATRY 348-57 (1985); and 
signs of cerebellar dysfunction in 155 never-treated individuals with schizophrenia to 155

matched normal controls. Among the patients, $21 \%$ had signs of cerebellar dysfunction, such as having an abnormal gait, whereas only $5 \%$ of the normal controls had such abnormalities. $^{54}$

\section{Neuropsychological Abnormalities}

For almost two centuries, it has been observed that individuals with schizophrenia have deficits in some neuropsychological functions, especially memory, attention, and planning (also called executive function). Since 1994, eight studies have been carried out on patients who had never received antipsychotic medications confirming these observations. For example, Brickman et al. compared twenty-nine never-medicated adolescents with schizophrenia to seventeen matched normal controls and reported that the patient group performed significantly worse than the normal controls, especially on memory, attention, and executive functioning. ${ }^{55}$ In addition to these eight studies, three other research groups studied individuals with first-episode schizophrenia, some of whom

G. Goldstein \& R.D. Sanders, The Effects of Antipsychotic Medication on Neurological Examination Abnormalities in Schizophrenia (abstract) 60 SCHIZOPHR. RES. 4 (2003).

54 B.-C. Ho, Cerebellar Dysfunction in Neuroleptic Nä̈ve Schizophrenia Patients: Clinical, Cognitive, and Neuroanatomic Correlates of Cerebellar Neurologic Signs, 55 BIOL. PSYCHIATRY 1146-53 (2004).

See A.M. Brickman et al., Neuropsychological Functioning in First-Break, Never-Medicated Adolescents with Psychosis, J. NERV. MENT., in press. See also A.J. Saykin et al., Neuropsychological Deficits in Neuroleptic Nä̈ve Patients with First-Episode Schizophrenia, 51 ARCH. GEN. PSYCHIATRY 124-31 (1994); R.G. McCreadie et al., Poor Memory, Negative Symptoms and Abnormal Movements in Never-Treated Indian Patients with Schizophrenia, 171B R. J. PSYCHIATRY 360-63 (1997); I. Lussier \& E. Stip, Memory and Attention Deficits in Drug Nä̈ve Patients with Schizophrenia, 48 SCHIZOPHR. RES. 4555 (2001); D. Schuepbach et al., Selective Attention in Neuroleptic-Nä̈ve First-Episode Schizophrenia: A Two-Year Follow-Up (abstract), 51 BIOL. PSYCHIATRY 118S (2002); and J.G. Kerns et al., ContextProcessing Deficits and Decreased Prefrontal Cortex Activity: Specific Associations with Unmedicated, First-Episode Schizophrenia and with Disorganization Symptoms (abstract), 60 SCHIZOPHR. RES. 225 (2003); S.K. Hill et al. Impairment of Verbal Memory and Learning in Antipsychotic-Nä̈ve Patients with First-Episode Schizophrenia, 68 SCHIZOPHR. RES. 127-36 (2004); K.P. Good et al., The Relationship of Neuropsychological Test Performance with the PANSS in Antipsychotic Naïve, First-Episode Psychosis Patients, 68 SCHIZOPHR. RES. 11-19 (2004). 
had never been medicated and some of whom had been briefly medicated, and reported that the never-medicated patients had significant neuropsychological deficits. ${ }^{56}$

\section{Neurophysiological Abnormalities}

Electrical impulses are one method used to communicate between brain cells. As noted previously, electroencephalograms (EEGs) have been used for many years to assess brain function in schizophrenia. Consistent with past studies, two recent studies used EEGs to examine sleep patterns in never-medicated individuals with schizophrenia, and both reported more abnormalities in the patients compared to the normal controls. ${ }^{57}$

Another technique commonly used in psychiatric research to measure neurophysiological function is a type of electrical impulse called an evoked potential, elicited by auditory, visual, or sensory input. For example, a startle reflex, measured electrically, may be evoked by a loud sound. Three recent studies of evoked potentials have been carried out on never-medicated individuals with schizophrenia; all three showed significantly more abnormalities in the patients than in normal controls. ${ }^{58}$

56 D.M. Censits et al., Neuropsychological Evidence Supporting a Neurodevelopmental Model of Schizophrenia: A Longitudinal Study, 24 SCHIZOPHR. RES. 289-98 (1997); S. Mohamed et al., Generalized Cognitive Deficits in Schizophrenia: A Study of First-Episode Patients, 56 ARCH. GEN. PSYCHIATRY 74954 (1999); and E.M. Riley et al., Neuropsychological Functioning in First-Episode Psychosis-Evidence of Specific Deficits, 43 SCHIZOPHR. RES. 47-55 (2000). There are recent studies that show that antipsychotic medications improve neuropsychological functioning; see, for example, R.S. Keefe et al., The Effects of Atypical Antipsychotic Drugs on Neurocognitive Impairment in Schizophrenia: A Review and MetaAnalysis, 25 ScHIZOPHR. BULL. 201-22 (1999); H.Y. Meltzer \& S.R. McGurk, The Effects of Clozapine, Risperidone, and Olanzapine on Cognitive Function in Schizophrenia, 25 SCHIZOPHR. BULL. 233-55 (1999); and M.C.G. Merlo et al., Improvement of Cognitive Functions in Acute First-Episode Psychosis Treated with Risperidone (abstract), 53 SCHIZOPHR. RES. 27 (2002).

57 R. Ganguli et al., Electroencephalographic Sleep in Young, Never-Medicated Schizophrenics, 44 ARCH. GEN. PSYCHIATRY 36-44 (1987) and Julie Poulin et al., Sleep Architecture and Its Clinical Correlates in First Episode and Neuroleptic-Nä̈ve Patients with Schizophrenia, 62 SCHIZOPHR. RES. 14753 (2003).

58 Torben Mackeprang et al., Effects of Antipsychotics on Prepulse Inhibition of the Startle Response in Drug-Nä̈ve Schizophrenic Patients, 52 BIOL. PsyCHIATRY 863-73 (2002), and Katja Ludewig et al., Deficits in Prepulse Inhibition and Habituation in Never-Medicated, First-Episode Schizophrenia 54 BIOL. PSYCHIATRY 121-28 (2003). Another recent study included five patients who had never been medicated 
Another measure of neurophysiological brain function is the recently developed transcranial magnetic stimulation (TMS), in which the brain is stimulated using magnets. A study of twenty-one neuroleptic-naïve individuals with schizophrenia reported them to be significantly different from twenty-one normal controls on some TMS measures. ${ }^{59}$ These studies suggest abnormal electrical and magnetic circuits in the brains of individuals with schizophrenia, evidence of neurophysiological dysfunction.

\section{Cerebral Metabolic Abnormalities}

The measurement of cerebral metabolic activity is comparatively new and technically complex. Three ways of doing this are by positron emission tomography (PET), single photon emission computed tomography (SPECT), and functional magnetic resonance imaging (fMRI). Since it is known that antipsychotic medications can affect these tests, ${ }^{60}$ it is important to use individuals who have not been treated whenever possible.

Since 1991, twenty studies have examined cerebral metabolic abnormalities in individuals with schizophrenia never treated with antipsychotic medications. Representative of these studies is one by Braus et al., in which twelve never-medicated patients with schizophrenia were compared to eleven normal controls by functional MRI. According to the researchers: "In comparison with control subjects, patients showed

and two others who had been off all medication for more than six months. It showed that antipsychotic medication improves neurophysiological function, as measured by the acoustic startle reflex; see Almut I. Weike et al., Effective Neuroleptic Medication Removes Prepulse Inhibition Deficits in Schizophrenia Patients, 47 BIOL. PSYCHIATRY 61-70 (2000); M. Valkonen-Korhonen, Altered Auditory Processing in Acutely Psychotic Never-Medicated First-Episode Patients, 17 BRAIN RES. COGN. BRAIN RES. 747-58 (2003).

59 P. Eichhammer et al., Cortical Excitability in Neuroleptic-Nä̈ve First-Episode Schizophrenic Patients, 67 SCHIZOPHR. RES. 253-59 (2004).

60 R.T. Loeber et al., Cerebellar Blood Volume in Bipolar Patients Correlates with Medication, 51 Biol. Psychiatry 370-76 (2002). 
reduced activation in the right thalamus, the right prefrontal cortex, and the parietal lobe

. . bilaterally." ${ }^{, 61}$ Of the twenty studies reported to date, all except one found more

cerebral metabolic abnormalities in the individuals with schizophrenia compared to the

controls.

In summary, since 1975 at least 103 separate studies have demonstrated that

individuals with schizophrenia, who have never been treated with antipsychotic

medications, have significant abnormalities in brain structure and function. This listing of

studies includes only those related to brain abnormalities; additional studies have been

61 Dieter F. Braus et al., Sensory Information Processing in Neuroleptic-Nä̈ve First-Episode Schizophrenic Patients: A Functional Magnetic Resonance Imaging Study, 59 ARCH. GEN. PSYCHIATRY 696-701 (2002). See also J.M. Cleghorn et al., Apomorphine Effects on Brain Metabolism in NeurolepticNä̈ve Schizophrenic Patients, 40 PSYCHIATRY RES.: NEUROIMAGING 135-53 (1991; M.S. Buchsbaum et al., Frontostriatal Disorder of Cerebral Metabolism in Never-Medicated Schizophrenics, 49 ARCH. GEN. PSYCHIATRY 935-42 (1992); L. Shihabuddin et al., Dorsal Striatal Size, Shape, and Metabolic Rate in Never-Medicated and Previously Medicated Schizophrenics Performing a Verbal Learning Task, 55 ARCH. GEN. PSYCHIATRY 235-43 (1998); M. Laruelle et al., Increased Dopamine Transmission in Schizophrenia: Relationship to Illness Phases, 46 BIOL. PSYCHIATRY 56-72 (1999); D.M. Barch et al., Selective Deficits in Prefrontal Cortex Function in Medication-Nä̈ve Patients with Schizophrenia, 58 ARCH. GEN. PSYCHIATRY 280-88 (2001); C. Clark et al., Regional Cerebral Glucose Metabolism in Never-Medicated Patients with Schizophrenia, 46 CAN. J. PSYCHIATRY 340-45 (2001); W.J. Brewer et al., Functional Neuroimaging Follow-Up of Stroop Performance in Neuroleptic-Nä̈ve First-Episode Psychosis (abstract), 53 (suppl) SCHIZOPHR. RES. 109 (2002); P. Karlsson et al., PET Study of D Dopamine Receptor Binding in Neuroleptic-Nä̈ve Patients with Schizophrenia, 159 AM. J. PSYCHIATRY 761-67 (2002); J. Tauscher, J. et al., Brain Serotonin 5-HT ${ }_{1 A}$ Receptor Binding in Schizophrenia Measured by Positron Emission Tomography and $\left({ }^{11} \mathrm{C}\right)$ WAY 100635, 59 ARCH. GEN. PSYCHIATRY 514-20 (2002); C.S. Carter et al., Prospective Longitudinal fMRI Study of Prefrontal Cortex Based Context Processing in Never Medicated First-Episode Schizophrenia (abstract), 60 SCHIZOPHR. RES. 214 (2003); Jean Théberge et al., Glutamate and Glutamine Measured with 4.0 T Proton MRS in Never-Treated Patients with Schizophrenia and Healthy Volunteers, 159 AM. J. PSYCHIATRY 1944-46 (2002); H. Tuppurainen et al., Extrastriatal Dopamine $D_{2 / 3}$ Receptor Density and Distribution in Drug-Nä̈ve Schizophrenic Patients, 8 MoL. PSYCHIATRY 453-55 (2003); J.A. Stanley et al., Age and Comorbidity Effects in First-Episode NeverMedicated Schizophrenia Subjects: An In Vivo ${ }^{1} H$ Spectroscopy Study (abstract), 53 BIOL. PSYCHIATRY 178S (2003); and Perumbava N. Jayakumar et al., Membrane Phospholipid Abnormalities of Basal Ganglia in Never-Treated Schizophrenia: A ${ }^{31}$ P Magnetic Resonance Spectroscopy Study 54 BIOL. PSYCHIATRY 491-94 (2003); D. Fannon et al., Selective Deficit of Hippocampal N-Acetylaspartate in AntipsychoticNaïve Patients with Schizophrenia, 54 BIOL. PSYCHIATRY 587-98 (2003); M.-C. Hsiao et al., Dopamine Transporter Change in Drug-Nä̈ve Schizophrenia: An Imaging Study with ${ }^{99 m}$ Tc-TRODAT-1, 65 SCHIZOPHR. RES. 39-46 (2003); B.N. Gangadhar et al., Basal Ganglia High-Energy Phosphate Metabolism in Neuroleptic-Nä̈ve Patients with Schizophrenia: A 31-Phosphorus Magnetic Resonance Spectroscopic Study, 161 AM. J. PSYCHIATRY 1304-1306 (2004); D. S. Lehrer et al., Prefrontal, Striatal and Thalamic FDG Uptake in Never-Medicated Patients with Schizophrenia (abstract) 55 BIOL. PSYCHIATRY 166S (2004); A.-L. Nordstrom, D2 Receptor Binding in Drug-Nä̈ve Patients Examined with FLB457 and Raclopride (abstract), 55 BIOL. PSYCHIATRY 72S (2004). 
carried out on antipsychotic-naïve patients with schizophrenia that have demonstrated other types of abnormalities such as altered interleukins, nerve growth factor, and red blood cell membrane essential fatty acids. ${ }^{62}$ Studies of medication-naïve patients thus demonstrate that abnormalities in schizophrenia are part of the disease process, not a result of medication being taken to treat the disease.

For neurological, neuropsychological, and neurophysiological abnormalities of cerebral function, in fact, there is evidence suggesting that antipsychotic medications decrease the abnormalities and return the brain to more normal function. This is consistent with the known effectiveness of antipsychotic medications in reducing the clinical symptoms of schizophrenia.

The 103 studies cited, which were restricted to those in which the patients had not previously taken antipsychotic medication, are part of a much larger cohort of studies of cerebral structure and function in patients who had been medicated. Studies of neurologic soft signs in schizophrenia, for example, number over 50, and studies of neuropsychological abnormalities number well over $200 .{ }^{63}$ Altogether, there are now over 1,000 published studies on brain structure and function in individuals with schizophrenia. It should also be emphasized that none of the cerebral abnormalities cited above are specific to schizophrenia. All of them can be found in some other brain diseases and

62 X.Y. Zhang et al., Decreased Production of Interleukin-2 (IL-2), IL-2 Secreting Cells and CD4+ Cells in Medication-Free Patients with Schizophrenia, 36 J. PSYCHIATR. RES. 331-36 (2002); V. Parikh et al., Nerve Growth Factor in Never-Medicated First-Episode Psychotic and Medicated Chronic Schizophrenic Patients: Possible Implications for Treatment Outcome, 60 ScHIZOPHR. RES. 117-23 (2003); M.M. Khan et al., Reduced Erythrocyte Membrane Essential Fatty Acids and Increased Lipid Peroxides in Schizophrenia at the Never-Medicated First-Episode of Psychosis and After Years of Treatment with Antipsychotics, 58 SCHIZOPHR. RES. 1-10 (2002).

63 R.D. Sanders \& M.S. Keshavan, The Neurologic Examination in Adult Psychiatry: From Soft Signs to Hard Science 10 J. NeuropsyChiatry Clin. NeurosCI. 395-404 (1998), and R.W. Heinrichs \& K.K. Zakzanis, Neurocognitive Deficit in Schizophrenia: A Quantitative Review of the Evidence, 12 NEUROPSYCHOLOGY 426-45 (1998). 
occasionally in normal individuals, although they occur statistically more frequently in individuals with schizophrenia. Thus, the brain abnormalities found in schizophrenia are similar to the tremor seen in many patients with Parkinson's disease. Tremor may also be found in other brain diseases; it occurs in some normal individuals [benign intention tremor], but it occurs statistically much more frequently in Parkinson's disease.

\section{Anosognosia: Competence To Make Informed Treatment Decisions}

Advances in the understanding of anosognosia in recent years have profound implications for mental health laws. Anosognosia remains, however, little known and poorly understood, both by the legislators who make the laws and by the law enforcement officials and judges who implement them. Indeed, only recently a small number of mental health law scholars became aware of the phenomenon. ${ }^{64}$ In Descartes' Error, neurologist Antonio Damasio called anosognosia "one of the most eccentric neuropsychological presentations one is likely to encounter." ${ }^{65}$ Neurologist Oliver Sacks in The Man Who Mistook His Wife for a Hat described anosognosia as being "singularly

64 Xavier F Amador \&Andrew A. Shiva, Insight into Schizophrenia: Anosognosia, Competency, and Civil Liberties, 11 GeORGE MAsOn Civil RightS-Civil Liberties L. J. 25 (2000); Ken Kress, An Argument for Assisted Outpatient Treatment for Persons with Serious Mental Illness Illustrated with Reference to a Proposed Statute for Iowa, 85 IOWA (2000) (hereinafter KRESS, AN ARGUMENT FOR Assisted OUtPatient TREATMENT) 1269, 1274; Ken Kress, Why Lack of Insight Should Have a Central Place in Mental Health Law, in Xavier Amador \& Anthony David, INSIGHT AND PSYCHOSIS: AwARENESS OF ILLNESS IN SCHIZOPHRENIA AND RELATED DISORDERS, 2d ed., (2004) (hereinafter AMADOR \& DAVID, INSIGHT AND PSYCHOSIS) (hereinafter KRESS, WHY LACK OF INSIGHT SHOULD HAVE A CENTRAL PLACE) 257; E. Fuller Torrey, The Relationship of Insight to Violent Behavior and Stigma, in AMADOR \& DAVID, INSIGHT AND PSYCHOSIS (hereinafter TORREY, THE RELATIONSHIP OF INSIGHT TO VIOLENT BEHAVIOR AND STIGMA) 243.

65 Antonio R. Damasio, DESCARTES' ERROR: EMOTION, REASON, AND THE HUMAN BRAIN 62 (1995) (hereinafter DAMASIO, DESCARTES’ ERROR). 
difficult, for even the most sensitive observer, to picture the inner state ... for this is unimaginably remote from anything he himself has ever known.",66

Etymologically, anosognosia is derived from the Greek nosos, "disease," and gnosis, "knowledge." It literally means to not know a disease. As commonly used, it means to not know one's own disease and is used interchangeably with such terms as "lack of awareness of illness" and "lack of insight." In psychiatry, anosognosia usually connotes three overlapping dimensions: the failure to recognize that one has a psychiatric disease; the inability to recognize that one's unusual mental events, such as delusions and hallucinations are pathological; and noncompliance with treatment. ${ }^{67}$ Anosognosia is a biologically based inability to appreciate one's own illness. Thus, it differs from denial, which is a psychologically based mechanism we all commonly use. In some individuals with brain disorders, anosognosia and denial may both be operant.

\section{A. Before 1975: Confined to Neurology}

Anosognosia has been known to neurologists for over a century. In 1893, Gabriel Anton in Germany published a paper describing a patient who had become paralyzed on

66 Oliver Sacks, The Man Who Mistook His WIFE FOR A HAT 5 (1990).

67 Anthony S. David, Insight and Psychosis, 156 BR. J. PSYCHIATRY 798-808 (1990). Other researchers have added additional dimensions to the use of the term, including failure to perceive the need for treatment, lack of awareness of the benefits of treatment, and lack of awareness of the social consequences of having a psychiatric disorder. See Xavier F. Amador \& Regine Anna Seckinger, The Assessment of Insight: A Methodological Review, 27 PSYCHIATR. ANN. 798-805 (1997). As used in neurology, anosognosia has been defined as "an impaired ability to recognize the presence or appreciate the severity of deficits in sensory, perceptual, motor, affective, or cognitive functioning”; see Susan KotterCope \& Cameron J. Camp, Anosognosia in Alzheimer Disease 9 AlZHEIMER Dis. ASSOC. DISORD. 52-56 (1995) (hereinafter KoTTER-COPE \& CAMP, ANOSOGNOSIA IN ALZHEIMER DiSEASE). 
his side from a stroke but who claimed that there was nothing wrong. ${ }^{68}$ Additional cases were reported, and in 1914 Joseph Babinski, at a meeting of the French Neurological Society, coined the term "anosognosia" to describe this curious syndrome. ${ }^{69}$

By mid-century, anosognosia had become well established in the neurological literature and was usually associated with strokes or brain tumors. A 1952 review of one hundred cases of stroke reported that twenty-three of them had complete anosognosia and five others "fluctuated in their responses from awareness to total denial." ${ }^{, 70}$ As examples of anosognosia, the authors cited:

One patient, when asked why she could not move her hand, said, "Somebody has a hold of it...." One woman when asked whether she could walk said, "I could walk at home, but not here. It's slippery here." One patient, when asked if anything was wrong with his arm, said, "It's just a little stiff-from the cold or something." When asked why he couldn't raise it, he said, "I have a shirt on.,"71

In 1955, a neurological monograph described fifty-two additional cases of complete anosognosia. Included were examples such as the following:

The patient denied there was anything the matter with her left arm or leg. When asked to raise her left arm, she repeatedly raised her left leg. When

68 Gabriel Anton, Beitrage zur klinischen Beurtheilung und zur Localisation der Muskelsinnstörungen im Grosshirne, 14 Z. HELIK. 313-48 (1893). Anton also published papers describing individuals who became blind because of brain lesions but who then claimed to be able to see perfectly well. This syndrome is now known as Anton's syndrome. See Gabriel Anton, Über die Selbstwahrnehmung der Herderkrankungen des Gehirns durch den Kranken bei Rindenblindheit und Rindentaubheit, 32 ARCH. PSYCHIATR. NERVENKR. 86-127 (1899).

69 Joseph Babinski, Contribution à l'étude des troubles mentaux dans l'hémiplégie organique célébrale (anosognosie), 27 REV. NEUROL. (PARIS) 845-48 (1914). Babinski described two cases, one of whom had had a paralysis of her left side for many years but denied that there was anything wrong. When asked to move her left hand, she simply ignored the command.

70 Morton Nathanson et al., Denial of Illness: Its Occurrence in One Hundred Consecutive Cases of Hemiplegia, 68 ARCH. NEUROL. PSYCHIATRY 380-87 (1952).

71 Ibid. 
this error was pointed out to her, she said, "Oh, some people call it an arm, some a leg. What's the difference!"72

In some cases of stroke-associated anosognosia, the anosognosia remits as the person's stroke resolves and the patient can then acknowledge the problem, but in many cases the person's anosognosia is permanent.

One of the most striking aspects of these cases of anosognosia is the absence of concern in the person affected. As Damasio describes it: "The lack of update on the real states of body and person is nothing less than astounding ... [including] the lack of concern they show for their overall situation, the lack of emotion they exhibit, the lack of feeling they report when questioned about it.,"73

In contrast to neurology, prior to 1975 there was almost no discussion of anosognosia among individuals with psychiatric disorders. There had been observations in the nineteenth and early twentieth centuries that individuals with what was then called “insanity" were often unaware of their own illness, but connection to the neurologists' concept of anosognosia was not made. For example, in 1869, an article in the American Law Review noted: "Generally, insane people do not regard themselves as insane and, consequently, can see no reason for their confinement other than the malevolent designs of those who have deprived them of their liberty." 74 Some psychiatrists of that period

72 Edwin A. Weinstein \& Robert L. Kahn, DENIAL OF ILLNESS 20 (1955) (hereinafter WEINSTEIN \& KAHN, DENIAL OF ILLNESS). Some descriptions of anosognosia are even more bizarre, such as patients who deny the absence of amputated arms or legs and a patient who "claimed that the left hand did not belong to her but had been forgotten in the ambulance by another patient”; see Edoardo Bisiach \& Giuliano Geminiani, Anosognosia Related to Hemiplegia and Hemianopia, in AWARENESS OF DEFICIT AFTER BRAIN INJURY: CliniCAL AND ThEORETICAL ISSUES 25 (George P. Prigatano \& Daniel L. Schacter eds., 1991) (hereinafter BISIACH \& GEMINIANI, ANOSOGNOSIA RELATED TO HEMIPLEGIA AND HEMIANOPIA).

73 DAMASIO, DESCARTES' ERROR 64. On this subject, WEINSTEIN AND KAHN, DENIAL OF ILLNESS 18, add: "Anosognosic patients seemed to maintain a serene faith that they were well which remained firm despite all disbelief by others."

Anonymous, Confinement of the Insane, 3 AM. LAW REV. 215 (1869). 
even suggested that lack of awareness of one's insanity should be the central criterion for the form of insanity then labeled "moral insanity." 75 It was an echo of Thomas Dekker's 1604 play The Honest Whore, in which a character declaims: "That proves you mad because you know it not."76

By the early twentieth century, psychiatrists occasionally noted lack of insight in psychiatric patients. Emil Kraepelin, for example, in his classic 1919 textbook observed that "understanding of the disease disappears fairly rapidly as the malady progresses in the overwhelming majority of cases, even where in the beginning it was more or less clearly present."77

At the time Kraepelin published his textbook, the writings of Sigmund Freud were already circulating in Europe and the United States. Freud taught that denial was one of the most common and important defense mechanisms used by people. As Freud's theories became more widely known, the concept of denial became increasingly influential and was invoked to explain why individuals with schizophrenia and other severe psychiatric disorders did not acknowledge their illnesses. Denial as a psychologically-based defense mechanism continued to be a prominent psychiatric explanatory principle throughout the twentieth century. Thus, in the 1960s and 1970s, when laws governing the treatment of psychiatric patients were undergoing changes, there was no discussion regarding the possibility that unawareness of one's illness might

75 For a discussion of this, see German E. Berrios, The History OF MENTAL SyMPTOMS (1996).

76 Thomas Dekker, THE HONEST WHORE (1604), cited by J. Thomas Dalby, Elizabethan Madness on London's Stage 81 PSYCHOL. REP. 1331-43 (1997).

77 Emil Kraepelin, DEMENTIA PRAECOX AND PARAPHRENIA 26 (1971), originally published in 1919. Kraepelin also quotes one of his patients as saying: "Whoever thinks that I am mad, is himself mad." Id. at 22. 
be a biologically-based symptom of the illness. The concept of anosognosia simply did not exist in the corpus of psychiatric writings.

\section{B. Since 1975: Established in Psychiatry}

Since the mid 1970s, there has been a marked increase in interest in, and understanding of, anosognosia. This increase can be measured by the number of articles written about anosognosia, as determined by a search of the National Library of Medicine's database. ${ }^{78}$ Between 1970 and 1979, 12 articles about anosognosia were published; from 1980 to 1989, 50 additional articles were published; and between 1990 and 1999, the number was 119. This increased interest is reflected in both neurology and psychiatry.

\section{Alzheimer's Disease and Huntington's Disease}

In the 1980s, neurologists extended their interest in anosognosia from strokes and brain tumors to Alzheimer's disease and Huntington's disease. In Alzheimer's disease, studies showed that patients in the earliest stages of the disease are aware of, and increasingly anxious about, their memory problems. Once beyond the early stages, however, most individuals with Alzheimer's diseases become less anxious and gradually lose awareness of their deficits. ${ }^{79}$ Recent studies have also reported that anosognosia is most common in Alzheimer's patients who have the most severe cognitive impairments

\footnotetext{
78 Searches can be carried out using MEDLINE/PubMed, the National Library of Medicine's database of over 12 million citations to medical journal articles from 1966 to the present.

79 See, for example, one of the first studies of anosognosia in patients with Alzheimer's disease: M. K. Schneck et al., An Overview of Current Concepts of Alzheimer's Disease: 139 AM. J. PSYCHIATRY 165
} (1982). 
and deficits in activities of daily living, although not all studies have found a linear relationship. ${ }^{80}$ Several researchers have noted that individuals with Alzheimer's disease may have almost total anosognosia for their cognitive deficits, such as memory loss, and yet, at the same time, retain awareness for other aspects of function, such as their behavior. $^{81}$ The fact that individuals can be completely unaware of some aspects of their brain function yet aware of other aspects is often confusing to family members and other observers.

Huntington's disease is another neurological illness in which anosognosia is found, especially in the later stages of the disease. Huntington's disease is genetically transmitted and includes abnormal movements and severe memory impairment. One study of thirty patients with Huntington's disease reported that seven of them had complete, and four others partial, anosognosia. ${ }^{82}$ Especially striking in Huntington's disease is the possibility that anosognosia may occur for both the person's memory impairment and also for their abnormal movements. Thus, one patient was described as follows:

He fidgeted, sat about, got up, sat about some more and was euphoric. When I asked about his ability to perform certain movements, he said he was fine and walked over to the bookcase, picked up a book and threw it into the air and let it crash to the

80 See, for example, Ricardo Migliorelli et al., Anosognosia in Alzheimer's Disease: A Study of Associated Factors 7 J. NeUROPSYCHIATRY Clin. NeUROSCI. 338-44 (1995), and Orazio Zanetti et al., Insight in Dementia: When Does It Occur? Evidence for a Nonlinear Relationship Between Insight and Cognitive Status, 54B J. GERONTOL.: PSYCHOL. SCI. 100 (1999).

81 KOTTER-COPE \& CAMP, ANOSOGNOSIA IN AlZHEIMER DisEASE.

82 A good summary of such studies can be found in Susan M. McGlynn \& Alfred W. Kaszniak, Unawareness of Deficits in Dementia and Schizophrenia, in AWARENESS OF DEFICIT AFTER BRAIN INJURY: CliniCAL And TheORETICAL Issues 84-110 (George P. Prigatano \& Daniel L. Schacter eds., 1991) (hereinafter MCGLYNN \& KASZNIAK, UNAWARENESS OF DEFICITS). It is of interest that when individuals with Huntington's disease commit suicide, they usually do so in the early stages of their illness, when their awareness of their illness is still intact. 
deck. This event did not worry him; he just said it was a mistake. $^{83}$

It is important to note that not all neurological diseases are accompanied by anosognosia. Most patients with Parkinson's disease, for example, retain relatively good comprehension of their illness. One study compared thirty three patients with Alzheimer's disease with thirty-three patients with Parkinson's disease on awareness of illness, and the patients with Parkinson's disease had almost no anosognosia. ${ }^{84}$

\section{Schizophrenia}

The concept of anosognosia was not clearly linked to schizophrenia until the 1980s. Joseph McEvoy, a psychiatrist at the University of Pittsburgh, began investigating the link between lack of awareness of illness and the need for involuntary treatment in individuals with schizophrenia. McEvoy and his associates developed a scale, the Insight and Treatment Attitudes Questionnaire (ITAQ), to measure awareness of illness and noted that "committed patients require coercive hospitalization because they fail to recognize their need for care." 85

In the early 1990s, anosognosia rapidly ascended to prominence in psychiatric writings. Xavier Amador, a psychologist at Columbia University in New York, and Anthony David, a psychiatrist at the Institute of Psychiatry in London, began studies with their colleagues that have continued to the present. Both groups developed assessment

83 K. Bradley, Diseases of the Basal Ganglia, in THE BASAl GANGLiA 338 (J. S. McKenzie et al. eds., 1984).

84 Sergio E. Starkstein et al., Neuropsychological and Psychiatric Differences Between Alzheimer's Disease and Parkinson's Disease with Dementia 61 J NeUrOL. NEUROSURG. PSYCHIATRY 381-87 (1996).

85 Joseph P. McEvoy et al., Measuring Chronic Schizophrenic Patients' Attitudes toward Their Illness and Treatment, 32 HosP COMMUNITY PSYCHIATRY 856-58 (1981); Joseph P. McEvoy et al., Why Must Some Schizophrenic Patients Be Involuntarily Committed? The Role of Insight 30 COMPR. PSYCHIATRY 13-17 (1989). 
tools that can be used to measure awareness of illness: the Scale to Assess Unawareness

of Mental Illness (SUMD) and the Schedule for the Assessment of Insight (SAI), respectively. ${ }^{86}$ The availability of instruments that can be used to measure anosognosia in large groups of patients has advanced this research area rapidly.

One issue on which there has been an emerging consensus is the percentage of individuals with schizophrenia who have anosognosia. A study carried out by Amador and his colleagues reported that $57 \%$ of patients with schizophrenia "had moderate to severe unawareness of having a mental disorder." ${ }^{87}$ Another study of eighty-seven stable outpatients with schizophrenia, all of whom were receiving treatment, found that $50 \%$ "were rated as having at least a moderate impairment in insight about their illness." ${ }^{, 8}$ The large MacArthur treatment competence study similarly found that approximately half of the individuals with schizophrenia lacked an understanding of their illness and/or an appreciation of the importance of treatment. ${ }^{89}$ Another study directly compared patients with schizophrenia and patients with focal neurological disorders, such as strokes and brain tumors, on awareness of their illnesses. Among the patients with schizophrenia,

86 Xavier F. Amador et al., Assessment of Insight in Psychosis 150 AM. J. PSYCHIATRY 873-79 (1993); Xavier F. Amador et al., Awareness of Illness in Schizophrenia 17 SCHIZOPHR. BULL. 113-32 (1991); Anthony David et al., The Assessment of Insight in Psychosis 161 BR. J. PSYCHIATRY 599-602 (1992). In addition to the ITAQ, SUMD, and SAI scales, other scales have also been proposed. Studies comparing them have reported a high degree of inter-correlation between the scales. See M. Sanz et al., A Comparative Study of Insight Scales and Their Relationship to Psychopathological and Clinical Variables 28 PSYCHOL. MED. 437-46 (1998).

87 Xavier F. Amador et al., Awareness of Illness in Schizophrenia and Schizoaffective and Mood Disorders, 51 ARCH. GEN. PSYCHIATRY 826-36 (1994).

88 Faith B. Dickerson et al., Lack of Insight Among Outpatients with Schizophrenia 48 PSYCHIATR. SERV. 195-99 (1997).

89 Thomas Grisso \& Paul S. Appelbaum, The MacArthur Treatment Competence Study. III. Abilities of Patients To Consent to Psychiatric and Medical Treatments 19 LAW HuMAN BEHAV. 149-74 (1995). 
$47 \%$ were unaware of their illness, while among the neurological patients, $57 \%$ were unaware. ${ }^{90}$

Studies thus demonstrate that approximately half of all individuals with schizophrenia have moderate to severe impairment in awareness of their illness. Moreover, it appears that this impairment in awareness occurs somewhat more often in individuals whose symptoms of schizophrenia are more severe, ${ }^{91}$ but that it is not a direct product of delusions, depression, or other symptoms. Rather, the impairment in awareness of illness seen in individuals with schizophrenia is itself a symptom of the disease and is true anosognosia. Thus, it is the same phenomenon as is observed in many neurological patients with strokes, brain tumors, Alzheimer's disease, and Huntington's disease.

Studies of individuals with schizophrenia who also have tardive dyskinesia illustrate the fundamental similarity of anosognosia found in schizophrenia and that found in individuals with neurological disorders. Tardive dyskinesia is a side effect of antipsychotic medication commonly used to treat schizophrenia and occurs in approximately $10 \%$ of patients. It consists of involuntary movements of the tongue and jaw and, in more severe cases, the arms and legs.

As early as 1970 , it was noted that many individuals with schizophrenia who also had tardive dyskinesia appeared to be unaware of their own involuntary movements. ${ }^{92}$ Since that time, at least eight studies have been carried out confirming this. In one study,

90 Xavier F. Amador et al., Awareness Deficits in Neurological Disorders and Schizophrenia (abstract) 24 SCHIZOPHR. RES. 96 (1997).

${ }_{91}$ Alisa R. Mintz et al., Insight in Schizophrenia: A Meta-Analysis, 61 SCHIzOPHR. Res. 75-88 (2003). (1970), and G. M. Simpson, CNS effects of neuroleptic agents, 5 PSYCHIATR. ANN. 53 (1975). 
for example, "75\% of [the] patients were completely or partially unaware of their abnormal involuntary movements"; in another study, "most of them (88\%) were oblivious to or not concerned with their abnormalities, despite noticeable disturbances of speech that these symptoms incurred." $" 93$ In 1985, Myslobodsky and his colleagues correctly labeled this lack of awareness of symptoms of tardive dyskinesia a form of anosognosia. $^{94}$

Other studies have demonstrated that individuals with schizophrenia who are unaware of their tardive dyskinesia are also likely to be unaware of their schizophrenia, thus suggesting that unawareness of the neurological and psychiatric symptoms are part of the same process. ${ }^{95}$ Studies of anosognosia in individuals who have schizophrenia and tardive dyskinesia have also reported that some individuals who are unaware of their own abnormal movements may be completely aware of similar abnormal movements in other patients. ${ }^{96}$ This finding is similar to studies showing that individuals with schizophrenia who are not aware of their own psychiatric symptoms, such as delusions and hallucinations, may be fully aware of the same symptoms in other patients." 97

93 Giovanni Caracci et al., Subjective Awareness of Abnormal Involuntary Movements in Chronic Schizophrenic Patients, 147 AM. J. PSYCHIATRY 295 (1990), and M. S. Myslobodsky et al., Cognitive Impairment in Patients with Tardive Dyskinesia, 173 J. NERV. MENT. DIs. 156-60 (1985) (hereinafter MYSLOBODSKY ET AL., COGNITIVE IMPAIRMENT). See also George S. Alexopoulos, Lack of Complaints in Schizophrenics with Tardive Dyskinesia, 167 J. NERV. MENT. DIS. 125 (1979); Celso Arango et al., Relationship of Awareness of Dyskinesia in Schizophrenia to Insight into Mental Illness, 156 AM. J. PSYCHIATRY 1097 (1999); Fabien Trémeau et al., Insight and Anosognosia of Tardive Dyskinesia in Schizophrenia (abstract), 24 SCHIZOPHR. RES. 273 (1997) (hereinafter TRÉMEAU ET AL., INSIGHT AND Anosognosia); Arnold M. Rosen et al., Perception of Tardive Dyskinesia in Outpatients Receiving Maintenance Neuroleptics, 139 AM. J. PsYCHIATRY 372 (1982); and James M. Smith et al., A Systematic Investigation of Tardive Dyskinesia in Inpatients, 136 AM. J. PSYCHIATRY 918 (1979) (hereinafter SMITH ET AL., A SYSTEMATIC INVESTIGATION).

94 MYSLOBODSKY ET AL., COGNITIVE IMPAIRMENT. TRÉMEAU ET AL., INSIGHT AND ANOSOGNOSIA. SMITH ET AL., A SySTEMATIC INVESTIGATION.

97 Mike Startup, Awareness of Own and Others' Schizophrenic Illness 26 SCHIZOPHR. RES. 203-11 (1997). This discrepancy between self-observation and the observation of others is difficult for others to comprehend. As one research group noted: "Although it is conceivable that these patients might have been 
Another question that has received considerable research attention is whether awareness of illness can be improved in individuals with schizophrenia. Attempts have been made to do this with specific forms of psychotherapy ${ }^{98}$ and with antipsychotic medications. Studies to date suggest that medication can improve awareness of illness in approximately one-third of those for whom it is lacking, but the majority of individuals do not show much improvement, even though other symptoms of their illness may improve. ${ }^{99}$ Claims have also been made that one or another type of antipsychotic medication is more effective in improving awareness of illness, but none of these claims have been substantiated. ${ }^{100}$

\section{Anatomical Localization of Anosognosia}

Debate about the possible anatomical localization of anosognosia has been taking place for a century. It was early noted that anosognosia in individuals with strokes and brain tumors occurred most often when the brain lesions were in the right hemisphere. Subsequent studies have confirmed that right hemisphere lesions are four times more likely to produce anosognosia compared to left hemisphere lesions. ${ }^{101}$ Thus, it appears

unaware of their own tongue or mouth movements, it is difficult to see how they could not have observed their own hand, feet, or leg movement (see SMith ET AL., A SYSTEMATIC InVESTIGATION).

98 R. Kemp et al., Can Insight and Compliance Be Improved in Psychosis? (abstract) 15 SCHIZOPHR. RES. 217 (1995). Psychological attempts to improve what we now call anosognosia date to Dr. Benjamin Rush's efforts in the early nineteenth century. "He urged the insane to write their thoughts and secrets on paper in hopes that when they saw what they had written they would be shocked into rejecting their pathological ideas" (see NORMAN DAIN, CONCEPTS OF INSANITY IN THE UNITED STATES, 1789, 20 (1964)). (1995)

P. Jørgensen, Recovery and Insight in Schizophrenia 92 ACTA PSYCHIATR. SCAND. 436-40

100 Stefano Pallanti et al., Effects of Clozapine on Awareness of Illness and Cognition in Schizophrenia 86 PSYCHIATRY RES. 239-49 (1999); Martha Sajatovic et al., Insight into Illness and Attitudes Toward Medications Among Inpatients with Schizophrenia 53 PSYCHIATR. SERV. 1319-21 (2002); Eugenio Aguglia et al., Insight in Persons with Schizophrenia: Effects of Switching from Conventional Neuroleptics to Atypical Antipsychotics 26 PROG. NEUROPSYCHOPHARMACOL. BIOL PSYCHIATRY 1229-33 (2002).

101 John Cutting, Study of Anosognosia, 41 J. NeUROL. NeUROSURG. PSYCHIATRY 548 (1978). 
that brain circuits controlling self-awareness are situated predominantly in the right hemisphere in the majority of people.

Attempts to localize the origins of anosognosia more precisely are continuing but have yielded inconsistent data. A major reason for this is that, anatomically, brain areas are discrete, but functionally, they are extensively interconnected with each other; thus, abnormal function in one part of the brain inevitably affects many other areas. Computerized tomography (CT) scans of individuals who have had strokes have associated anosognosia with the inferior parietal lobule, the thalamus, and basal ganglia. ${ }^{102}$ Other researchers have also stressed the importance of the inferior parietal lobule in producing anosognosia in individuals with strokes and brain tumors, while others have also suggested involvement of the insula. ${ }^{103}$ A CT scan study of individuals with Alzheimer's disease, in contrast to the above, reported abnormalities in the prefrontal region in the right hemisphere, while a similar study of individuals with Huntington's disease suggested that the caudate portion of the basal ganglia was associated with anosognosia. ${ }^{104}$

Attempts to localize the anatomical basis of anosognosia in schizophrenia have also yielded conflicting data. Such attempts have been carried out using neuropsychological testing and neuroimaging techniques such as CT and MRI scans. Multiple studies have attempted to correlate measures of unawareness of illness, using assessment scales such as described previously, with neuropsychological measures of

102 BisiaCH \& GEMINIANI, ANOSOGNOSIA RELATED TO HEMIPLEGIA AND HEMIANOPIA.

103 For a thorough discussion of these theories, see Susan M. McGlynn \& Daniel L. Schacter, Unawareness of Deficits in Neuropsychological Syndromes, 11 J. CLIN. EXP. NEUROPSYCHOL. 143(1989).

104 Bruce R. Reed et al., Anosognosia in Alzheimer's Disease: Relationships to Depression, Cognitive Function, and Cerebral Perfusion, 15 J. Clin. EXP. NEUROPSYCHOL. 231 (1993), and MCGLYNN \& KASZNIAK, UNAWARENESS OF DEFICITS. 
frontal lobe function. The neuropsychological test most widely used has been one that measures the ability of a person to rapidly shift their analytic mindset. ${ }^{105}$ The results of these studies have been contradictory, with several claiming that anosognosia correlates with impairment on this test, whereas others have reported no correlation. ${ }^{106}$ One attempt has also been made to correlate unawareness of illness with neuropsychological measures of parietal lobe function. ${ }^{107}$ A major problem with all such attempts using neuropsychological measures is that such measures are relatively nonspecific for anatomical areas of the brain.

The use of neuroimaging techniques to localize anosognosia in individuals with schizophrenia has also yielded contradictory findings. Two studies examined the size of the brain ventricles; one reported that enlarged brain ventricles were found more frequently in individuals with impaired awareness of illness, but the other found no association. ${ }^{108}$ Two other studies measured brain volume; one reported that decreased brain volume occurred more commonly in individuals with decreased awareness of illness, but the other study did not. ${ }^{109}$

Other researchers have focused neuroimaging attention to specific parts of the brain. Two studies have reported decreased volumes of specific parts of the frontal lobe

105 The test is called the Wisconsin Card Sort and measures what is usually called executive function. This function is thought to be primarily associated with the prefrontal part of the frontal lobe.

106 For example, see Richard James Drake \& Shôn William Lewis, Insight and Neurocognition in Schizophrenia 62 SCHIZOPHR. RES. 165-73 (2003), and Manuel J. Cuesta \& Victor Peralta, Lack of Insight in Schizophrenia 20 SCHIZOPHR. BULL. 359-66 (1994).

107 Laura Flashman et al., Unawareness of Illness in Schizophrenia: Relationship to Frontal and Parietal Lobe Structure and Cognitive Function (abstract) 9 J. NEUROPSYCHIATRY Clin. NEUROSCI. 670 (1997).

Akihiro Takai et al., Insight and Its Related Factors in Chronic Schizophrenic Patients: A Preliminary Study 6 EUR. J. PSYCHIAT. 159-70 (1992), and Anthony David et al., Insight and Psychotic Illness: Cross-Sectional and Longitudinal Associations 167 BR. J. PSYCHIATRY 621-28 (1995).

109 S. L. Rossell et al., Insight: Its Relationship with Cognitive Function, Brain Volume and Symptoms in Schizophrenia 33 PSYCHOL. MED. 111-19 (2003), and Laura Flashman et al., Smaller Brain Size Associated with Unawareness of Illness in Patients with Schizophrenia 157 AM. J. PSYCHIATRY 116769 (2000). 
in individuals who have impaired awareness of illness, and another has reported generalized atrophy of the frontal lobe in such cases. ${ }^{110}$ Still another study, carried out in individuals with schizophrenia who had recently developed the disease, found that deficits in the cingulate gyrus and insula correlated with poor awareness of illness. ${ }^{111}$

Given advances in neuroimaging techniques, such research is likely to move forward rapidly in the coming years. At this point in time, the most that can be said with certainty regarding the anatomical localization of anosognosia is that it primarily involves the right hemisphere of the brain and that the inferior parietal and frontal lobes are involved. The fact that there are very close connections between these two areas, as well as to the thalamus and cingulate, which appear to also be involved in anosognosia, provides a promising basis forfuture research.

\section{Consequences of Anosognosia}

It has been increasingly recognized that anosognosia may have adverse consequences. Individuals who are unaware of their brain disorder often refuse treatment and may behave in a manner that endangers themselves or other people.

For Alzheimer's disease, such consequences were illustrated by the publicized case of Ralph Thompson, an eighty-two-year-old man who suffered from this disorder. On November 8, 2000, Mr. Thompson was stopped by a police officer in the District of

110 S. D. Sahni et al., Insight and the Prefrontal Cortex in Psychotic Disorders (abstract) 51 BIOL. PSYCHIATRY 62S (2002); Laura A. Flashman et al., Specific Frontal Lobe Subregions Correlated with Unawareness of Illness in Schizophrenia: A Preliminary Study 13 J. NEUROPSYCHIATRY CliN. NEUROSCI. 255-57 (2001); Frank Larøi et al., Unawareness of Illness in Chronic Schizophrenia and Its Relationship to Structural Brain Measures and Neuropsychological Tests 100 PSYCHIATRY RES.: NEUROIMAGING SECTION 49-58 (2000).

111 K. D. Morgan et al., Neuroanatomical Correlates of Poor Insight: The Aesop First-Onset Psychosis Study (abstract) 53 SCHIZOPHR. RES. 101 (2002). For a helpful review of all these studies, see Laura A. Flashman \& Robert M. Roth, Neural Correlates of Unawareness of Illness in Psychosis, in AMADOR \& DAVID, INSIGHT AND PSYCHOSIS 157. 
Columbia for driving erratically. Mr. Thompson reacted angrily, challenging the officer to either arrest him or let him go. Since there were no legal grounds for arrest, the officer released him; eight hours later, Mr. Thompson died after his car swerved across the median and hit two oncoming tractor-trailers. The news account of this tragedy noted that “it can still be nearly impossible to rescue or help people who don't know they need either."112

Other accounts verify the fact that "people with Alzheimer's disease ... are increasingly getting entangled with law enforcement" because of their anosognosia. ${ }^{113}$ Most often, they are taken into police custody "after they wander away from their homes or caretakers and are found acting erratically." ${ }^{114}$ Occasionally, however, such individuals commit crimes, including homicides, because of their brain dysfunction.

For individuals with schizophrenia, the consequences of anosognosia include noncompliance with medication, relapse, homelessness, incarceration, and violent behavior.

\section{a. Noncompliance with Medication}

There are many reasons why people do not take medication that has been prescribed for them by a physician, including the cost of the medication, side effects, and concurrent substance abuse, among others. For individuals with schizophrenia, however, the main reason they do not take medication is anosognosia - they do not believe they are sick and therefore do not believe they need medication.

112 David A. Fahrenthold, Police Often Stymied by Ailing 'Wanderers,' WASHINGTON Post, Dec. 9, 2000, at B1, B4.

113 Rob Stein, Legal System Struggles with Dementia Patients, WASHINGTON POST, July 28, 2003, at A1, A11.

114 Ibid. 
At least fifteen studies have identified lack of awareness of illness as a major determinant of medication noncompliance in individuals with schizophrenia. In one study, for example, individuals who were unaware of their illness were only half as likely to take medication compared to individuals who were aware. ${ }^{115}$ In another study, $63 \%$ of psychiatric patients with anosognosia were noncompliant with medications compared to a $24 \%$ noncompliance rate for patients who were aware of their illness. ${ }^{116}$ As reported in another study, "the participants who were more aware of their mental illnesses and of the beneficial effects of medication were more likely to be compliant with prescribed medications."117

\section{b. Relapse, Homelessness and Incarceration}

Since individuals with schizophrenia who have impaired awareness of illness are less likely to be compliant with helpful medication, it logically follows that the outcome of their illness is more likely to be problematic. Multiple studies have confirmed this.

For example, studies have shown that individuals with schizophrenia who are noncompliant with medication have significantly more frequent and more severe relapses, compared to individuals who are compliant. ${ }^{118}$ Additional studies have shown that having impaired awareness of illness predicts more admissions to hospitals, and especially more

115 Ih Foo Lin et al., Insight and Adherence to Medication in Chronic Schizophrenics 40 J. CLIN. PSYCHIATRY 430-32 (1979).

116 H. Rittmannsberger et al., Medication Adherence among Psychotic Patients before Admission to Inpatient Treatment, 55 PSYCHIATR. SERV. 174-79 (2004).

117 Cedric M. Smith et al., Effect of Patient and Family Insight on Compliance of Schizophrenic Patients 37 J. Clin. Pharmacol. 147-54 (1997). For a review of many of these studies, see Jonathan P. Lacro et al., Prevalence of and Risk Factors for Medication Nonadherence in Patients with Schizophrenia: A Comprehensive Review of Recent Literature 63 J. CLIN. PSYCHIATRY 892-909 (2002); June R. Husted, Insight in Severe Mental Illness: Implications for Treatment Decisions 27 J. AM. ACAD. PSYCHIATRY LAW 33-49 (1999); and Joseph P. McEvoy, The Relationship Between Insight in Psychosis and Compliance with Medications, in AMADOR \& DAVID, INSIGHT AND PSYCHOSIS.

118 D. A. W. Johnson et al., The Discontinuance of Maintenance Neuroleptic Therapy in Chronic Schizophrenic Patients: Drug and Social Consequences 67 ACTA PSYCHIATR. SCAND. 339-52 (1983). 
involuntary admissions. ${ }^{119}$ In one of those studies, "only $8 \%$ of patients with insight required hospitalization for their relapse, in contrast to $50 \%$ of those without insight."120

Other studies have shown that individuals with schizophrenia with impaired awareness of illness have poorer social and rehabilitation outcomes. One study found a correlation between poor insight and poor social skills. ${ }^{121}$ A rehabilitation study similarly reported that "poor insight was significantly related to fewer weeks of participation as well as poorer social skills and personal presentation on the job."122

Homelessness is a common outcome for many individuals with schizophrenia and other severe psychiatric disorders, with multiple studies estimating that approximately one-third of the homeless population have these disorders. Many of these individuals also have problems with substance abuse. A 1989 study of individuals discharged from a state psychiatric hospital reported that among those who became predominantly homeless, $63 \%$ were noncompliant with medication, whereas among those who remained in stable housing, only $18 \%$ were noncompliant. ${ }^{123}$ Other studies have reported that

119 Joseph P. McEvoy et al., Insight and the Clinical Outcome of Schizophrenic Patients 177 J. NERV. MENT. DiS. 48-51 (1989); D. Hubbeling et al., Relationship Between Insight and Compulsory Admission (abstract) 49 SCHIZOPHR. RES. 15 (2001).

120 Douglas W. Heinrichs et al., Early Insight and the Management of Schizophrenic Decompensation 173 J. NERV. MENT. DIS. 133-38 (1985).

121 J. L. Francis \& D. L. Penn, The Relationship Between Insight and Social Skill in Persons with Severe Mental Illness J. NERV. MENT. DIS. 822-29 (2001).

${ }^{122}$ Paul Lysaker et al., Insight and Psychosocial Treatment Compliance in Schizophrenia 57 PSYCHIATRY 307-15 (1994). A study that quantified the role of insight in outcome reported that "insight into illness accounts for ... approximately half of the common variance associated with functional skill level and global functioning scores after long-term treatment"; (Robert C. Schwartz et al., Does Insight Affect Long-Term Inpatient Treatment Outcome in Chronic Schizophrenia? 38 COMPR. PSYCHIATRY 28388 (1997).

123 Robert E. Drake et al., Housing Instability and Homelessness Among Aftercare Patients of an Urban State Hospital 40 HosP. COMMUNITY PSYCHIATRY 46-51 (1989). 
noncompliance with medication is a risk factor for becoming homeless among men and women with schizophrenia. ${ }^{124}$

Arrest and incarceration in jails and prisons is another increasingly common outcome for individuals with schizophrenia and other severe psychiatric disorders. A 1998 Department of Justice survey reported that $16 \%$ of inmates in the nation's jails and prisons were mentally ill. ${ }^{125}$ This includes a growing number of mentally ill repeat offenders, such as Gloria Rodgers in Memphis, who in 1998 was reported to have had 258 previous arrests and to have been jailed 114 times in the previous four years. ${ }^{126}$

As far as the authors are aware, no study has specifically assessed awareness of illness among mentally ill prisoners. There is evidence, however, that such individuals tend to have been noncompliant with medication prior to their arrest and therefore can be assumed to have less awareness of their illness. One study of mentally ill individuals who have been arrested found that "two highly significant predictors of arrest were substance abuse ... and noncompliance with medication." $" 127$

A study of sixty-five patients with severe psychiatric disorders discharged from an Ohio state psychiatric hospital illustrates the problem. Within six months, thirty-three

124 Carol L. M. Caton et al., Risk Factors for Homelessness Among Schizophrenic Men: A CaseControl Study 84 AM. J. Public HeAlth 265-70 (1994); Carol L. M. Caton et al., Risk Factors for Homelessness Among Women with Schizophrenia 85 AM. J. PUBlic HeALTH 1153-56 (1995).

125 Paula M. Ditton, Mental HeAlth AND TREATMENT OF INMATES AND PROBATIONERS (1999). Since the nation's jail and prison population now includes more than 2 million individuals, that would mean that approximately 320,000 of them are mentally ill.

126 Graphic Lesson: Assault Sharpens Debate Over Jailed Mentally Ill, THE COMMERCIAL APPEAL (MEMPHIS, TN), Oct. 28, 1998.

127 Bentson H. McFarland et al., Chronic Mental Illness and the Criminal Justice System 40 HosP. COMMUNITY PSYCHIATRY 718-23 (1989). Such individuals tend to be arrested for misdemeanors such as disorderly conduct and threatening people. For example, one young man smashed a store window "because he saw a dinosaur jumping out at him," and a young woman refused to pay for her meal in a restaurant because she claimed to be "the reincarnation of Jesus Christ"; see Gary E. Whitmer, From Hospitals to Jails: The Fate of California's Deinstutionalized Mentally Ill 50 AMER. J. ORTHOPSYCHIAT. 65-75 (1980), and Edwin V. Valdiserri et al., A Study of Offenses Committed by Psychotic Inmates in a County Jail 37 HosP. COMMUNITY PSYCHIATRY 163-66, 1986. 
of the sixty-five individuals had become homeless, and twenty-one of these had been arrested and jailed. Most of them had been arrested for misdemeanors, such as threatening and bizarre behaviors. The authors of the report noted that "psychotropic medication had been prescribed upon their discharges from the state hospital, but the respondents failed to take their medication."128

\section{c. Violent Behavior}

Violent behavior by individuals with schizophrenia and other severe psychiatric disorders is another important consequence of anosognosia. In recent years, three studies have been carried out that link violent behavior directly to impaired awareness of illness. One study, carried out in Ohio, assessed 122 patients with schizophrenia who had committed violent acts and compared them with 111 patients with schizophrenia who had not committed such acts. The violent patients had more symptoms and significantly less awareness of their illness. ${ }^{129}$ A second study, carried out in New York, examined causes of behavior in sixty severely mentally ill men who had been charged with violent crimes. The authors reported that lack of awareness of illness and medication noncompliance both played significant roles in causing the men's violent behavior. ${ }^{130}$ Finally, a study carried out in Spain on sixty-three patients with schizophrenia admitted to a psychiatric hospital assessed both their violent behavior and their awareness of illness. The authors reported a statistically significant association between impaired awareness of illness and

128 John R. Belcher, Are Jails Replacing the Mental Health System for the Homeless Mentally Ill? 24 COMMUNITY MENT. HEALTH J. 185-95 (1988). Substance abuse was also a major problem among this group and contributed to their homelessness and incarceration.

129 L. Friedman et al., Psychometric Relationships of Insight in Patients with Schizophrenia Who Commit Violent Acts (abstract) 60 SCHIZOPHR. RES. 81 (2003).

130 Nelly Alia-Klein, Violence and Psychosis in Relationship to Insight into Illness and Medication Compliance, submitted for publication. 
increased violent acts and concluded that "the single variable that best predicted violence was [impaired] insight into psychotic symptoms."

Finding a relationship between impaired awareness of illness and increased violent behavior in individuals with schizophrenia is not surprising, since there is abundant evidence that medication noncompliance is also linked to increased violent behavior. Anecdotal stories abound and are frequently seen in media accounts of tragedies, e.g., "his daughter was not taking her medication at the time of the slaying."132 There are also multiple studies showing that individuals with severe psychiatric disorders who are unmedicated or undermedicated are significantly more likely to commit violent acts. $^{133}$

In summary, anosognosia has important consequences for individuals with schizophrenia and other severe psychiatric disorders. It is a major determinant of medication noncompliance; increases the chances of relapse, homelessness, and incarceration; and increases violent behavior. Any legislation bearing on the treatment of psychiatrically ill individuals must take anosognosia into account.

131 Celso Arango et al., Violence in Inpatients with Schizophrenia: A Prospective Study 25 SCHIZOPHR. BULL. 493-503 (1999).

132 Crofton Woman Found Guilty in Mother's Slaying, WASHINGTON Post, Sept. 28, 1990, at D3.

133 John A. Kasper et al., Prospective Study of Patients' Refusal of Antipsychotic Medication Under a Physician Discretion Review Procedure 154 AM. J. PSYCHIATRY 483-89 (1997); T. Steinert et al., How Common Is Violence in Schizophrenia Despite Neuroleptic Treatment? 33 PHARMACOPSYCHIATRY 98-102 (2000). 
One of the most important state mental health laws enacted in the late 1960s and early 1970s was the Lanterman-Petris-Short Act, widely referred to as LPS, which went into effect in California on July 1, 1969. ${ }^{134}$ It was widely referred to as "the Magna Carta of the mentally ill" and said to include "the broadest changes in the procedures for the involuntary commitment of the mentally disordered since the process began in the early 1800s." ${ }^{135}$

Speaking at the time the bill was passed, Assemblyman Frank Lanterman, the prime mover of the legislation, said that "the entire thrust of the Lanterman-Petris-Short Act is to promote voluntary treatment for the mentally disordered.... provisions for involuntary treatment have been written so that they are the last resort rather than the first, as is now so often the case." ${ }^{136}$ The legislation restricts initial involuntary hospitalization to individuals who are dangerous to others, dangerous to self, or gravely disabled and is for a maximum of 17 days. Suicidal individuals may be held involuntarily for an additional 14 days. Involuntary commitments for up to 90 days beyond the initial 17 days are restricted to those individuals who are deemed to be "imminently dangerous"

134 LPS was passed by the California Legislature by a unanimous vote in 1967 but did not take effect until 1969. It was officially entitled the California Mental Health Act of 1967 and was included in Division 5 of the California Welfare and Institutions Code, 1967 Cal. State, ch. 1667, §36.

135 The Magna Carta designation was given by Maurice Rodgers, spokesperson for the California State Psychological Association, at the initial hearing on the proposed legislation. See Eugene Bardach, THE SKILl FACTOR IN POLITICS 126 (1972) (hereinafter BARDACH, THE SKILL FACTOR). The other assessment was given in 1978 by Dr. Albert H. Urmer, President of ENKI Research Institute, which had studied LPS after its implementation. See Albert H. Urmer, An Assessment of California's Mental Health Program: Implications for Mental Health Delivery Systems (hereinafter URMER, AN ASSESSMENT OF California's Mental Health Program), in Dangerous Behavior: A Problem in LaW and Mental HEALTH 137-51 (Calvin J. Frederick, ed., 1978) (hereinafter FREDERICK, DANGEROUS BEHAVIOR).

136 New Mental Health Legislation, delivered by Assemblyman Frank Lanterman, Chairman, Assembly Ways and Means Subcommittee on Mental Health Services, March 23, 1968, Riverside, California (hereinafter LANTERMAn, New Mental HeAlth LEgISLATION). 
to others. This extended commitment had to be approved by a court hearing at which the detained individual had the right to be represented by a lawyer and could demand a jury trial. The criteria for approval of a 90-day commitment were very strict; as Lanterman explained it, "physical evidence of danger must be displayed in a court of law."137

The core of the LPS Act was "the absolute termination of indefinite periods of involuntary commitment." ${ }^{, 138}$ Under previous California mental health laws, commitment criteria merely required that individuals be "of such mental condition that they are in need of supervision, treatment, care or restraint." ${ }^{, 139}$ This was basically a need-forhospitalization standard, and the length of such commitments could be indeterminate. Under the new law, the only grounds for long-term commitment was imminent dangerousness to others, and the commitment must be reviewed by the court every 90 days.

At the time of its passage, LPS was widely praised by legal advocates for mental health reform. Prominent mental health law jurists such as Judge David Bazelon noted that LPS "promises virtually to eliminate involuntary hospitalization except for short

137 Lanterman, New Mental Health Legislation. The LPS Act also included other provisions in addition to restricting long-term commitments to those individuals who were a danger to others. It allowed for the appointment of a conservator for individuals who were gravely disabled, which was defined as being "unable to provide for his basic personal needs for food, clothing or shelter." A review of the use of conservatorships in California for individuals who are gravely disabled is found in Grant H. Morris, Conservatorship for the "Gravely Disabled”: California's Nondeclaration of Nonindependence 1 INT. J. LAW PSYCHIATRY 395-426 (1978) (hereinafter MORRIS, CONSERVATORSHIP FOR THE "GRAVELY DISABLED”). The LPS Act also included a financing mechanism to shift state funds to the counties and defined the rights of involuntarily committed patients, including their right to access to a telephone, to retain personal clothing, to receive and send mail without its being opened, and to refuse electroshock treatment.

138 URmer, An ASSESSMENT OF CALIFORNIA's MENTAl HEALTH PROGRAM.

139 THE DILEMMA OF MENTAL COMMITMENTS IN CALIFORNIA, prepared for the Assembly Interim Committee on Ways and Means, Subcommittee on Mental Health Services, 1966, and reprinted by the Assembly Rules Committee, California Legislature, Sacramento (hereinafter THE DILEMMA REPORT). 
term crisis situations." ${ }^{140}$ LPS was also praised by Bruce Ennis, the director of the New York Civil Liberties Union Mental Illness Litigation Project, who called LPS “far from perfect," insofar as it retained grounds for any involuntary commitment, but commended it for restricting such commitments "to persons who have committed dangerous acts and are demonstrably dangerous to themselves or to others." ${ }^{141}$ One of the most notable aspects of LPS was the enthusiastic support it drew from both conservative and liberal ends of the political spectrum. ${ }^{142}$

A. Assumptions Regarding the Causes of Psychiatric Disorders

The assumptions underlying the LPS Act were laid out in The Dilemma of Mental Commitments in California, a 1966 report of the California Assembly's Subcommittee on Mental Health Services. Assemblyman Nicholas Petris, the "P" in LPS, became chairman of this subcommittee in June 1966. The report, often referred to as the Dilemma Report, was the planning document for the LPS legislation.

140 MORRIS, CONSERVATORSHIP FOR THE “GRAVELY DiSABLED," quoting Bazelon, Implementing the Right to Treatment 36 U. CHI. L. REV. 742, 753 (1969).

141 Bruce Ennis, PRISONERS OF PSYCHIATRY: MENTAL PATIENTS, PSYCHIATRISTS AND THE LAW 223 (1972) (hereinafter ENNIS, PRISONERS OF PSYCHIATRY).

142 Frank Lanterman was a conservative Republican from Pasadena and one of the most powerful members of the Assembly. He called himself "a conservative curmudgeon" and valued highly individual rights and privacy (BARDACH, THE SKILL FACTOR 119). Southern California in the 1950s and 1960s was the heartland of a conservative anti-mental health movement, most prominent in the John Birch Society, which equated psychiatry with Communism. For example, in 1958, a large billboard was erected in suburban Los Angeles that said: "It is amazing and appalling how many supposedly intelligent people have been duped by such Communist Schemes as Fluoridation and 'Mental Health' especially since both the American Legion and the D.A.R. have publicly branded 'Mental Health' as a Communist Plot to take over our country” ( see E. Fuller Torrey, NowhERE To Go: THE TRAGIC ODYSSEY OF THE HOMELESS MENTALLY ILL 88ff (1988)). Thus, there was widespread support among California conservatives for decreasing the use of involuntary commitments and for phasing out state psychiatric hospitals. The second major sponsor of the LPS Act, Nicholas Petris, was a liberal Democrat from Oakland. Liberal Californians supported LPS and its restriction of involuntary commitments in order to protect civil rights. 
The Dilemma Report discussed in detail the nature of mental illness, which it defined as "a nonscientific, generalized, popular label used to explain or describe a wide range of behavior which is considered 'peculiar' or 'sick' or 'objectionable.'” The report continued:

It is also evident that when a person's behavior is labeled "mental illness," those who do the labeling are guided by their own conceptions of what is normal and abnormal. Madness, like beauty, may exist in the eye of the beholder. ${ }^{143}$

The sponsors of the LPS legislation clearly shared these assumptions about the nature of psychiatric disorders. Frank Lanterman referred to patients in state psychiatric hospitals as "unwanted, burdensome and eccentric members of society." 144 Similarly, Nicholas Petris called the hospitals "warehouses for the idiosyncratic, the aged, the senile, the odd, and the different" and further added: "We remembered that throughout history some of today's madman can become tomorrow's heroes."145 In stating such views, Petris acknowledged having been influenced by the thinking of antipsychiatry activists in San Francisco who at that time were publishing the "Madness Network News." Petris labeled as "provocative" their thesis "that either we are all mad or none of us is mad." 146

The Dilemma Report and assumptions of the LPS architects were profoundly influenced by antipsychiatry writers prominent in the 1960s. One of these was Thomas Scheff, a sociologist at the University of California who believed that mental illness

143 THE DILEMMA REPORT 10, 11.

144 LANTERMAN, NEW MENTAl HEALth LEGISLATION.

145 Nicholas C. Petris, The Lanterman-Petris-Short Act with a Focus on Dangerousness (hereinafter Petris, THE LANTERMAN-PETRIS-SHORT ACT, in FrEDERICK, DANGEROUS BEHAVIOR 102-108.

146 PETRIS, THE LANTERMAN-PETRIS-SHORT ACT, 
existed only because eccentric persons were so labeled. His writings were referenced multiple times in the Dilemma Report and were also reflected by Petris when he claimed that psychiatric professionals use a "middle-class model" in determining who may be mentally ill. ${ }^{147}$

Also influential in the deliberations of the LPS architects was Don Jackson, a Palo Alto psychiatrist who believed that families cause mental illness in general and schizophrenia in particular. For example, Petris publicly claimed that "the 'patient' is only one part of a family problem and ... his bizarre behavior may be a very appropriate response to other family members." ${ }^{148}$ In the bibliography of the Dilemma Report, Jackson's writings were listed seven times, more than any other individual. ${ }^{149}$

Erving Goffman, a sociologist, was influential as well. The book for which Goffman was best known, Asylums, was praised in the Dilemma Report as "a most incisive and revealing study of the dehumanizing effects of institutional living."150 Goffman had argued that the experience of being hospitalized for individuals labeled as mentally ill was the cause of many of their symptoms. Such thinking was reflected in Lanterman's statement that, following commitment, "by the time the individual receives any treatment, his condition is often worse than it was when he was apprehended." ${ }^{\prime 15}$

147 Nicholas C. Petris, New Approaches to Mental Health in the California Legislature, in Calvin J. Frederick (ed.), THE FUtURE OF PSYCHOTHERAPY 361-78 (1969) (hereinafter PETRIS, THE FUTURE OF PSYCHOTHERAPY).

148 PETRIS, The FutURE OF PSYChOTHERAPY.

149 The Dilemma Report cites other family interaction theorists as well, including Jay Haley, Gregory Bateson, and Fuller: Stick in the text. All had written that faulty family communications and interactions were the origins of some psychiatric disorders. Laing, for example, was praised in the Dilemma Report for having written "a dramatic and authoritative account of the ways that family difficulties can produce 'sick' behavior." See THE DILEMMA REPORT 72.

150 THE DILEMMA REPORT 69.

151 Lanterman, New Mental Health Legislation. 
Finally, the architects of the LPS Act were influenced in their thinking about psychiatric disorders by the writings of Thomas Szasz. Szasz, a psychiatrist, had published The Myth of Mental Illness in 1961 and Law, Liberty and Psychiatry two years later, and his ideas were being widely discussed in late 1960s. The Dilemma Report cited Szasz as "a vocal champion of eliminating involuntary treatment" and referenced his 1966 article in the New York Times Magazine entitled "Mental Illness Is a Myth." In the article, Szasz said that "labeling someone mentally ill is a special kind of name-calling," and that stopping all involuntary commitments to mental hospitals and emptying the hospitals are "to be sure...desirable goals.",152

In summary, the architects of the LPS legislation, which profoundly changed commitment laws in California and influenced the laws in many other states, clearly did not subscribe to biological theories of psychiatric disorders. Instead they claimed that what is called mental illness was merely an arbitrarily assigned label for various forms of deviant behavior. Since mental illness was merely a labeling problem, there was no legal justification for the involuntary commitment of such individuals to hospitals.

\section{B. Assumptions Regarding Competence To Make Informed Treatment Decisions}

The architects of the LPS Act believed that almost all individuals with psychiatric disorders are competent to make informed decisions about whether or not they need treatment. Lanterman noted that "individuals are involuntarily hospitalized and treated with little regard to their own desires concerning hospitalization or treatment." $\mathrm{He}$

152 Thomas S. Szasz, Mental Health Is a Myth, NeW YoRK Times MAGAZINE (June 12, 1966). 
explicitly rejected any suggestion that such individuals may not be aware of their own illness:

For too many years the presumption has been that a mentally disturbed individual will not admit to being "sick" and will not accept recommended treatment. Therefore, it is thought necessary to contain him so he cannot escape from treatment. This is sometimes justified on the grounds that "the individual will later recognize it was all for his own good." To me this concept is indefensible.

The proposed legislation, said Lanterman, would free "thousands of persons from the 'tyranny of help,' which has camouflaged for so many years the denial of liberty and basic human dignity."153

The Dilemma Report explicitly assumed that individuals with psychiatric disorders are rational and capable of making intelligent decisions regarding their own needs. The report emphasized that under the LPS legislation "citizens will be free to decide whether they wish to enter or leave the hospitals." The report also claimed that much disturbed behavior exhibited by hospitalized patients is not due to the fact that patients are not capable of thinking rationally but rather is a byproduct of being involuntarily hospitalized: "The virtual disappearance of antisocial and irresponsible behavior when patients are treated and trusted as responsible fellow beings is most convincing and forces us to a total re-examination of our traditional procedures."154 At several points the Dilemma Report stressed the need for all treatment to be voluntary:

“...these citizens will be voluntary patients in every sense"

153 Lanterman, New Mental Health Legislation 2, 3, 9.

154 THE DILEMMA REPORT 123-24. 
“...it is difficult to accept the notion that sending a wide variety of people to institutions against their wishes can be justified because 'they are in need of treatment.",

Making the treatment system a voluntary system would, according to the report, fundamentally change the nature of state psychiatric hospitals. "When these steps have been taken, state hospitals as we know them will no longer exist."

In summary, in repealing the existing civil commitment scheme and replacing it with a scheme relying almost entirely on voluntary treatment, the LPS Act assumed that most individuals with psychiatric disorders are competent and capable of seeking treatment when they need it. There is no mention in the planning documents or legislation that some individuals may have impaired awareness of their illness. The only acknowledgement that impaired awareness was even possible was for individuals with chronic organic brain syndromes such as may be found in individuals with chronic alcoholism or Alzheimer's disease. The LPS Act allowed for conservatorships in such cases. $^{156}$

155 THE DILEMMA REPORT 77, 103, 105. A related issue that was extensively discussed in the Dilemma Report was whether individuals with psychiatric disorders were more or less dangerous than the general population. This was a critical issue for the public, since the proposed legislation would make the hospitalization of most psychiatric patients voluntary. The report concluded that there was no evidence that psychiatric patients were more dangerous, and it even quotes those who claimed they were less dangerous: "Actually it has been demonstrated that the incidence of crimes of violence (or of any crime) is much lower among former mental patients than in the general population." (18) At the time the Dilemma Report was written in 1966, there was, in fact, no evidence that discharged psychiatric patients were dangerous, because those who were potentially dangerous had been kept in hospitals for long periods of time. For a summary of these early studies, see George G. Gulevich and Peter G. Bourne, Mental Health and Violence, in VIOLENCE AND THE STRUGGLE FOR EXISTENCE 309-26 (David N. Daniels et al., eds., 1970).

156 The Dilemma Report had relatively little to say about conservatorship. As noted by Morris (MORRIS, CONSERVATORSHIP FOR THE “GRAVELY DISABLED”), “the LPS background document contains 204 pages, but it devotes only four pages to the LPS conservatorship question.” In fact, conservatorships have been used in California since LPS was passed as a way to effectively bring about some long-term involuntary commitments, thus circumventing the intent of the LPS architects. 


\section{The Effects of the Lanterman-Petris-Short Act}

California's LPS Act influenced legislation in many other states. Washington State implemented a similar law in $1974 .{ }^{157}$ By 1975 , it was being said that "many psychiatrists view LPS as the model law to be adopted by other states," and Massachusetts, New York and Pennsylvania were moving toward new legislation "closely patterned after the success of LPS." ${ }^{, 158}$ By 1988, it was noted that "most state commitment statutes today are modeled after California's Lanterman-Petris-Short Act." 159

In California, the changes in commitment procedures mandated by the LPS Act brought about immediate changes in California's mental health system. Since commitments were so difficult to obtain, petitions for commitment orders decreased sharply, and by 1978, it was said that there had been "a 99 percent decrease in the number of petitions filed with the courts." ${ }^{160}$ For the small number of mentally ill individuals who were involuntarily admitted, the average length of hospital stay decreased from 180 days prior to LPS to 15 days four years later. ${ }^{161}$

Furthermore, since many patients who were already in the hospitals at the time LPS was implemented did not meet criteria of imminent dangerousness to others, they had to be discharged. The number of patients in California state psychiatric hospitals thus

157 Morris, ConservatorshiP FOR THE "Gravely disABLED”; WASH. REv. CODE ANN. $\S \S$ 71.05.010-71.05.920 (1974). See also Lynne N. Henderson, "We're Only Trying to Help": The Burden and Standard of Proof in Short-Term Civil Commitment, 31 STANFORD LAW REV. 425-55 (1979).

158 Donald G. Langley \& James T. Barter, Community Mental Health in California 122 WeST. J. MED. 271-76 (1975) (hereinafter LANGLEY \& BARTER, COMMUNITY MENTAL HEALTH IN CALIFORNIA).

159 Steven P. Segal et al., Civil Commitment in the Psychiatric Emergency Room: II. Mental Disorder Indicators and Three Dangerousness Criteria 45 ARCH. GEN. PSYCHIATRY 753-58 (1988).

160 URMER, AN ASSESSMENT OF CALIFORNIA's MENTAL HEALTH PROGRAM.

161 Albert H. Urmer, Implications of California's New Mental Health Law 132 AM. J. PSYCHIATRY 251-54 (1975) (hereinafter URMER, IMPLICATIONS OF CALIFORNIA's NEW MENTAL HEALTH LAW). 
decreased from 18,831 to 12,671 in the first two years following passage of LPS $^{162}$ and further decreased to 7,000 by $1973,{ }^{163}$ a $63 \%$ decrease in just four years.

Many of the discharged patients went to live with family members and did well.

However, many others were housed in board-and-care homes. An observer in 1971 noted that many of the board-and-care homes "are in most respects like small long-term state hospital wards isolated from the community... . It is only an illusion that patients who are placed in boarding or family-care homes are 'in the community.",164 A 1972 followup of 170 patients who had been discharged from state hospitals under LPS reported that "more than two-thirds are living in an institutional setting," including hospitals, boarding homes, and prisons. ${ }^{165}$

Especially troubling was the fact that many of the board-and-care homes were clustered in inner cities, often forming "ghettos of former state hospital patients." ${ }^{166}$ In San Jose in 1973, for example, it was said that "in a 20 -square-block area-an area also heavily populated by alcoholics, drug users, and prostitutes-live over 1,100 of the

162 E. Bardach, ThE IMPLEMENTATION GAME: WhAT HAPPENS AFTER A BILL BECOMES LAW 289-90 (1977) (hereinafter BARDACH, THE IMPLEMENTATION GAME).

163 Janet Chase, Where Have All the Patients Gone? 2 Hum. BeHAv. 14-21 (1973) (hereinafter Chase, Where Have All the Patients Gone?).

164 H. Richard Lamb \& Victor Goertzel, Discharged Mental Patients-Are They Really in the Community? 24 ARCH. GEN. PSYCHIATRY 29-34 (1971).

165 H. Richard Lamb \& Victor Goertzel, The Demise of the State Hospital-A Premature Obituary? 26 ARCH. GEN. PSYCHIATRY 489-95 (1972). Other observers noted that most of the patients being "deinstitutionalized " from the California state hospitals were really being "transinstitutionalized" to other institutions. For example, among geriatric patients discharged from Modesto State Hospital, 60\% were sent to nursing homes and an additional $19 \%$ to convalescent hospitals (Milton Greenblatt \& Elizabeth Glazier, The Phasing Out of Mental Hospitals in the United States 132 AM. J. PSYCHIATRY 1135-40 (1975) (hereinafter GreEnBlatt \& GlaZIER, The Phasing OUT OF MENTAL HosPitals).

166 Gary E. Whitmer, From Hospitals to Jails: The Fate of California's Deinstitutionalized Mentally Ill 50 AMER. J. ORTHOPSYCHIAT. 65-75 (1980) (hereinafter WHITMER, FROM HOSPITALS TO JAILS). As early as 1971, the Mercury of San Jose complained about the "mass invasion of mental patients" following the closing of beds at nearby Agnews State Hospital. These ghettos of discharged patients were sometimes referred to as "little Agnews." By 1973, professionals had labeled this patient shift as being "from back wards to back alleys" (Uri Aviram \& Steven P. Segal, Exclusion of the Mentally Ill: Reflection of an Old Problem in a New Context 29 ARCH. GEN. PSYCHIATRY 126-31 (1973) (hereinafter AVIRAM \& SEGAL, EXCLUSION OF THE MENTALLY ILL). 
mentally disordered." ${ }^{167}$ Most of them had come from nearby Agnews State Hospital, which had closed in 1972.

Not surprisingly, many of the discharged patients who were not receiving treatment became homeless, evoking protest "from an alarmed general public, concerned for public safety." 168 The number of discharged patients who ended up homeless is also reflected by studies of mentally ill persons in the Los Angeles County jail in the early 1980s: $36 \%$ of the mentally ill men and $42 \%$ of the mentally ill women had been homeless immediately preceding their incarceration. ${ }^{169}$

LPS also produced an immediate increase in mentally ill persons in California's jails and prisons. In 1972 Marc Abramson, a psychiatrist in San Mateo County, published data showing that the number of mentally ill persons entering the criminal justice system had doubled in the first year after LPS was implemented. According to Abramson: "As a result of LPS, mentally disordered persons are being increasingly subjected to arrest and criminal prosecution." ${ }^{170}$ In adjacent Santa Clara County, a study showed that the jail population increased by $300 \%$ in the first four years after the closing of Agnews State Hospital, located in that county. ${ }^{171}$ A five-county study in 1975 also reported a $300 \%$ increase in severely mentally ill jail inmates over 10 years. ${ }^{172}$

167 Chase, Where Have All the Patients Gone?

168 Rael Jean Isaac \& Virginia Armat, MADNESS IN THE STREETS: HOW PSYCHIATRY AND THE LAW ABANDONED THE MENTALLY ILL 123 (1990).

169 H. Richard Lamb \& Robert W. Grant, The Mentally Ill in an Urban County Jail, 39 ARCH. GEN. PSYCHIATRY 17-22 (1982); H. Richard Lamb \& Robert W. Grant, Mentally Ill Women in a County Jail 40 ARCH. GEN. PSYCHIATRY 363-68 (1983).

170 Marc F. Abramson, The Criminalization of Mentally Disordered Behavior: Possible Side-Effect of a New Mental Health Law 23 HosP. COMMUNITY PSYCHIATRY 101-105 (1972) (hereinafter ABRAMSON, THE CRIMINALIZATION OF MENTALly DisORDERED BEHAVIOR).

171 Linda A. Teplin, The Criminalization of the Mentally Ill: Speculation in Search of Data 94 PSYCHOL. BULL. 54-67 (1983), quoting a 1973 study. By 1973, it was widely accepted that the discharge of patients from the California state psychiatric hospitals was directly related to the increasing number of mentally ill being seen in California's jails. One study noted that law enforcement officers were seeing "a great increase in the number of former mental patients." Because the patients could not be rehospitalized, 
By 1981, twelve years after LPS had been implemented, the problem of an explosive increase in mentally ill persons in California's jails and prisons had been clearly documented. A study of almost 500 mentally ill individuals who had been arrested reported that "at the time of arrest, 94 percent were not involved in any outpatient program." 173 A newspaper report, headlined "The Crime of Mental Health," noted: "Jails have replaced state mental hospitals as the new asylums for the insane. Reforms which released mental patients from state hospitals unexpectedly stuck them on a merry-goround of streets, cops, courts and jails.” The reporter described mentally ill inmates in the county jail such as those "who try to escape by smearing themselves with their own feces and flushing themselves down the toilet." ${ }^{174}$ By 1991, the Los Angeles County Jail had become de facto "the largest mental institution in the United States" because of the large number of mentally ill individuals among its 24,000 inmates. ${ }^{175}$

In 1972, in the first published evaluation of the effects of LPS on the criminal justice system, Marc Abramson had observed: "It would indeed be ironic if the Magna

the police "arrest the mentally ill and charge them with a minor crime." (AVIRAM \& SEGAL, EXCLUSION OF THE MENTALLY ILL) Albert Urmer, who did a follow-up study on the effects of LPS, similarly noted: "Since LPS, these individuals (discharged psychiatric patients) have been ineligible for commitment, but now their behavior comes to the attention of law enforcement agencies; they are therefore placed in jail." (URMER, IMPLICATIONS OF CALIFORNIA's NEW MENTAL HEALTH LAW).

172 A. Bolton, A Study of THE NeEd for AND Availability of MENTAL Health SERVICES For MENTALLY DisORDERED JAIL INMATES AND JUVENILES IN DETENTION FACILITIES (1976). The increase in mentally ill prisoners was seen in California's prisons as well as in its jails. One prison psychiatrist wrote: "We are literally drowning in patients, running around trying to put our fingers in the bursting dikes, while hundreds of men continue to deteriorate psychiatrically before our eyes into serious psychoses. ... The crisis stems from recent changes in the mental health laws allowing more mentally sick patients to be shifted away from the mental health department into the department of corrections. ... Many more men are being sent to prison who have serious mental problems." (ABRAMSON, THE CRIMINALIZATION OF MENTALLY DISORDERED BEHAVIOR).

173 WhitMER, FROM HOSPITALS TO JAILS.

174 Merrill Collett, The Crime of Mental Health: Mental Patients Freed from Hospitals Are Winding Up in Jail, Where They Aren't Safe, THE VALLEY Times (December 15, 1981, Pleasanton, Calif.). Many other vignettes of severely mentally ill persons in California's jails and prisons have been published. See especially WHITMER, FROM HOSPITALS TO JAILS; Whitmer described many examples, such as the young man who had "smashed the plate-glass window of a retail store because he saw a dinosaur jumping out at him."

175 Hector Tobar, When Jail Is a Mental Institution, Los ANGELES TIMES, August 25, 1991. 
Carta of the mentally ill in California led to their criminal stigmatization and incarceration in jails and prisons, where little or no mental health treatment is provided." ${ }^{176}$ Within a decade, it was clear that Abramson's prophecy had come to pass. An increase in violent behavior by mentally ill persons who were not receiving treatment was yet another unintended consequence of the LPS Act. This was politically sensitive, since the issue of possible violent behavior by mentally ill persons had been specifically raised several times during public hearings prior to passage of the LPS legislation.

The first suggestion that violent behavior by mentally ill persons might be increasing came from a 1973 study carried out by the California Department of Health. Among 6,623 individuals convicted of murder, manslaughter, or felony assault during 1971,760 of them (12\%) had previously been in a state psychiatric hospital or treated in a community mental health program. The rate of such crimes in the general population for individuals ages 16 and over was 0.47 per 1000 ; for those treated in a community mental health program, 2.88 per 1000; and for those treated in a state hospital 3.49 per 1000. ${ }^{177}$ By one account, in the first four years following passage of LPS, "At least $72 \ldots$ murders, suicides and 'unfortunate accidents' have directly involved former patients or those who tried unsuccessfully to get psychiatric care."178

Many of the homicide cases were high-profile, such as Charles Soper, who murdered his wife and three of his five children, and Mary Maloney, who "decapitated

176 ABRAmSOn, The CRIMINALIZATION OF MENTALly DisORDERED BEHAVIOR.

177 This study is described in Larry Sosowsky, Crime and Violence among Mental Patients Reconsidered in View of the New Legal Relationship between the State and the Mentally Ill 135 AM. J. PSYCHIATRY 33-42 (1978) (hereinafter SOSOWSKY, CRIME AND VIOLENCE). The study itself was apparently never published, perhaps because of its politically sensitive nature.

178 Chase, Where HaVe All the Patients Gone? 
her infant daughter and year-old son." ${ }^{179}$ Santa Cruz County alone had twenty-eight murders committed by severely psychiatrically ill individuals between 1970 and 1973 . John Frazier, for example, killed a prominent surgeon and four members of his family on October 19, 1970; Frazier had paranoid schizophrenia, and his "wife and mother [had] tried desperately to obtain psychiatric treatment for him." ${ }^{\text {"180 }}$ Herbert Mullin, also suffering from paranoid schizophrenia, killed thirteen persons between October 1972 and February 1973. Mullin had been hospitalized and prematurely released five times. At the termination of Mullin's trial, the foreman of the jury on the case wrote an open letter to then Governor Ronald Reagan:

Five times prior to Mr. Mullin's arrest he was entered into mental facilities. At least twice it was determined that his illness could cause danger to lives of human beings. . . According to testimony at this trial, Herb Mullin could and did respond favorably to treatment of his mental illness. Yet, the laws of this state certainly prohibit officials from forcing continued treatment of his illness, and I have the impression that they, as a matter of fact, discourage continued treatment by state and county institutions. ... [My] convictions [are] that the laws surrounding mental illness in the State of California are wrong, wrong, wrong.", 181

The definitive study on the effects of LPS on violent behavior by mentally ill persons was carried out by Larry Sosowsky at the University of California in Berkeley. He compared the arrest rates for all hospitalized mentally ill persons from San Mateo County for the three-and-a-half-year period before implementation of LPS and the four-

179 Chase, Where Have All the Patients Gone?

180 Donald T. Lunde, MuRdER AND MADNESS 51 (1975).

181 Donald T. Lunde \& Jefferson Morgan, THE DIE SONG: A JOURNEY INTO THE MIND OF A MASS MURDERER 313 (1980). In 1976, the Wall Street Journal, in a story headlined "Release of Mentally Ill into Communities Stirs Much Debate and Fear," described a psychiatrically ill young man who had killed his grandparents, then been released by a California state hospital after five years, whereupon he murdered his mother and seven other individuals (Stephen J. Sansweet, WALL STREET JouRnAL, August 19, 1976). Another report in 1976 noted: "Several dramatic mass murders have occurred in California since the enactment of LPS and in some instances the alleged murderer was a former state hospital patient." (LANGlEy \& BARTER, COMMUNiTy MENTAL HEALTH IN CALIFORNIA). 
and-a-half-year period following its implementation. He divided crimes into violent offenses causing bodily harm (e.g., murder, assault, rape), violent offenses with the potential for harm (e.g., robbery, possession of weapons, arson), and nonviolent crimes (e.g., public intoxication, possession of drugs, petty theft).

The results of the study showed clearly that limiting commitment of mental patients under LPS had increased crime. Comparing the pre-LPS to the post LPS periods, Sosowsky reported that violent offenses causing bodily harm increased three and a half times; violent offenses with the potential for harm, one and a half times; and nonviolent crimes, three times. He concluded that changes in hospital admission and discharge policies, such as LPS brought about, "may well incur a heretofor unassessed social costmore crime and violence in the nation's communities."182

By 1975 it had also become clear that the transfer of clinical care from the state psychiatric hospitals to the newly funded community mental health clinics had been a failure. As envisioned by the architects of LPS, patients who were being discharged from the hospitals were supposed to get follow-up outpatient care at the clinics. As noted by Eugene Bardach in his book on the implementation of LPS, the community mental health clinics "did relatively little to help the chronically mentally ill, even those who were released from the state hospitals in the great wave of discharges following LPS." ${ }^{183}$ In one study, only $41 \%$ of the patients discharged from Napa State Hospital had received

182 SOSOWSKY, CRIME AND VIOLENCE, and Larry Sosowsky, Explaining the Increased Rate among Mental Patients: A Cautionary Note 137 AM. J. PSYCHIATRY 1602-1605 (1980).

183 BARDACH, THE IMPLEMENTATION GAME 291. 
follow-up psychiatric care in the community. ${ }^{184}$ Thus, it is not surprising that many of them ended up homeless, incarcerated, or incarcerated for violent acts.

V. The Lessard Decision: Wisconsin, 1972

On October 29, 1971, Ms. Alberta Lessard was picked up at her apartment in West Allis, Wisconsin, by two police officers and involuntarily committed to the Milwaukee Mental Health Center for examination. This was the third time that day that police had been called to her apartment. She was said to have been "running up and down the apartment aisle on the second floor banging on doors and shouting that the communists were taking over the country that night" and "threatening to jump off the second floor window ledge." 185

A preliminary psychiatric evaluation found that Ms. Lessard was suffering from paranoid schizophrenia and in need of treatment. Ms. Lessard retained counsel through the Milwaukee Legal Services, which filed a class action suit on her behalf and on behalf of "and all other persons 18 years of age and older who are being held involuntarily

184 BARDACH, THE IMPLEMENTATION GAME 2-3. Rather than focusing on the discharged patients, the community mental health clinics utilized the increasing funds they received following passage of LPS to provide services to individuals who were less severely affected. As Albert Urmer, who evaluated the effects of LPS, described it in 1975: "The increase in outpatient services appears to have had an unanticipated impact on a new group of clients who had not previously used public mental health services and who were never in jeopardy of involuntary commitment." (URMER, IMPLICATIONS OF CALIFORNIA'S NEW MENTAL HEALTH LAW) Other observers at that time reported the same thing: “... for California at least, the community mental health programs do not appear to be serving the increasing population of ex-patients." (Greenblatt \& Glazier, The Phasing Out OF Mental Hospitals).

185 Civil Action Case No. 71-C-602, Lessard v. Schmidt, Stipulation of Facts, Appendix I, Testimony of Officer James D. Mejchar, March 30, 1972. 
pursuant to any emergency, temporary or permanent commitment provision of the Wisconsin involuntary commitment statute." 186

On October 18, 1972, a three-judge panel of the U.S. District Court declared Wisconsin's existing civil commitment statute unconstitutional and handed down a decision granting most of the provisions sought by the plaintiffs. The case was appealed and ultimately made its way to the U.S. Supreme Court, which vacated and remanded it in 1974 and 1975. ${ }^{187}$ In 1975, the Wisconsin Legislature then passed a law implementing the provisions of the Lessard decision.

The three-judge panel reasoned, as summarized by one observer, that "under the due-process provisions of the Constitution persons facing involuntary civil commitment are guaranteed the full array of procedural safeguards formerly guaranteed only to individuals charged with a crime."188 These procedural safeguards included the right to an initial hearing within 48 hours; the right to a full hearing within two weeks; the right to trial by jury; the right to have the assistance of counsel; the right to be warned by the examining psychiatrist "that statement [sic] he may make may be basis for commitment, and that he does not have to speak to psychiatrist"; ${ }^{189}$ no admission of hearsay evidence; proof of mental illness "beyond a reasonable doubt"; a strict standard of immediate dangerousness as the only grounds for commitment; and the use of "involuntary hospitalization only as a last resort" 190 after all alternatives to inpatient commitment have

186 Lessard v. Schmidt, 349 F. SUPP. 1078 (E. D. WIS. 1972) (hereinafter LESSARD V. SCHMIDT).

187 Darold A. Treffert, The MacArthur Coercion Studies: A Wisconsin Perspective 82 MARQUETTE LAW REV. 759-85 (1999) (hereinafter TREFFERT, THE MACARTHUR COERCION STUDIES).

188 Alan Meisel, Rights of the Mentally Ill: The Gulf Between Theory and Reality 26 HosP. COMMUNITY PSYCHIATRY 349-53 (1975).

189 LESSARD V. SCHMIDT.

190 LESSARD V. SCHMIDT. 
been investigated and ruled out. The procedural safeguards in the Lessard decision became known among legal advocates as "the ten commandments for the mentally ill."191

From the viewpoint of psychiatric professionals, three aspects of the Lessard decision were especially problematic. Having to warn patients that anything they say can be used against them is antithetical to the traditional doctor-patient relationship; if patients choose to remain silent, psychiatric examinations are impossible. Proof of dangerousness "beyond a reasonable doubt" is much more difficult to achieve than "clear and convincing evidence" or the "preponderance of evidence," the standards of proof that had traditionally been used. Finally, the criteria for dangerousness deemed necessary to permit involuntary commitment were defined so strictly that the criteria would be extremely difficult to meet; the Lessard decision said that "the state must bear the burden of proving that there is an extreme likelihood that if the person is not confined he will do immediate harm to himself or others ... and dangerousness is based upon a finding of a recent overt act, attempt or threat to do substantial harm to oneself or another" (emphases added). ${ }^{192}$ Because of this provision, the Lessard decision was called "the first landmark case dealing with the concept of dangerousness . . . a high-water mark in 'dangerousness' law."193

191 Loren H. Roth, Mental Health Commitment: The State of the Debate, 1980, 31 HoSP. COMMUNITY PSYCHIATRY 385-96 (1980) (hereinafter Roth, MENTAL HEAlth COMMITMENT).

192 LESSARD V. SCHMIDT.

193 Alexander D. Brooks, Notes on Defining the "Dangerousness" of the Mentally Ill, in Calvin J. Frederick (ed.), Dangerous Behavior: A Problem in LaW AND Mental Health (1978). 


\section{A. Assumptions Regarding the Causes of Psychiatric Disorders}

Among the sources cited in support of their ruling, the three judges who rendered the Lessard decision identified the statements by Bruce J. Ennis and Dr. Thomas S. Szasz, both of whom had testified at Hearings on the Constitutional Rights of the Mentally Ill before the U.S. Senate Subcommittee on Constitutional Rights. Robert H. Blondis, one of the lawyers who represented Ms. Lessard and submitted the original brief, said in an interview that his views on psychiatric disorders had also been strongly influenced by Dr. Szasz's books The Myth of Mental Illness (1961) and Law, Liberty and Psychiatry (1963); "that is where I was coming from," Blondis recalled. He said that he had also been influenced by William Ryan's Blaming the Victim (1971). ${ }^{194}$

In their ruling, the three-judge panel reflected the views of Ennis, Szasz, and Ryan. Ennis, the director of the New York Civil Liberties Union Mental Illness Litigation Project, had testified that "mental illness" is "at most a "theory' to explain unconventional conduct or belief. As such, its boundaries expand or contract according to the life styles and value judgments of the theorist." ${ }^{195}$ Szasz had explicitly stated that mental illnesses do not exist "as scientific entities." ${ }^{\text {"196 }}$ Ryan had similarly written that the state psychiatric hospital patient populations consisted mostly of "the poor, the aged, the drunk and the

194 Telephone interview with Robert H. Blondis by E. Fuller Torrey, Jan. 14, 2004. Mr. Blondis acknowledged that when Ms. Lessard called him to ask for his help in 1971 he "knew nothing about mental health law."

195 Statement of Bruce J. Ennis, Hearings on the Constitutional Rights of the Mentally Ill, Subcommittee on Constitutional Rights, Committee on the Judiciary, U.S. Senate, November 4, 5, 12, 13, 18, and 19, 273 (1969) (hereinafter ENNIS, SENATE HEARINGS, 1969).

196 Thomas S. Szasz, LAW, LIBERTY, AND PSYCHIATRY 16 (1963). In this book, Szasz also states: "Psychiatric activity is medical in name only. . . (P)sychiatry is a form of social engineering. It should be recognized as such." (vii). 
inept petty criminal."197 Thus, in their ruling the judges noted: "Obviously, the definition of mental illness is left largely to the user and is dependent upon the norms of adjustment that he employs. ... The diagnostician has the ability to shoehorn into the mentally diseased class almost any person he wishes, for whatever reason, to put there."198 This view suggests that there are no scientific definitions or boundaries for psychiatric disorders but rather that they are simply relative categories of behavior.

In their ruling, the three-judge panel included two other statements that reflected their assumptions regarding the causes of psychiatric disorders. Quoting from the 1970 Senate hearings, the judges noted that "often it is the drugs (i.e., medications) themselves which are responsible for 'crazy' behavior.” And quoting Bruce Ennis's Senate testimony, they noted that there is "substantial evidence that any lengthy hospitalization, particularly where it is involuntary, may greatly increase the symptoms of mental illness." 199 In this view, when symptoms of a psychiatric disorder are present, the symptoms may not signify a true disease but rather may be caused by medications being given to the person or by the effects of hospitalizing the person.

\section{B. Assumptions Regarding Competence To Make Informed Treatment Decisions}

The three-judge panel that rendered the Lessard decision clearly indicated their assumptions regarding the competence of individuals with psychiatric disorders to make informed treatment decisions: "Persons in need of hospitalization for mental illness

197 William Ryan, BLAMING THE VICTIM 155 (1971) (hereinafter RYAN, BLAMING THE VICTIM).

198 LESSARD V. SCHMIDT, quoting Livermore et al., On the Justifications for Civil Commitment, 117 Pa. L. Rev. 75, 80 (1968).

199 LESSARD V. SCHMIDT. 
should be allowed choice of whether to undergo hospitalization and treatment or not unless the state can prove that the person is unable to make decision about hospitalization because of nature of illness." ${ }^{200}$ The court did not further define what it meant by "unable to make decision" or how the state was supposed to establish this deficit. However, the testimony of Bruce Ennis in the 1969 Senate hearings, which was cited multiple times by the judges, included the following: "A patient suffering from cancer, heart disease, or pneumonia can't be committed, even for his own welfare. Apparently, involuntary treatment of the mental patient is based on the assumption first, that he is incompetent to make a 'rational' choice between liberty and treatment, and second, that he would, if competent, choose treatment. There is not to my knowledge any evidence to support either of these assumptions."201

Overall, Bruce Ennis appears to have had a substantial influence on the judges who rendered the Lessard decision. In 1969, Ennis had testified at the U.S. Senate hearings: "Commitment because of alleged danger to self or to others should require proof beyond a reasonable doubt, based on a recent overt act or threat, that the person would, if at liberty, inflict substantial physical injury upon himself or others within the immediate future."202 The 1972 Lessard decision included "beyond a reasonable doubt," "a recent overt act," "substantial harm to oneself or another," and "immediate harm" as its standards for dangerousness.

200 LESSARD V. SCHMIDT. The judges also cite John Stuart Mill: "Each is the proper guardian of his own health, whether bodily or mental and spiritual" (emphasis in original).

201 ENNIS, SENATE HEARINGS, 1969. Similarly, Szasz claimed that "the argument that so-called mentally ill persons do not know what they 'really' need for their own welfare is deceptive" (LAW, LIBERTY, AND PSYCHIATRY 240).

202 Id. 


\section{Effects of the Lessard Decision}

In 1976, legal scholar Alan Stone noted that the provisions of the Lessard decision, if strictly followed, would "put a virtual end to involuntary confinement" of individuals with psychiatric disorders. ${ }^{203}$ For Bruce Ennis and his associates, this was exactly what they intended; Ennis wrote at the time that the ultimate goal of mental health laws should be "nothing less than the abolition of involuntary hospitalization."204

An analysis of the Lessard decision published one year after it was handed down said that "the decision effectively obliterated a major portion of the Wisconsin civil commitment statute" 205 by limiting the use of parens patriae as grounds for involuntary commitment and replacing it with dangerousness as the sole grounds. As summarized by Darold A. Treffert, a Wisconsin psychiatrist who has written extensively about the Lessard case: "Provisions for the state to use parens patriae powers in the absence of dangerousness narrowly defined were effectively abolished; the pendulum swung entirely to dangerousness in terms of imminent physical harm as the only authority on which the state could infringe on individual liberty."206 The decision also guaranteed that individuals facing civil commitment would have many of the same procedural safeguards as are given to individuals charged under the criminal law.

203 Alan A. Stone, Mental Health And LAW: A System in Transition 52 (1976).

204 ENNIS, PRISONERS OF PSYCHIATRY 232.

205 Michael J. Remington, Lessard v. Schmidt and Its Implications for Involuntary Civil Commitment in Wisconsin 57 MARQUETTE LAW REV. 63-101 (1973).

206 Darold A. Treffert, The Obviously Ill Patient in Need of Treatment: A Fourth Standard for Civil Commitment 36 HosP. COMMUNITY PSYCHIATRY 259-64 (1985) (hereinafter TREFFERT, THE OBVIOUSLY ILL PATIENT). 
The Lessard decision had a major influence on courts in other states. Prior to the decision, according to one account, nine states used "dangerousness" as the sole criterion for involuntary psychiatric hospitalization, but by 1980, "every state had changed its statute to restrict hospitalization to persons who were dangerous to themselves or others ... or had interpreted its preexisting statute in a way so as to save it from being found unconstitutional." ${ }^{207}$ Many of the procedural safeguards included in the Lessard decision, such as the right to trail by jury, were also adopted by other states. Similarly, between 1972 and 1980, 5 other states and federal courts copied the Lessard decision by adopting "beyond a reasonable doubt" as the standard by which dangerousness and mental illness should be judged; however, 14 other courts "rejected that standard as too demanding in the context of civil commitment."208

Overall, the Lessard decision was a major victory for the movement to restrict involuntary commitment. As summarized in a 1975 overview of civil commitment laws: "Both courts and legislation are moving more towards the police power concept of 'dangerousness' as a ground for commitment and away from the parens patriae concept of 'unable to care for self' or 'in need of mental treatment,' because a deprivation of liberty is a serious curtailment of personal rights and should only be imposed when absolutely necessary."209

In Wisconsin, the implementation and effects of the Lessard decision varied widely from county to county. As described in a 1976 analysis: "Because many Wisconsin county judges disagreed with much of the Lessard decision, and because

207 Paul S. Applebaum, Almost a Revolution: Mental Health Law AND the Limits of Change 28 (1994).

208 Roth, Mental Health COMmitment.

209 The "Crime" of Mental Illness: Extension of "Criminal" Procedural Safeguards to Involuntary Civil Commitments, 66 J. CRIM. LAW CRIMINOLOGY 255-70 (1975). 
much of the decision contained ambiguities, many of the fundamental Lessard requirements were given interpretations that were so broad that they were rendered meaningless. ${ }^{, 210}$ There was a sharp decrease in involuntary admissions in most counties; for example, at the Milwaukee County Mental Health Center, involuntary admissions decreased by more than half from immediately prior to the Lessard decision to immediately after it. $^{211}$ At the same time, there was a sharp increase in criminal commitments of individuals with serious psychiatric disorders to the three state psychiatric hospital; ${ }^{212}$ bringing criminal charges against individuals with severe psychiatric disorders is one of the only ways to get such individuals hospitalized when civil commitment is no longer possible.

In Wisconsin counties in which the Lessard court definition of dangerousness was strictly adhered to, it became almost impossible to get involuntary civil commitments for individuals with serious psychiatric disorders. Darold Treffert documented these difficulties in great detail, including, for example, the case of a man diagnosed with schizophrenia who was in jail, overtly psychotic, and observed to be eating his feces from the toilet bowl. When a psychiatrist recommended that he be committed to a psychiatric hospital for treatment, the following court discussion took place:

Public defender: "Doctor, would the eating of fecal material on one occasion by an individual pose a serious risk of harm to that person?

210 Thomas K. Zander, Civil Commitment in Wisconsin: The Impact of Lessard v. Schmidt 1976 WISC. LAW REV. 503-62 (1976) (hereinafter ZANDER, CIVIL COMMITMENT IN WISCONSIN). The author, who has been a strong proponent of the Lessard decision, detailed the myriad ways in which judges and hospital administrators circumvented the Lessard provisions. For example, many judges continued to use "preponderance of evidence" rather than "beyond a reasonable doubt" as the standard for evidence, and also to define dangerousness more leniently than the court had recommended.

211 Ashok Ramprakash Bedi, The Effect of the Lessard Decision on Adult Commitment Statistics at Milwaukee County Institutions 77 WISC. MED. J. S77-80.

212 TREFFERT, THE MACARTHUR COERCION STUDIES. 
Doctor: "It is certainly not edible material. . . It contains elements that are considered harmful or unnecessary."

Public defender: "But, doctor, you cannot state whether the consumption of such material on one occasion would invariably harm a person?

Doctor: "Certainly not on one occasion."

The public defender then moved to dismiss the petition for commitment on the grounds that the patient did not meet the strict Lessard criteria for dangerousness. The judge agreed, and the man was released. ${ }^{213}$

The consequences of the Lessard decision can also be measured by its effects on the community. A few years after implementation of the decision, the governor of Wisconsin "became concerned about the number of obviously mentally ill persons on the streets of the capital who were wandering into the capital building and into his office."214 As has happened in other states, the number of psychiatrically ill homeless individuals continued to steadily increase in Wisconsin so that in 2000, shelter workers in Milwaukee estimated "that half of the 2,000 or so who live on Milwaukee's streets are chronically and persistently mentally ill.",215

Similarly, in 1981, the Milwaukee Sentinel carried a series of articles entitled "Mentally Ill Behind Bars," detailing how mentally ill persons were being shunted to the criminal justice system since implementation of the Lessard decision. ${ }^{216}$ Increasingly, police realized that it was useless to try to get commitments for mentally ill individuals, so they arrested them instead.

213 TREFFERT, THE MACARTHUR COERCION STUDIES.

214 TREFFERT, THE OBVIOUSLy ILl PATIENT.

215 Meg Kissinger, Teacher's Case Opened Door for Mentally Ill, MiLWAUKEE JOURNAL SENTINEL, Aug. 27, 2000 (hereinafter KISSINGER, TEACHER's CASE).

216 M. Zahn \& P. Patrinos, Mentally Ill Behind Bars, MilwaukeE SEnTinel, August 1981. 
In Madison, Wisconsin, the most common charges brought against mentally ill persons who were arrested were "lewd and lascivious behavior (such as urinating on a street corner), defrauding an innkeeper (eating a meal, then not paying for it), disorderly conduct (such as being too loud), menacing panhandling, criminal damage to property, loitering or petty theft." ${ }^{217}$ By 2000, two decades after implementation of the Lessard provisions, jail officials in Milwaukee claimed that "one-third of 2,500 inmates at the county jail and the House of Corrections are suffering from a major mental illness, ${ }^{218}$

Following the Lessard decision, there also appeared to be an increase in suicides and violent acts by mentally ill individuals who were not being treated. Within three months following implementation of Lessard, three deaths had been directly attributed to the new law. Darold Treffert noted that "each of these patients needed commitment; none qualified," and he eloquently referred to such deaths as "dying with one's rights on."219

Violent episodes involving mentally ill individuals continued to occur regularly in Wisconsin. Such episodes became especially common in Dane County, where the court was said to place "heavy emphasis on the Lessard commitment standard, requiring the defendant to be dangerous to himself or others. ${ }^{, 220}$ In Madison, a community of 200,000, such violent episodes peaked in a 13-month period in 1988 and 1989 during which "six separate incidents resulted in four homicides, three suicides, seven victims wounded by gunshot, and one victim mauled by a polar bear."221 The last occurred when a mentally ill man climbed into the den of the bear at the Madison zoo. Some observers attributed these

217 B. Mulhern, Everyone's Problem, No One's Priority, (MADISON, WisC.) CAPITAL TIMES, December 15-18, 1990.

218 Dave Umhoefer \& Meg Kissinger, A Blueprint for the Mentally Ill, MILWAUKEE JOURNAL SENTINEL, September 16, 2000.

219 Darold A. Treffert, Dying with One's Rights On (letter) 224 JAMA 1649 (1973).

220 ZANDER, CIVIL COMMITMENT IN WiSCONSIN

221 Thomas L. Kuhlman, Unavoidable Tragedies in Madison, Wisconsin: A Third View, 43 HosP. COMMUNITY PSYCHIATRY 72-73 (1992). 
incidents to "unduly stringent interpretations and applications of Wisconsin's civil commitment standards." ${ }^{222}$ Responding to a public outcry following these incidents, the strict county criteria for commitment were relaxed, with a subsequent decrease in violent episodes.

Finally, what effect did the class-action Lessard decision have on Ms. Lessard herself? Prior to the onset of her illness and her involuntary hospitalization, Ms. Lessard had been a successful schoolteacher for 26 years and had also taught student teachers at Marquette University. After the Lessard decision, Ms. Lessard was unable to work and lived on Social Security Disability Insurance (SSDI). During the intervening years, according to her recollection, she was involuntarily hospitalized "13 or 14 times" but never took medications except when forced to do so during her brief hospitalizations. ${ }^{223}$

Ms. Lessard also acknowledged having been put in jail "maybe a dozen times" on what she called "trumped up charges." On two or three occasions, she says, she was homeless, including two months of living on the streets of Milwaukee during the winter. During the years since the Lessard decision, Ms. Lessard has filed numerous suits against the government, including one seeking to declare "all elections from the time of Richard Nixon's illegal." That suit was dismissed with a comment by the judge that "it is clear from her complaint that the plaintiff wishes to challenge nearly every facet of government in existence today." ${ }^{224}$ When Ms. Lessard was recently asked in an interview if she

222 Id

223 Telephone interview with Ms. Alberta Lessard by E. Fuller Torrey, Jan. 26, 2004.

224 Lessard v. State of Wisconsin, 449 F. Supp. 914 and 462 F. Supp. 338. In the years following her initial hospitalization, Ms. Lessard appeared regularly as a spectator in the courtroom of one of the judges on the three-judge panel that handed down the Lessard decision. On occasion, she loudly, and without being solicited, voiced her opinion regarding the proceedings and on at least two occasions had to be escorted from the courtroom, according to telephone interviews by E. Fuller Torrey with Judge Myron L. Gordon, Dec. 11, 2003, and Jan. 14, 2004. 
believed that she had schizophrenia, she answered: “Absolutely not. I don't have any of the symptoms."225

\section{Implications of the New Biology for Laws Governing}

Involuntary Commitment and Treatment:

Principles for Consideration for Future Mental Health Legislation

Since the 1960s, there have been profound changes in state mental health laws, especially those concerning the involuntary commitment and treatment of patients. We have examined in detail two such laws, the 1969 Lanterman-Petris-Short (LPS) Act in California and the 1972 Lessard decision, which led, after several overturnings, to new legislation in Wisconsin. LPS and Lessard are perhaps the best-known statute and decision in civil commitment law, particularly for their era. We have argued that their assumptions about mental illness, and the brain, are seriously mistaken. Possibly because of their influence, they are representative of other statutes and caselaw that also make seriously inaccurate assumptions.

In both the LPS legislation and the Lessard decision, the legal changes were predicated on assumptions regarding the probable causes of psychiatric disorders and the competence of individuals who have been diagnosed with a severe psychiatric disorder to make informed treatment decisions. We have examined these assumptions in detail, using schizophrenia as the most common form, and representative example, of severe psychiatric disorders. Although scientific studies of bipolar disorder (manic-depressive

${ }^{225}$ Telephone interview with Ms. Alberta Lessard by E. Fuller Torrey, Jan. 26, 2004. 
illness) and major depression with psychotic features are less abundant than those of schizophrenia, those that do exist suggest that our conclusions probably apply to those disorders as well. ${ }^{226}$ However, the conclusions appear not to be applicable to other psychiatric disorders in which anosognosia is not a clinical feature.

226 At least eight studies have compared anosognosia in patients with bipolar disorder to anosognosia in those with schizophrenia. These studies included over 400 individuals with bipolar disorder; in two studies the patients with bipolar disorder had equally as much anosognosia as those with schizophrenia, and in the other six studies, they had almost as much, but slightly less, anosognosia. The two studies showing equal anosognosia are Martin A. Weiler et al., Insight and Symptom Change in Schizophrenia and Other Disorders 45 SCHIZOPHR. RES. 29-36 (2000) [hereinafter WEILER ET AL., INSIGHT AND SYMPTOM CHANGE] and Charmaine C. Williams \& April Collins, Factors Associated with Insight among Outpatients with Serious Mental Illness 53 PSYCHIATR. SERV. 96-98 (2002). The other six studies are Xavier F. Amador et al., Awareness of Illness in Schizophrenia and Schizoaffective and Mood Disorders 51 ARCH. GEN. PSYCHIATRY 826-36 (1994); A. Michalakeas et al., Insight in Schizophrenia and Mood Disorders and Its Relation to Psychopathology 90 ACTA PSYCHIATR. SCAND. 46-49 (1994) [hereinafter MICHALAKEAS ET AL., INSIGHT IN SCHIZOPHRENIA AND MOOD DISORDERS]; Shmuel Fennig et al., Insight in First-Admission Psychotic Patients 22 SCHIZOPHR. RES. 257-63 (1996) [hereinafter FENNING ET AL., INSIGHT IN FIRSTADMISSION PSYCHOTIC PATIENTS]; Charlie L. Swanson Jr. et al., Insight in Schizophrenia and Mania 183 J. NERV. MENT. DIS. 752-55 (1995); Stefano Pini et al., Insight into Illness in Schizophrenia, Schizoaffective Disorder, and Mood Disorders with Psychotic Features 158 AM. J. PSYCHIATRY 122-25 (2000); and Cheng-Fang Yen et al., Comparison of Insight in Patients with Schizophrenia and Bipolar Disorder in Remission 190 J. NERV. MENT. DIS. 847-49 (2002 [hereinafter YEN ET AL., COMPARISON OF INSIGHT]. Analyses of many of these studies are included in reviews by S. Nassir Ghaemi, Insight and Psychiatric Disorders: A Review of the Literature, with a Focus on Its Clinical Relevance for Bipolar Disorder 27 PSYCHIATR. ANN. 782-90 (1997) and Joseph P. McEvoy \& Michelle L. Wilkinson, The Role of Insight in the Treatment and Outcome of Bipolar Disorder 30 PSYCHIATR. ANN. 496-98 (2000) [hereinafter MCEvoY \& WILKInSON, THE ROLE OF INSIGHT]. A logical explanation for the fact that individuals with bipolar disorder have modestly less anosognosia, and thus better awareness of their illness, was put forth by one group of researchers (Yen et al., Comparison of Insight). In that study, they included patients with bipolar disorder who had psychotic features (e.g., hallucinations and delusions) as well as those who did not have psychotic features. Unlike schizophrenia, in which all patients must by definition have psychotic features in order to qualify for that diagnosis, individuals can qualify for the diagnosis of bipolar disorder by having severe mood swings alone without any psychotic features. In Yen et al.'s study, the researchers reported "no significant difference [in anosognosia] between those patients with schizophrenia and those with psychotic bipolar disorder" but "a significantly higher proportion of subjects with intact insight in the group of patients with nonpsychotic bipolar disorder than in the group of patients with either schizophrenia or psychotic bipolar disorder." See also Yen et al., Changes in Insight in Manic Episodes and Influencing Factors 44 COMPR. PSYCHIATRY 404-408 (2003). The implication of these findings is that anosognosia is a trait that is associated with psychotic features (e.g., delusions and hallucinations) and not specifically with schizophrenia per se. If this is true, then some individuals with severe depression in which psychotic features are present should also have anosognosia. Most individuals with depression do not have psychotic features and retain good awareness of their illness. It is this trait, in fact, that makes severe depression so painful and produces a higher suicide rate among those affected (Frederick Cassidy et al., Insight Is Greater in Mixed Than in Pure Manic Episodes of Bipolar I Disorder 189 J. NERV. MENT. 398-99 [2001]). See, for example, the exquisitely painful awareness of illness described by William Styron in DARKNESS VISIBLE: A MEMOIR OF MADNESS (1990). Another good example is Percy Knauth's A SEASON IN HELL 35 (1975), in which he says: "More realistically, I understood that the only tool I could fight with—my mind-was the very part of me that was affected." 
Regarding the causes of schizophrenia, we found that the architects of both LPS and the Lessard decision were understandably influenced by the prevailing beliefs of that era. They assumed that schizophrenia was a relative concept, a label that could be applied arbitrarily and for which there was no scientific basis. The framers of LPS wrote that "madness, like beauty, may exist in the eye of the beholder."227 The three-judge panel that handed down the Lessard decision wrote that "the definition of mental illness is left largely to the user and is dependent upon the norms of adjustment that he employs." ${ }^{228}$ Although every term has play around the edges-what H. L. A. Hart called open texture-these characterizations of mental illness are grossly exaggerated. ${ }^{229}$ Consistent with the belief that definitions of mental illness were arbitrary was the belief that state psychiatric hospitals were "warehouses for the idiosyncratic, the aged, the senile, the odd, the different," in the words of one of the sponsors of LPS, ${ }^{230}$ or "the poor, the aged, the drunk and the inept petty criminal," in the words of a writer who influenced the Lessard decision. $^{231}$

As we have demonstrated in part II, these assumptions about the causes of schizophrenia are now known to be erroneous. Literally hundreds of studies have shown that schizophrenia is a brain disease with measurable changes in brain structure and function, and that these changes are not caused by medications being used to treat it. In this sense, schizophrenia is in the same category of conditions as Alzheimer's disease, Parkinson's disease, multiple sclerosis, and other disorders known to be diseases of the brain but whose precise causes are not yet known. 
The architects of both LPS and the Lessard decision also assumed that individuals with serious mental illnesses were competent to make informed treatment decisions. One of the sponsors of LPS wrote that it was "indefensible" to presume "that a mentally ill individual will not admit to being 'sick' and will not accept recommended treatment."232 Similarly, Bruce Ennis, who strongly influenced the Lessard decision, wrote that "there is not to my knowledge any evidence to support" the assumption that "the mental patient . . . is incompetent to make a 'rational' choice between liberty or treatment." ${ }^{, 233}$ Thus, under LPS, "citizens will be free to decide whether they wish to enter or leave the hospitals," and under the Lessard decision, "persons in need of hospitalization for mental illness should be allowed choice of whether to undergo hospitalization and treatment ..."234 As we have demonstrated in part III, these assumptions about the competence of individuals with severe psychiatric disorders to make informed treatment decisions are, in many cases, wrong. Approximately half of individuals diagnosed with schizophrenia and bipolar disorder have anosognosia and are partially or completely unaware of their illness. Many of these individuals are not competent to make rational treatment decisions because they do not believe there is anything wrong with them or that they need treatment. ${ }^{235}$ Anosognosia is a biologically-based deficit, and individuals with severe psychiatric disorders who suffer from anosognosia are similar to individuals with Alzheimer's disease, Huntington's disease, or strokes. They are similar in the legally and

Lanterman, New Mental Health Legislation 2, 3.

ENNIS, SENATE HEARINGS, 1969.

THE DILEMMA REPORT 123; LESSARD V. SCHMIDT.

KRESS, Why LaCK OF Insight Should HaVe a CENTRAl Place 257 (arguing that in circumstances of coerced treatment, lack of insight can serve as superior proxy for incapacity because lack of insight better justifies coercion than incapacity does in most circumstances); KRESS, AN ARGUMENT FOR ASSISTED OUTPATIENT TREATMENT 1269, 1314-15, 1365-67 (2000). 
morally relevant respects. Actions by such individuals that are consequences of their anosognosia must be seen as symptoms of an illness, and not as free, informed choices.

Because current scientific knowledge suggests that approximately half of persons with schizophrenia and bipolar disorder lack insight into their illness and need for treatment, we should inquire as to which, if any, consequences follow for mental health law from these facts. Consistent with the rest of this Article, we will describe the consequences for civil commitment. However, similar conclusions could be drawn for coerced treatment.

There are two kinds of jurisdictions. The first requires competence for commitment; the second does not. This much follows as a matter of logic. Approximately ten jurisdictions have some kind of incapacity prerequisite for commitment explicitly in their statutory criteria. ${ }^{236}$ Careful analysis reveals that some of those requirements are not really a form of incapacity. ${ }^{237}$ Therefore, it might appear that fewer than ten jurisdictions require incapacity, but that conclusion would be premature. Some jurisdictions have incapacity as a result of judicial decisions, whereas other jurisdictions sneak incapacity in by the back door. ${ }^{238}$ Without a thorough, time consuming and probably unrewarding investigation, it is unclear how many jurisdictions require incapacity.

${ }^{236}$ E.g., AL STAT Sec. 22-52-10.2 iii; FL. STAT Sec. 394.467 1. (a) \& (b).; IOWA CODE Sec. 229.1(15).

${ }^{237}$ States that have a criterion in the vicinity of incapacity for commitment, but not quite incapacity, include Arizona and Colorado. Az. STAT. 36-533 (3) ("That the patient is unwilling to accept or incapable of accepting treatment voluntarily;") (The statute does not contemplate the prospect that the patient reasonably rejects treatment and is capable of doing so); In re Pima County, 817P.2d.945(Ariz. App.1991) (Failure to recognize the benefits of treatment serving as a proxy for incapacity); CO. STAT 27-10109(b)(Respondent rejects treatment after having been advised of its availability or is likely not to remain in a voluntary treatment program as a proxy for incapacity).

${ }^{238}$ For example, Wisconsin’s Fifth Standard for dangerousness, Wis. Stat. Ann. § 51.20(13)(a)3 (2001), recently held constitutional by the Wisconsin supreme court, In re Dennis H, sneaks in an incapacity requirement as part of the definition of dangerousness. 
Whatever the distribution, in those jurisdictions that require incapacity, anosognosia is evidence of legally relevant lack of insight, which is itself evidence of incapacity. Many legal theorists have argued that lack of insight is either nearly sufficient for incapacity, or else justifies commitment and coerced treatment as well or better than incapacity. ${ }^{239}$ Because approximately half of persons with schizophrenia or bipolar disorder have substantial or severe lack of insight, the strong presumption of capacity in doctrine and practice in California under the Lanterman-Petris-Short Act, and in Wisconsin under the Lessard decision, is misguided and should be discarded in consequence of advances in scientific knowledge. So too should jurisdictions with strong presumptions that follow California or Wisconsin, or that have independent grounds for a strong presumption, discard those presumptions.

We cannot overemphasize the importance of psychiatrists, lawyers, and courts paying greater attention to lack of insight. Still, we will not move too far in the opposite direction. We wish to replace dogmatism with reason, not with an opposing dogmatism. Our view is that lack of insight is substantial evidence of incapacity that should lead to further inquiry, not that it is conclusive.

If, because you lack insight, you irrationally believe that you are not mentally ill, do not have pathological symptoms, and do not need treatment, it may nonetheless seem natural from your perspective to reject treatment. But those beliefs block your ability to make an informed, free, capable decision because the existence of pathological symptoms, illness, and need for treatment are crucial facts necessary for informed

\footnotetext{
${ }^{239}$ Kress, Why LaCK OF Insight ShOUld HaVe a Central PlaCe 257; Elyn R. Saks \& Dilip V. Jeste, Capacity To Consent to or Refuse Treatment and/or Research: Theoretical Considerations, PROCEEDINGS OF THE INSTITUTE OF MEDICINE (forthcoming).
} 
decision making. A rational inference from seriously unjustified beliefs is generally not a capable decision, or a capable mental health treatment decision. ${ }^{240}$

Perhaps surprisingly, many individuals who lack insight, or the capacity to make mental health treatment decisions nonetheless accept treatment. There is no reason to waste government resources overseeing such individuals even if they meet the criteria for commitment. We have better ways to employ our scarce resources.

In summary, in jurisdictions that require incapacity for commitment, recent advances in our understanding of lack of insight suggest that there should be no strong presumption of capacity in doctrine or practice. Rather, it is likely, but not certain, that most persons who lack insight lack capacity. Moreover, most, but not all persons who lack insight will refuse treatment ${ }^{241}$; if there were to be any presumption, it should be in the other direction. But it is probably better to have no presumption, and put the State to its proof. Our most important point, however, is that all actors in the commitment and coerced treatment system should pay more attention to anosognosia and its consequences.

Both in jurisdictions that require incapacity for commitment, and those that do not, lack of insight is evidence, but not conclusive evidence, for both mental illness and dangerousness, the two nearly universal requirements for civil commitment by statute in American jurisdictions, ${ }^{242}$ and perhaps nearly all foreign jurisdictions as well. Most commentators believe the two are Constitutionally required by Foucha v. Louisiana, 504 U.S. 71(1992), ${ }^{243}$ but a careful analysis rejects that interpretation. ${ }^{244}$ In those jurisdictions

\footnotetext{
${ }^{240}$ Elyn Saks, Competency To Refuse Treatment, 69 N.C.L. Rev. 945 (1991).

241 TORREY, THE RELATIONSHIP OF INSIGHT TO VIOLENT BEHAVIOR AND STIGMA 243, 245 (and sources cited therein).

242 But see South Carolina Stat. Sec. 44-17-580 (mental illness and either incapacity or dangerousness).

243 See, e.g., Bruce J. Winick, The Right To Refuse MENTAl HEALTH TREATMENT, 289-91 (1977) (hereinafter Bruce J. Winick, The Right To Refuse MENTAl HeAlth TREATMENT.
} 
that do not require incapacity for commitment, as well as those that do, lack of insight is still relevant to proof of mental illness and dangerousness.

There are two possible routes by which lack of insight could help prove mental illness or more severe mental illness. First, there might be a correlation, although certainly not direct, between severity of lack of insight and severity of illness. More likely, there are known correlations between lack of insight, and failure to accept treatment. Additionally, failure to accept treatment is correlated with more severe illness. Finally, more severe illness is correlated with greater dangerousness and violence. Thus, lack of insight is evidence of greater mental illness and greater dangerousness. It is relevant to commitment even in jurisdictions that do not require competence for commitment. $^{245}$

Our normative consideration is that lack of insight, or lack of appreciation, better justifies coerced treatment than incapacity read as lack of practical reasoning ability, that is, lack of ability to rationally choose from among possible mental health treatments, including deciding to accept none. This holds for two reasons. First, it is unclear how so

244 In Foucha v. Louisiana, 504 U.S. 71, 73 (1992), language in the plurality opinion asserts that the Constitution requires both mental illness and dangerousness, but the Court's statements about dangerousness are both dicta and based upon a misunderstanding of the Court's prior opinions in Jones $v$. United States, 463 U.S. 354 (1983) and O'Connor v. Donaldson, 422 U.S. 563 (1975). Whether substantive due process requires dangerousness was not before the Court. Moreover, as Justice Thomas noted in his dissent, Jones held that mental illness and dangerousness was constitutionally sufficient for commitment, whereas the plurality of the Court misstated Jones as holding that mental illness and dangerousness were necessary for a commitment that is constitutional. Id. at 120. More importantly, the plurality had only four votes. Justice O'Connor made it clear that her fifth and deciding vote was premised upon the opinion applying only to Louisiana's criminal commitment statute, and does not apply to other more narrowly drawn criminal commitment statutes. A fortiori, the opinion does not apply to civil commitment statutes, including Wisconsin' s Fifth Standard: "I write separately, however, to emphasize that the Court's opinion addresses only the specific statutory scheme before us, which broadly permits indefinite confinement of sane insanity acquittees in psychiatric facilities." Id. at 86-87 (O'Connor, J., concurring in part).

Moreover, Justice O'Connor reiterated that Jones had noted that psychiatry is an inexact science, and that for that reason, "'courts should pay particular deference to reasonable legislative judgments' about the relationship between dangerous behavior and mental illness," such as those embodied in Wisconsin's Fifth Standard. Id. at 87 (quoting Jones, 463 U.S. at 364, 365 \& n.13).

245 TORREY, THE RELATIONSHIP OF INSIGHT TO VIOLENT BEHAVIOR AND STIGMA 243. 
many courts and commentators could have thought that inability to reason by a method that has a good chance of picking the best, or a good treatment, justifies paternalistic government intervention. That is to take a socialsciencecentric perspective. It is to force cost-benefit rationality upon others, on pain of denominating them incapable. That persons with mental illness do not make decisions as the advocates of practical reason would recommend does not justify coercing those individuals. On the other hand, individuals who don't realize that they are ill, or how ill they are, or that they need treatment—who lack insight—cannot make free and informed decisions. The inability to make free and informed decisions has justified state paternalism in both legal doctrine and philosophical writings for centuries.

Moreover, because lack of insight is easier to determine than inability to rationally choose-indeed, the concept of rationality itself is controversial —intervening on the basis of lack of insight results in the law being more reliable and certain. When the law is more reliable and certain, persons have more liberty because they know better where their liberty ends and the law's coercion begins. Moreover, where the law is more certain, persons are treated alike when appropriate more often, and the law treats its subjects more frequently with equal concern and respect. Finally, by basing coercion on lack of autonomy, rather than lack of practical reasoning ability, the state treats its citizens more justly, and also more equally. We do not want to follow Vince Lombardi, who said, "I treat all my players equally. Like dogs!" 246

Given the current state of knowledge regarding the causes of severe psychiatric disorders and the competence of some individuals affected by these disorders, we might

246 Kress, Why LaCK of Insight Should HaVe a Central PlaCe) 257. 
also ask what principles should be considered in framing future legislation? The following three principles should be considered:
A. Individuals with schizophrenia and other severe psychiatric disorders should be regarded as equal to individuals with other chronic brain disorders

The category of "psychiatric disorders," as defined by the American Psychiatric Association, includes an extremely wide and diverse group of behaviors. It is now clear that a subset of these that includes schizophrenia, bipolar disorder, and major depression consists of biologically-based brain diseases. As such, these disorders should be treated legislatively in the same manner as other brain diseases such as Alzheimer's disease, Parkinson's disease, and multiple sclerosis. Thus, there should be no discrimination against individuals with these psychiatric disorders for public programs such as Medicaid or Medicare coverage or for private programs such as medical insurance coverage. Insofar as discrimination exists, it should be corrected by legislation.

B. An assessment for anosognosia should be routinely included in all determinations of competency

Since studies have clearly demonstrated that many individuals with severe psychiatric disorder have anosognosia, its assessment should be included in all competency determinations. As noted in section III, there are now a variety of anosognosia assessment scales that can be used for this purpose. 
It is important to assess anosognosia, because it has been shown in individuals with schizophrenia to be the single most important determinant of medication noncompliance. Medication noncompliance, in turn, is a major determinant of relapses, readmissions to hospitals, homelessness, incarcerations, and violent behavior among individuals with schizophrenia. Thus, for an individual with schizophrenia who has a history of incarceration or violence, an assessment of anosognosia would be helpful to judicial authorities in recommending the conditions under which the person should be allowed to live in the community. ${ }^{247}$

C. Provision for assisted treatment should be available in all states and used when necessary

Since medication compliance is critical for successful community living for many individuals with severe psychiatric disorders, and since individuals with anosognosia are less likely to take medication because they do not believe they are ill, assisted treatment should be available and used when necessary. Many forms of assisted treatment are available, all of which involve some degree of coercion. These include representative payeeship, conditional release, outpatient commitment, and conservatorships.

Representative payeeship as a form of assisted treatment occurs when another individual, assigned by the court, is the recipient of the affected individual's SSI, SSDI, VA disability check, or other financial support and when medication compliance is a condition for releasing the funds. For individuals with severe psychiatric disorders,

247 TORREY, THE RELATIONSHIP OF INSIGHT TO VIOLENT BEHAVIOR AND STIGMA 243. 
studies have shown representative payeeship to be effective in reducing rehospitalization, substance abuse, and homelessness. ${ }^{248}$

Conditional release occurs when patients who have been legally committed to a hospital are released on the condition that they follow treatment instructions, including taking medication when indicated. Violation of the condition may result in involuntary rehospitalization, or a rehearing on whether rehospitalization is proper. Forty states have laws permitting conditional release, ${ }^{249}$ but it is used primarily for criminally committed patients. In most states, the director of the state psychiatric hospital, or her agent, has the authority to issue conditional releases without asking permission of the court. ${ }^{250}$ In New Hampshire the permission has also been legally delegated to the directors of state-owned community mental health centers. New Hampshire has deployed conditional release particularly widely in civil cases. In these circumstances, conditional release decreases violence. ${ }^{251}$ Among forensic patients, conditional release has been shown in studies in Oregon and other states to be highly effective in reducing future criminal behavior. ${ }^{252}$

248 Studies have shown that using a representative payee reduces hospitalization days, substance abuse, and days spent homeless; see Daniel J. Luchins et al., An Agency-based Representative Payee Program and Improved Community Tenure of Persons with Mental Illness, 49 PSYCHIATR. SERV. 1218-22 (1998), Daniel J. Luchins et al., Representative Payeeship and Mental Illness: A Review, 30 ADM. PoLICY MENT. HeAlth 341-53 (2003), Robert Rosenheck et al., Impact of Representative Payees on Substance Use among Homeless Persons with Serious Mental Illness and Substance Abuse, 48 PSYCHIATR. SERV. 800-806 (1997), and M.R. Stoner, Money Management Services for the Homeless Mentally Ill, 40 HoSP. COMMUNITY PSYCHIATRY 751-53 (1989). In a U.S. Third Circuit Court of Appeals ruling, the court ruled that a man with epilepsy and borderline mental retardation was not entitled to SSDI benefits unless he demonstrated compliance with his anti-epileptic medication (Brown v. Bowen, 845 F2d 1211, 3rd Circuit, 1988).

249 Christopher Slobogin, Involuntary Community Treatment of People Who Are Violent and Mentally Ill: A Legal Analysis, 45 HOSP. COMMUNITY PSYCHIATRY 685-89 (1994).

250 See, e.g., IOWA CODE Sec. 229.14(2003); In Re Melodie L.,591 N.W.2d 4,9 (Iowa 1999).

251 Christopher O'Keefe et al., Treatment Outcomes for Severely Mentally Ill Patients on Conditional Discharge to Community-based Treatment, 185 J. NERV. MENT. DIS. 409 (1997).

252 Joseph D. Bloom et al., Monitored Conditional Release of Persons Found Not Guilty by Reason of Insanity, 148 AM. J. PSYCHIATRY 444-48 (1991); Joseph D. Bloom et al., Evaluation and Treatment of Insanity Acquittees in the Community, 14 BULL. AM. ACAD. PSYCHIATRY LAW 231-44 (1986). 
Outpatient commitment occurs when a court orders a patient to comply with treatment, usually including medication, as a condition for living in the community. Violation of an outpatient commitment order can result in involuntary inpatient commitment, or rehearing and involuntary hospitalization. Schopp has developed a particularly powerful argument why a failure to comply with an outpatient order may justify inpatient commitment. He argues that under the least restrictive alternative doctrine failure to comply with the outpatient commitment order may demonstrate that the respondent is incapable of living safely as an outpatient. ${ }^{253}$ Some form of outpatient commitment is available in forty-two states but is little used in most of them. ${ }^{254}$ Multiple studies have demonstrated that outpatient commitment for individuals with severe psychiatric disorders is effective in increasing treatment compliance and in decreasing psychiatric readmissions, episodes of violence, and arrests and incarcerations. ${ }^{255}$

253 Robert F. Schopp, Outpatient Civil Commitment: A Dangerous Charade or a Component of a Comprehensive Institution of Civil Commitment?,9 Psychology, PUB. POL, Y \& L. 33 (2003).

254 The states for which no outpatient statute exists are Connecticut, Maine, Maryland, Massachusetts, Nevada, New Jersey, New Mexico, and Tennessee.

${ }_{255}$ Outpatient commitment has been shown to be effective as a form of assisted treatment in increasing treatment compliance. In North Carolina, only $30 \%$ of patients on outpatient commitment refused medication during a six-month period compared to $66 \%$ of patients not on outpatient commitment; see Virginia Hiday \& Teresa L. Scheid-Cook, The North Carolina Experience with Outpatient Commitment: A Critical Appraisal, 10 INT. J. LAW PSYCHIATRY 215-32 (1987). A more recent North Carolina study showed similar effectiveness; see Marvin S. Swartz et al., Effects of Involuntary Outpatient Commitment and Depot Antipsychotics on Treatment Adherence in Persons with Severe Mental Illness, 189 J. NERV. MENT. DIS. 583-92 (2001). In Ohio, outpatient commitment increased patients' compliance with outpatient psychiatric appointments from 5.7 to 13.0 per year and with attendance at day treatment sessions from 23 to 60 per year; see Mark R. Munetz et al., The Effectiveness of Outpatient Civil Commitment, 47 PSYCHIATR. SERV. 1251-53 (1996) (hereinafter MUNETZ, THE EFFECTIVENESS OF OUTPATIENT CIVIL COMMITMENT). In Arizona, among patients who had been outpatient committed, "71 percent of the patients voluntarily maintained treatment contacts six months after their orders expired" compared to "almost no patients" who had not been put on outpatient commitment; see Robert A. Van Putten et al., Involuntary Outpatient Commitment in Arizona: A Retrospective Study, 39 HOSP. COMMUNITY PSYCHIATRY 953-58 (1988). And in Iowa, "it appears as though outpatient commitment promotes treatment compliance in about 80 percent of patients while they are on outpatient commitment. After commitment is terminated about three-quarters of that group remain in treatment on a voluntary basis"; see Barbara M. Rohland, THE ROLE OF OUTPATIENT COMMITMENT In THE MANAGEMENT OF PERSONS WITH SCHIZOPHRENIA (1998) (hereinafter ROHLAND, THE ROLE OF OUTPATIENT COMMITMENT). The effectiveness of outpatient commitment in decreasing hospital admissions has been clearly established. In Washington, D.C., admissions decreased from 1.81 per year to 0.95 per year before and after outpatient commitment; see Guido Zanni \& Leslie 
Conservatorships or guardianships occur when an individual is assigned by the court to make decisions for another person who is considered not to be competent. In the United States, they are widely used for individuals who have moderate or severe mental retardation and for individuals with neurological conditions such as Alzheimer's disease. Conservatorships and guardianships are theoretically available in most states for individuals with severe psychiatric disorders but have been little used except in California.

These various forms of assistance have been shown to reduce violence, arrests, incarceration, treatment costs from inpatient commitment, homelessness, and substance abuse, although not each form of assistance has yet been demonstrated by empirical studies to reduce each of these social problems. Despite these considerable virtues, some will object that coercion violates autonomy rights and therefore cannot be justified.

We will respond to this concern by distinguishing three circumstances. First, we will consider individuals who are dangerous to others. Second, we will examine

\footnotetext{
deVeau, Inpatient Stays Before and After Outpatient Commitment 37 HoSP. COMMUNITY PSYCHIATRY 941-42 (1986). Similarly, in Ohio the decrease was from 1.5 to 0.4 (MUNETZ, THE EFFECTIVENESS OF OUtPATIENT CIVIL COMMITMENT), and in Iowa from 1.3 to 0.3 (ROHLAND, THE ROLE OF OUTPATIENT COMMITMENT). In North Carolina, admissions for patients on outpatient commitment decreased from 3.7 to 0.7 per 1,000 days; see Gustavo Fernandez \& Sylvia Nygard, Impact of Involuntary Outpatient Commitment on the Revolving-Door Syndrome in North Carolina, 41 HOSP. COMMUNITY PSYCHIATRY 1001-1004 (1990). In New York, the reduction in readmissions was from 87\% to 20\%; see New York State Office of Mental Health, KENDRA's LAW: AN INTERIM REPORT ON THE STATUS OF ASSISTED OUTPATIENT TREATMENT (2003) (hereinafter KENDRA'S LAW: AN INTERIM REPORT). The only study that failed to find outpatient commitment effective in significantly reducing admissions was a Tennessee study. However, in that study, it was evident that "outpatient clinics are not vigorously enforcing the law" and so nonadherence had no consequences; see Ben Bursten, Posthospital Mandatory Outpatient Treatment, 143 AM. J. PSYCHIATRY 1255-58 (1986). Outpatient commitment, when extended for more than six months, has also been shown to decrease episodes of violence by $40 \%$ in a study in North Carolina; see Jeffrey W. Swanson et al., Involuntary Out-Patient Commitment and Reduction of Violent Behaviour in Persons with Severe Mental Illness, 176 BR. J. PSYCHIATRY 324-31 (2000). The North Carolina study also showed that outpatient commitment reduced arrests from $45 \%$ to $12 \%$; see Jeffrey W. Swanson et al., Can Involuntary Outpatient Commitment Reduce Arrests among Persons with Severe Mental Illness?, 28 CRIM. JUSTICE BEHAV. 156-89 (2001). Finally, in a study in New York, outpatient commitment was shown to reduce the incidence of arrests from $30 \%$ to $5 \%$ and to reduce the incidence of incarceration from $21 \%$ to $3 \%$ (KENDRA'S LAW: AN INTERIM REPORT).
} 
individuals who lack the relevant capacity. Our third, and most controversial claim, considers individuals who are partly, but not completely, incapacitated. Most of these individuals, if dangerous, will be mostly dangerous to self. Because our position in this area is the most novel and controversial of these three circumstances, we will examine it at greater length.

Nearly every current scholar maintains that dangerousness to others, in combination with mental illness, and perhaps beneficial treatment, justifies coercive commitment. $^{256}$ The overwhelming majority of states agree. Society has also found danger to others from disease and illness sufficient to justify coercive reductions in liberty. For example, many states commit individuals with tuberculosis, especially if they are incapable of following, or fail to follow, prescribed treatment regimens. ${ }^{257}$ When we believed that leprosy was very contagious, we isolated persons with leprosy from society by sending them to "lepers' colonies" on remote islands or in special hospitals. ${ }^{258}$ Similarly, the driving privileges of individuals with epilepsy are restricted when their epilepsy is not controlled. ${ }^{259}$

In connection with civil commitment, some would restrict the use of the term 'dangerous' to the level of dangerousness required for inpatient commitment. Were that perspective correct, assisted treatment could rarely be justified on the basis of dangerousness, because few individuals who are that dangerous are safe enough to be treated in the community. A more thoughtful approach, however, analyzes 'dangerous' as

256 See, e.g., Elyn R. Saks, REFusing CARE: ForCED TREATMEnT And THE Rights Of ThE Mentally Ill (2002); Robert F. Schopp, Competence, CondeMnAtion, And COMMITMENT: AN INTEGRATED THEORY OF MENTAL HEALTH LAW (2001).

257 M. Rose Gasner et al., The Use of Legal Action in New York City To Ensure Treatment of Tuberculosis 340 NEW ENGLAND JOURNAL OF MEDICINE 359-66 (1999).

258 http://rarediseases.about.com/cs/infectiousdisease/a/071203.htm, visited August 25, 2004

259 See, e.g., Hammontree v. Jenner, 20 Cal.App.3d 528, 97 Cal.Rptr. 739 (1972). 
relative to context. Dangerous is defined as a level of risk that is worth reducing a particular amount in light of the cost of less risky alternatives. ${ }^{260}$ Consider an individual who is not so dangerous as to meet the test for dangerousness required for inpatient commitment. Still, that individual might create a significant risk of injury to others. If the cost of placing that individual on outpatient commitment—conceived broadly—is less than the value of the reduction in risk that would be expected to result from that placement, then the individual meets the less stringent test of dangerousness for outpatient commitment. We conclude that an appropriate level of dangerousness to others will support coercion for assisted treatment.

Philosophers, mental health law scholars, and courts all agree that individuals who are incapacitated in the relevant area-whether it be mental health treatment decision making or handling finances_-are justifiably subject to paternalistic intervention. ${ }^{261}$ Some would say that such persons, because they lack the relevant capacity, are not autonomous, and therefore have no relevant rights. A more respectful description is that because they are unable to capably act on their own behalf, the state is permitted, and perhaps morally obligated, to act in these individuals' interests or to delegate that task to others. ${ }^{262}$

Some would urge that paternalistic intervention is justified only if the incapacitated individual receives a benefit. For example, in commitment they must receive beneficial treatment, ${ }^{263}$ but not just any beneficial treatment will do. To take an

260 Robert F. Schopp, Outpatient Civil Commitment: A Dangerous Charade or a Component of a Comprehensive Institution of Civil Commitment?, 9 PSYCHOLOGY, PUB. POL'Y \& L. 33 (2003).

261 Kress, An ARgument FOR AsSisted OUtPATIENT TREATMENT) 1269, 1314-15 (2000).

262 KRESS, AN ARGUMENT FOR AsSiSTED OUTPATIENT TREATMENT) 1269, 1314-15 (2000).

263 Bruce J. Winick, The Right To Refuse Mental Health Treatment; Bruce J. Winick, Ambiguities in the Legal Meaning and Significance of Mental Illness, 1 PSYCHOL., PUB. POL'Y, \& L., 534, 587 (1995). 
extreme example, taping the broken toe of a manic patient to reduce pain, and therefore minimally reduce stress and mania, will not suffice as beneficial treatment. On the other hand, providing that treatment that has the best combination of excellent prospects for minimizing the illness while avoiding side effects is a beneficial treatment. There remains room for disagreement over intermediate cases. Is a well intended, but poorly thought out, treatment plan beneficial treatment? Can massage and reflexology therapy be beneficial treatment? The question of what is beneficial treatment that could justify paternalistic intervention deserves more extensive discussion than it has received in the literature. We will say more about it in a moment. For now, we will simply note that most think that massage mostly provides temporary relief from stress and is therefore a mere interest of the patient. This may explain why many have doubts that massage can be a beneficial treatment. It also explains why patients who believe that massage reduces stress and therefore treats mania on a long-term basis believe that it is a beneficial treatment. By contrast, treatment with excellent prospects for maximizing mental health is clearly a beneficial treatment because it maximizes the basic good of mental health, which is itself instrumental to autonomy and ordinary, non-basic goods in the future.

Most rights theorists contend that only when a person is incapacitated in the sense of not being autonomous is paternalistic intervention defensible. Dangerousness and lack of autonomy, however, will not support all cases of assisted treatment. For example, some outpatient commitment laws, such as Kendra's Law ${ }^{264}$ and Laura's Law, ${ }^{265}$ do not require total incapacity. Nor do most payeeship relationships. Might coercion in these circumstances nevertheless be justifiable? Contrary to the conventional wisdom, we shall

\footnotetext{
264 N.Y. MENTAL HYG. Sec. 9.60 (c) (4)\&(5) (2003).

265 A.B. 1421 (CA 2003).
} 
urge that there are circumstances in which partial, but not complete, impairment will justify paternalistic intervention. But we must first take a small detour into the justification for the conventional wisdom before exploring our disagreement with it.

Deontological, or rights-based, theories receive powerful support from certain counterintuitive results that appear to flow from consequentialist theories. Consequentialist theories, a generalization of utilitarianism, maintain that the morally preferred action is that one that will maximize the amount of good, or things of value.

Such theories have been critiqued from the perspective of rights theorists, including advocates of strong autonomy rights, by hypotheticals such as the following. It would appear that if five friends of Smith want to use his car to go to a great party, and he is going to use the car to drive one block to the corner store for milk, then it maximizes the good (utility, preference satisfaction, what have you) for his friends to take Smith's car to the party. It therefore seems that consequentialism requires Smith to let them use the car; he should walk to the store. ${ }^{266}$ But our intuitions about what it means to own the car include his right to loan the car or not at his whim. This is not to say that Smith cannot be criticized as selfish, a character flaw. Rather, we are merely asserting that it is morally permissible for Smith to exercise his right.

A more familiar form of this example states that we should not cut up one individual, distributing his kidneys, lungs, and heart to five hopeful organ recipients, at a net gain of four lives. Rather, his right to life trumps the net gain in lives.

Rights theorists therefore urge that we may not violate rights, especially autonomy rights for the sake of well-being, or even other rights. This has been thought to

266 Assume that for some reason the obvious solution, namely, that Smith picks up the milk and then relinquishes the car, is not available. Perhaps the car must be picked up to go to the party before the store opens. 
apply even to an individual's own rights: I may not take your car without your permission, even in certain pursuit of two better cars, which I give to you. A consequentialism of rights, so to speak, is not permissible. One principle that rights theorists frequently promote is that we cannot violate A's right for the sake of B's right or interest. We have just seen that a second such principle has been advocated: one may not violate A's right for the sake of a greater amount of rights or goods for A. But we believe that there is an exception to this principle when the individual partially or completely lacks certain capacities, as the following examples demonstrate.

We take keys away from friends of ours who are drunk and intend to drive. Some cases involve individuals who are dangerous to others. Other cases involve individuals who are completely incapacitated. However, there will be some circumstances in which the driver is only partly incapacitated and risks injury only to himself, perhaps because the route that he will take involves only his own private property. Even in these cases, we paternalistically intervene.

We will now describe cases that involve mostly dangerousness to self and that can be described so as to involve only dangerousness to self. We prevent children from playing on the highway. We prevent children and delusional persons from jumping from tall buildings in the belief that they can fly. We prevent people from committing suicide without stopping to determine if they are even partially incapacitated. These cases may be described as preventing injury to self, although the highway example might be better described as putting oneself in a situation creating a great likelihood of being injured by others. At times, we draft people into the military. Although these individuals may not be dangerous to others, a public safety rationale exists since they are trained to support an 
effort to reduce risks to the public. On the other hand, of course, the draft often increases risks to the drafted individual.

Examples best described as coercing people in order to improve their health, a basic good, include forcing children to take their medicine and enforcing advance directives when the current self objects and is legally incompetent. Notice that basic goods, like health and mental health, are instrumental for many—if not mostautonomous activities, and many interests or ordinary goods. A third class of cases does not require dangerousness by or to the coerced individual. For example, we coerce children and teenagers into attending school in order to have greater capacities for action and abilities to participate in public governance after attainment of majority. Coercion appears justified here in order to create greater autonomous abilities in the future. We are less comfortable coercing children or others into playing the trumpet, so as to receive pleasure or have one more ability in the future, by contrast to forcing individuals to accept treatment or obtain a basic education.

These examples provide evidence that we are justified in coercing individuals even when they are partially autonomous and not completely lacking in autonomy or totally incapacitated. Three general principles appear to be applicable here, although these should be taken as guidelines with the expectation of occasional counterexamples. First, the more dangerous an individual is, the more justified are coercive restraints. Second, the less capable an individual is, the more comfortable we are with paternalistic intervention. Third, the greater the benefit that the individual is likely to receive, the more justified we are in infringing on her liberty. In considering benefits, restricting liberty is best justified by greater autonomy in the future. Secondarily, restricting liberty is, at the 
next level, best justified by increasing basic goods, like mental health, that are instrumental to most autonomous activities and non-basic goods. Finally, we consider ordinary goods and interests in determining the magnitude of the benefit that an individual receives.

We will now apply these principles to assisted treatment. Providing treatment to individuals who would be dangerous in the community without assisted treatment, but are likely not to be dangerous with assisted treatment, is justified. Whether providing assisted treatment to a dangerous individual that probably would reduce the risk that the individual would injure others but not to the point of not being dangerous is justified depends on the facts of individual cases. Individuals who are incapacitated in the relevant respect may be provided with assisted treatment if they are likely to benefit from it. The greater the benefit they are likely to receive, the more comfortable we are about intervening on their behalf. Finally, when an individual is partially incapacitated, whether assisted treatment is justified will depend upon the kind and magnitude of the benefit that the individual receives.

\section{Conclusion}

In 1690, John Locke, in Two Treatises of Government, recommended government protection for "Madmen, which for the present cannot possibly have the use of right 
Reason to guide themselves." For Locke, this application of parens patriae was "no more than Duty, which God and nature has laid on Man.,267

Since the 1960s, state mental health laws have moved away from parens patriae as a basis for state action and moved toward the use of dangerousness as the exclusive grounds for state intervention. This move has often been justified by claiming that it supports the civil rights and liberty of the persons. As Frank Lanterman, one of the sponsors of the Lanterman-Petris-Short Act phrased it: The proposed legislation would free 'thousands of persons from the 'tyranny of help' that has camouflaged for so many years the denial of liberty and basic human dignity.",268

This represents a fundamental misunderstanding of the concept of liberty and the goal of treating all individuals with severe psychiatric disorders with the least restrictive alternative. As Supreme Court Justice Anthony Kennedy recently noted:

It must be remembered that for the person with severe mental illness who has no treatment, the most dreaded of confinements can be the imprisonment inflicted by his own mind, which shuts reality out and subjects him to the torment of voices and images beyond our powers to describe. ${ }^{269}$

Robert Reich observed that "freedom to be sick, helpless and isolated is not freedom, ${ }^{, 270}$ and Stephen Rachlin et al. similarly asked: "Can we really call it

267 John Locke, Two TREATISES OF GOVERNMENT 348-52 (1690).

268 LANTERMAN, NEW MENTAL HEALTH LEGISLATION.

269 Olmstead v. Zimring, 527 U.S. 581, 609-610, 119 S.Ct. 21762191 (1999) (Justice Kennedy, concurring in the judgment).

270 Robert Reich, Care of the Chronically Mentally Ill-A National Disgrace, 130 AM. J. PSYCHIATRY 911-12 (1973). 
'liberty' if someone walks the streets in terror because of paranoid delusions or threatening hallucinations?",271

For individuals with severe psychiatric disorders, the consequences of nontreatment can be severe. Homelessness, incarceration, and victimization are often the daily fare. In commenting on the effects of the Lessard decision on affected individuals, Darold Treffert put it succinctly and eloquently:

It is not "freedom" to be wandering the streets, severely mentally ill, deteriorating and getting warmth from a steam grate or food from a garbage can; that's abandonment. And it is not "liberty" to be in a padded jail cell instead of a hospital, hallucinating and delusional, without treatment because that is all the law will allow. ${ }^{272}$

271 Stephen Rachlin et al., Civil Liberties versus Involuntary Hospitalization, 132 AM. J. PSYCHIATRY 189-91 (1975).

272 Darold A. Treffert, 1995 Wisconsin Act 292: Finally, the Fifth Standard, 95 WISC. MED. J. 53740 (1996). 